\begin{abstract}
UNIVERSIDADE DE SÃO PAULO
INSTITUTO DE ASTRONOMIA, GEOFÍSICA E CIÊNCIAS ATMOSFÉRICAS

DEPARTAMENTO DE GEOFÍSICA
\end{abstract}

Dissertação de Mestrado

Utilização de dados gravimétricos derivados de altimetria por satélite e geofísica marinha no estudo de estruturas do embasamento na região da Bacia de Santos, SP

\author{
Aluna \\ Renata Constantino \\ Orientador \\ Prof. Dr. Eder Cassola Molina
}

SÃO PAULO

2012 
RENATA CONSTANTINO

\section{Utilização de dados gravimétricos derivados de altimetria por satélite e geofísica marinha no estudo de estruturas do embasamento na região da Bacia de Santos, SP}

Dissertação apresentada ao Instituto de Astronomia, Geofísica e Ciências Atmosféricas da Universidade de São Paulo como parte dos requisitos para obtenção do título de Mestre em Ciências na área de Geofísica, versão corrigida. 


\section{Sumário}

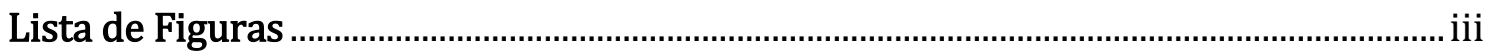

Lista de Tabelas

Agradecimentos ……................................................................................................. vii

Resumo

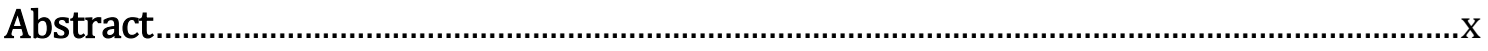

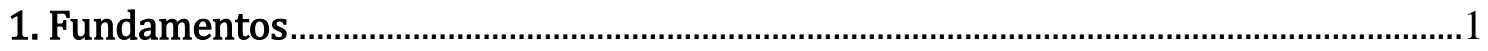

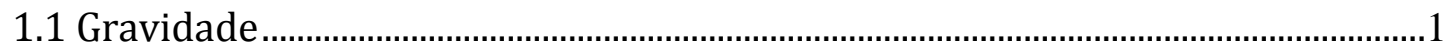

1.1.1 Lei da Gravitação Universal................................................................................1

1.1.2 Potencial Gravitacional .............................................................................................

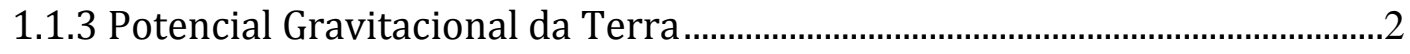

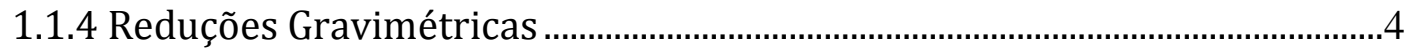

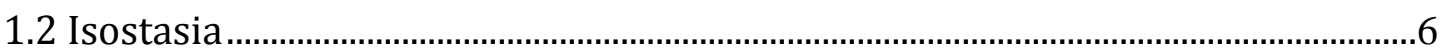

1.2.1 Modelo de Airy ..........................................................................................................6

1.2.2 Modelo de Pratt...............................................................................................................

1.2.3 Modelo de Vening-Meinesz..................................................................................

1.2.4 Espessura Elástica e Rigidez Flexural.................................................................9

1.2.4 Estimando a Rigidez Flexural ........................................................................... 10

1.2.4 ASEP (solução analítica para uma placa elástica) …………………………... 12

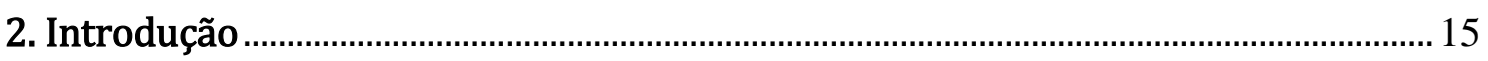

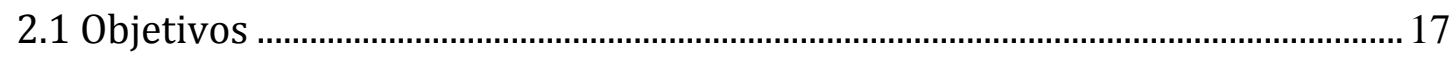

3. Dados

3.1 Bacia de Santos .........................................................................................................18

3.2 Dados de Gravidade ...............................................................................................20

3.3 Modelo de Espessura Sedimentar ..........................................................................21

3.4 Dados Batimétricos ......................................................................................................23

3.5 Dados de Espessura Crustal ....................................................................................24

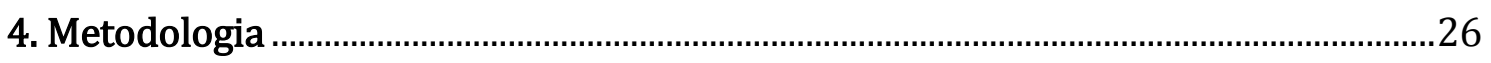

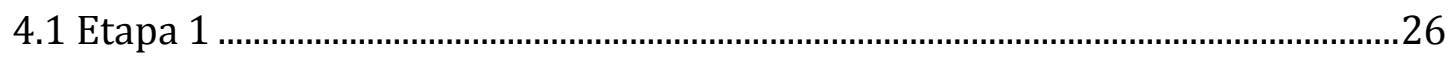

4.1.2 Modelo Inverso Iterativo com Vínculos...…………………………………...27

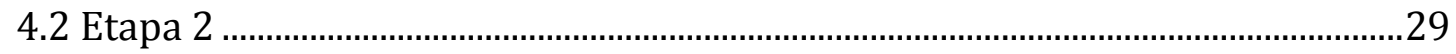

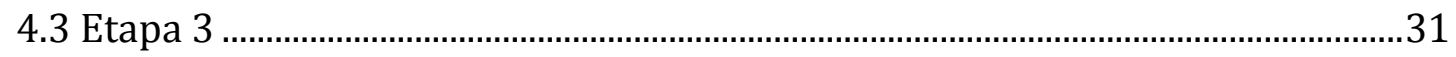




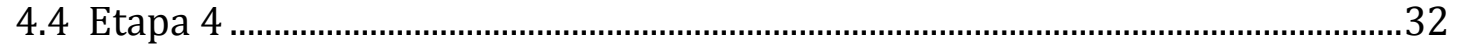

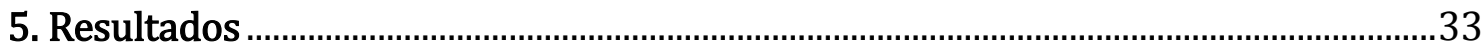

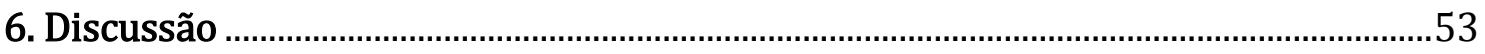

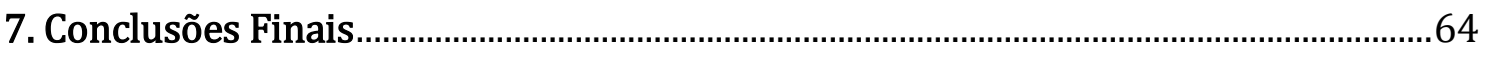

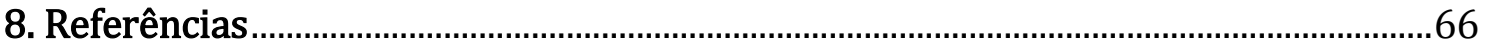




\section{Lista de Figuras}

Figura 1: Parâmetros usado por MacCullagh (Lowrie, 1997) ............................................ 3

Figura 2: Modelo de Isostasia Segundo Airy. Figura adaptada de Oliveira (2008).....

Figura 3: Modelo de Isostasia Segundo Pratt. Figura adaptada de Oliveira (2008).....

Figura 4: Diferentes comportamentos elástico de uma placa dependendo de sua rigidez flexural. Figura adaptada de Oliveira (2008) .................................................... 10

Figura 5: Solução analítica para uma placa elástica (ASEP), adaptada de Wienecke

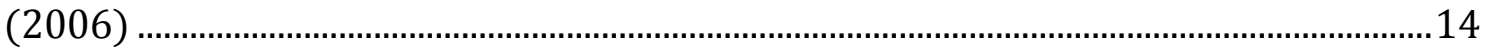

Figura 6: Dados batimétrico liberado pela GEBCO …........................................................19

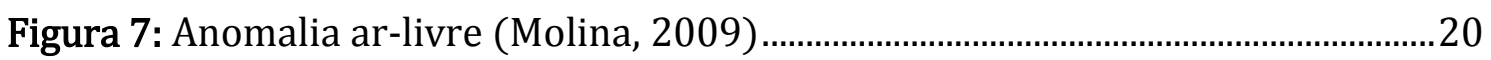

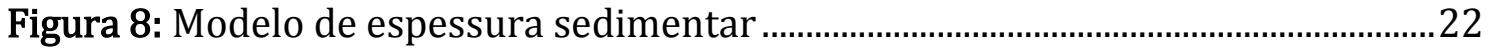

Figure 9: Rota do Glomar Challenger durante perfurações do Leg 39 ..........................23

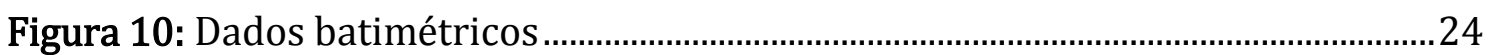

Figura 11: Mapa Batimétrico com valores de espessura crustal, em metros .............25

Figura 12: Modelo de espessura sedimentar obtidos pela NGDC …..............................33

Figura 13: Campo gravimétrico referente ao pacote sedimentar ...................................34

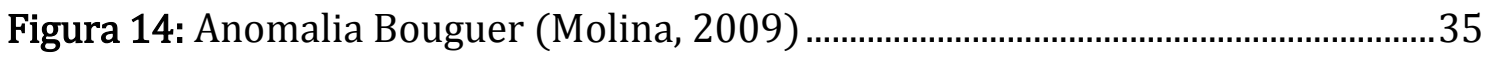

Figura 15: Campo gravimétrico corrigido, ou seja, sem o efeito gravimétrico gerado

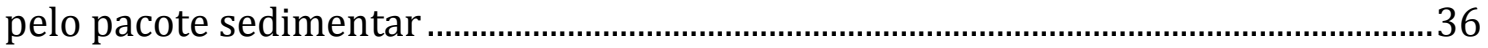

Figura 16: Gráfico do espectro de potência radial do campo gravimétrico .................37

Figura 17: Modelo de contraste de densidade entre a crosta e o manto.......................38

Figura 18: Mapa da Interface Crosta Manto (ICM) obtida a partir da inversão do campo gravimétrico com vínculos

Figura 19: Mapa da Interface Crosta Manto (ICM) obtida a partir da inversão do campo gravimétrico com diferenças entre os valores obtidos e os vínculos.............41 
Figura 20: Valores em metros da topografia equivalente (carga crustal) na área de estudo

Figura 21: Mapa da Interface Crosta Manto (ICM) obtida a partir de análise

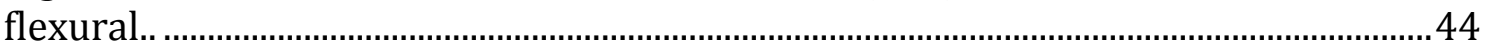

Figura 22: Diferença entre valores de profundidade obtidos por inversão do campo gravimétrico e por análise flexural

Figura 23: Efeito gravimétrico da Interface ICM calculado segundo Parker (1972) ...

Figura 24: Campo gravimétrico residual $\left(\mathrm{g}_{\mathrm{res}}=\mathrm{g}_{\mathrm{obs}}-\mathrm{g}_{\mathrm{CMI}}-\mathrm{g}_{\mathrm{sed}}\right)$

Figura 25: Estruturas do embasamento

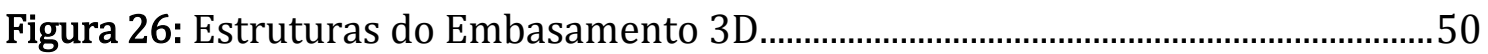

Figura 27: Profundidade do embasamento 3D, projeção em perspectiva....................51

Figura 28: Profundidade do embasamento 3D, projeção ortográfica.............................51

Figura 29: Mapa de contorno da profundidade do embasamento

Figura 30: Sinal Gravimétrico da ICM obtida através da inversão do campo gravimétrico

Figura 31: Diferença entre o campo gravimétrico utilizado como dado de entrada e o campo referente a ICM gravimétrica

Figura 32: Modelo de espessura elástica

Figura 33: Perfis sísmicos na Bacia de Santos. As setas pretas indicam diápiros e muralhas de sal

Figura 34: Perfil sísmico na Bacia de Santos .59

Figura 35: Estruturas do embasamento 3D com feições em evidência .60

Figura 36: Mapa estrutural da Bacia de Santos

Figura 37: Seção Geológica da Bacia de Santos .61

Figura 38: Localização dos poços 62 


\section{Lista de Tabelas}

Tabela 1: Coordenadas geográficas, vínculos e diferença de valores entre os dados obtidos por inversão do campo gravimétrico e os vínculos 40

Tabela 2: Valores utilizados como vínculos, profundidades do embasamento encontradas durante o trabalho e as respectivas diferenças 
Dedico este trabalho ao meu orientador, pela ajuda, confiança e dedicação 


\section{Agradecimentos}

Primeiramente a Deus por ser o Guia da minha vida;

Aos Meus pais por me apoiarem e estarem ao meu lado em todas as decisões da minha vida;

Ao Meu irmão querido e amigo para todas as horas;

Ao Meu namorado pela paciência durante esses anos de estudo;

Aos Meus amigos Gabriel, Helen e Emílio pelos momentos de café e risos: vocês fizeram tudo isso ser mais simples!

Suzan, Edu, Bob e todos os amigos que passaram por essa jornada junto a mim;

Ao Cleiton por não parar de falar nunca e me distrair sempre!

Ao Professor Marcelo Assumpção por ter me ajudado com sugestões e dados;

Ao Andrés Tassara por ter me disponibilizado dados de espessura elástica;

Ao Iata Anderson de Souza pela disposição em me ajudar;

A Todos os professores que contribuíram imensamente para meu conhecimento nesses dois anos de mestrado;

A Teca e Virgínia por estarem sempre dispostas a ajudar;

A Carla Braitenberg pela disponibilização do software Lithoflex;

Ao CNPq pela bolsa concedida;

E por último, não por ser menos importante, muito pelo contrário, por ser um agradecimento especial: Agradeço de coração meu orientador por ter acreditado em mim e tornado esse trabalho possível! 
"Bem-aventurado o homem que encontra sabedoria, e o homem que adquire conhecimento"

Provérbios 3:13 


\section{Resumo}

CONSTANTINO,R. Utilização de dados gravimétricos derivados de altimetria por satélite e geofísica marinha no estudo de estruturas do embasamento na região da Bacia de Santos, SP. 2012. 70p. Dissertação - Instituto de Astronomia, Geofísica e Ciências Atmosféricas, Universidade de São Paulo, São Paulo, 2012.

O embasamento oceânico representa a situação tectônica de uma determinada área e seu conhecimento é crucial em estudos que visam explorar o fundo marinho. Devido à alta taxa de sedimentação, principalmente em bacias oceânicas, a topografia do embasamento é mascarada e suas estruturas podem estar enterradas, inacessíveis à observação direta. Este trabalho visa estimar a profundidade do embasamento na região da Bacia de Santos a partir de uma análise combinada de dados gravimétricos obtidos a partir de altimetria por satélite e gravimetria marinha, dados batimétricos e modelo de espessura sedimentar de bancos de dados internacionais e dados de espessura crustal disponíveis na região. Na primeira etapa do trabalho foi calculado o efeito do pacote sedimentar no sinal gravimétrico na Bacia de Santos e a profundidade da Interface Crosta Manto (ICM) foi modelada a partir de inversão gravimétrica com vínculos. Na etapa seguinte, a confiabilidade dos modelos obtidos foi testada através de análise flexural. Os dados de profundidade da ICM flexural e gravimétrica se mostraram em concordância, sinalizando a adequação de seu uso na próxima etapa do trabalho. 0 efeito gravimétrico da ICM encontrada por análise flexural e o efeito gravimétrico dos sedimentos foram então calculados e subtraídos da anomalia Bouguer original. 0 campo residual assim obtido, que se admite representar as feições topográficas do embasamento, foi invertido na última etapa do trabalho, fornecendo informações que mostram um embasamento com feições topográficas de até $700 \mathrm{~m}$ em certas regiões isoladas. Este embasamento gravimétrico pode, dentro de suas restrições, oferecer importantes subsídios para a elaboração de modelos genéticos e tectônicos de interesse exploratório na região. 


\section{Abstract}

CONSTANTINO,R. Using gravity data derived from satellite altimetry and marine geophysics in the study of basement structures in the area of the Santos Basin, SP. 2012. 70p. Master's Thesis - Institute of Astronomy, Geophysics and Atmospheric Sciences of the University of São Paulo, São Paulo, 2012.

The ocean basement represents the tectonic situation of an specific area and their knowledge is crucial in studies aimed at exploring the seabed. Due to the high sedimentation rate, especially in ocean basins, the topography of the basement is masked and their structures can be buried, inaccessible to direct observation. This paper aims to estimate the depth of the basement in the region of the Santos Basin from a combined analysis of gravity data obtained from satellite altimetry and marine gravimetry, bathymetric data and sediment thickness from international data banks and crustal thickness data available in the region. In the first step of the work it was calculated the gravity effect of sediments in Santos Basin and the Crustal Mantle Interface (CMI) was modeled from constrained gravity inversion. In the next step, the reliability of the models obtained was tested by flexural analysis. The flexural and gravity CMI proved to be in agreement, indicating the appropriateness of its use in the next stage of work. The gravity effect of Flexural CMI and the gravity effect of sediments were then calculated and subtracted from the original Bouguer anomaly. The residual field thus obtained, which is assumed to represent the topographical features of the basement, was inverted in the last step of the work, providing information that show a basement with features of up to $700 \mathrm{~min}$ some isolated regions. This gravimetric basement may, within its restrictions, offer important insights for the development of genetic and tectonic models off exploration interest in the region. 


\section{Capítulo 1}

\section{Fundamentos}

Neste capítulo serão abordados fundamentos teóricos sobre o campo de gravidade e isostasia.

\subsection{0 campo da gravidade}

\subsubsection{Lei da Gravitação Universal}

De acordo com a Lei da Gravitação Universal formulada por Newton, dois pontos com massa $\mathrm{m}_{0}$ e $m$, separadas por uma distância $r$, se atraem mutuamente com uma força $\mathrm{F}$ tal que

$$
\overrightarrow{\mathrm{F}}=-\mathrm{G} \frac{\mathrm{m}_{0} \cdot m}{\mathrm{r}^{2}}
$$

onde G é a constante gravitacional de Newton.

Embora as massas $\mathrm{m}_{0}$ e $m$ se atraiam de forma simétrica, é conveniente chamar uma das massas de atrativa e outra de massa atraída. Por simplificação, considera-se a massa atraída como unitária e denota-se a massa atrativa por m:

$$
\vec{F}=-G \frac{m}{r^{2}}
$$

\subsubsection{Potencial Gravitacional}

O potencial gravitacional é a energia potencial de uma unidade de massa em um campo de atração gravitacional e pode ser representada da forma escalar por:

$$
V=G \frac{m}{r}
$$


As componentes $\mathrm{X}, \mathrm{Y}, \mathrm{Z}$ da força gravitacional $\vec{F}$ são dadas por:

$$
X=\frac{\partial \mathrm{V}}{\partial \mathrm{x}}, \mathrm{Y}=\frac{\partial \mathrm{V}}{\partial \mathrm{y}}, \mathrm{Z}=\frac{\partial \mathrm{V}}{\partial \mathrm{z}}
$$

Em notação vetorial, a equação é escrita como:

$$
\vec{F}=(X, Y, Z)=\nabla V
$$

Assim, para um sistema $n$ de massas pontuais $m_{1}, m_{2}, \ldots m_{n}$, o potencial do sistema é a soma das contribuições individuais de V (Heiskanen \& Moritz, 1967):

$$
V=\frac{G m_{1}}{r_{1}}+\frac{G m_{2}}{r_{2}}+\cdots+\frac{G m_{n}}{r_{n}}=G \sum_{i=1}^{n} \frac{m_{i}}{r_{i}}
$$

\subsubsection{Potencial Gravitacional da Terra}

A forma irregular muda o potencial da Terra em relação ao de uma esfera perfeita. Existem duas maneiras de estudá-lo: a partir da fórmula de MacCullagh ou através da equação de Laplace (Lowrie, 1997)

O potencial gravitacional de qualquer corpo, longe do corpo de massa desse corpo, pode ser definido como:

$$
V_{G}=-G \frac{M_{T}}{r}-G \frac{A+B+C-3 I}{2 r^{3}}
$$

sendo

$\mathrm{M}_{\mathrm{t}} \ldots$ massa da Terra

A, B e C ... momentos de inércia em relação aos eixos x, y, z.

I ... momento de inércia em relação à linha OP que liga o centro de coordenadas 0 ao ponto $\mathrm{P}(\mathrm{r}, \theta)$, com distância $\mathrm{r}$ de $\mathbf{O}$ e com ângulo $\theta$ com respeito ao eixo z (Figura 1).

O termo que depende de $(1 / r)$ fornece o potencial gravitacional de uma 
esfera de massa M. Já o termo que depende de $\left(1 / \mathrm{r}^{3}\right)$ fornece o desvio do potencial pelo fato da forma do corpo não ser esférica.

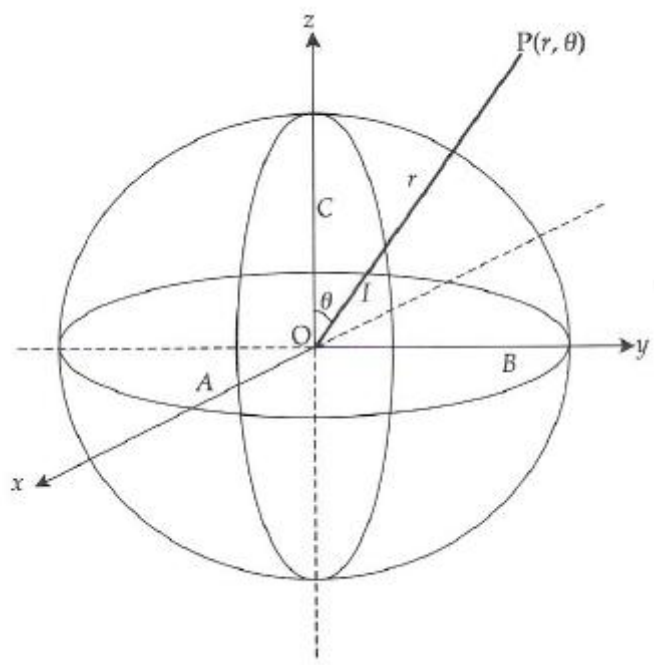

Figura 1: Parâmetros usado por MacCullagh (Lowrie, 1997)

Para uma terra elipsoidal, o momento de inércia I pode ser descrito como $\mathrm{I}=\mathrm{A} \sin ^{2} \theta+\mathrm{C} \cos ^{2} \theta$ e o potencial gravitacional como:

$$
V_{G}=-G \frac{M_{t}}{r}-G \frac{(C-A)\left(3 \cos ^{2} \theta-1\right)}{2 r^{3}}
$$

O potencial deve satisfazer a condição de diminuir à medida que se afasta do centro de massa que o produz e a aceleração gravitacional deve ser dirigida para o centro de massa, satisfazendo a equação de Laplace

$$
\Delta \mathrm{V}=0
$$

que escrita em coordenadas esféricas polares $(r, \theta, \phi)$, torna-se:

$$
\frac{1}{r^{2}} \frac{\partial V}{\partial r} r^{2} \frac{\partial V}{\partial r}+\frac{1}{r^{2} \sin \theta} \frac{\partial}{\partial \theta} \operatorname{sen} \theta \frac{\partial V}{\partial \theta}+\frac{1}{r^{2} \sin ^{2} \theta} \frac{\partial^{2} V}{\partial \phi^{2}}=0
$$

onde a derivada em $\phi$ é nula devido à simetria esférica adotada para o elipsóide de referência.

A solução para essa equação pode ser obtida considerando o potencial como 
uma soma infinita em termos de r e $\theta$ :

$$
V=-G \frac{M_{T}}{r}\left[1-\sum_{n=2}^{\infty}\left(\frac{R}{r}\right)^{n} J_{n} P_{n}(\cos \theta)\right]
$$

Onde $\mathrm{J}_{\mathrm{n}}$ são pesos dos coeficientes dos polinômios de Legendre $\left(\mathrm{P}_{\mathrm{n}} \cos \theta\right)$.

Para obtenção do geopotencial, é necessário acrescentar ao potencial V, o potencial centrífugo $V_{G}$ :

$$
\mathrm{V}_{\mathrm{G}}=-\frac{1}{2} \omega^{2} \mathrm{r}^{2} \sin ^{2} \theta
$$

0 geopotencial define superfícies equipotenciais onde $V_{G}$ assume valor constante ao longo da superfície e a aceleração da gravidade é perpendicular a essa superfície.

Em trabalhos gravimétricos, uma superfície equipotencial é utilizada como superfície de referência, a superfície geoidal.

\subsubsection{Reduções Gravimétricas}

A aceleração da gravidade varia de ponto a ponto sobre toda a superfície terrestre. Essas variações podem ocorrer devido a diversas causas. Quando o objetivo da análise gravimétrica é estudar variações da aceleração da gravidade causadas por diferenças de densidade na crosta e no manto, é necessário eliminar todas as demais variações conhecidas. Esse processo de eliminação é conhecido como correção gravimétrica.

\section{- Correção ar-livre}

A correção ar-livre permite corrigir todos os pontos de medidas feitos na superfície física da Terra a uma altura h, para o nível médio dos oceanos, o geóide. 0 geóide é a superfície equipotencial do campo de gravidade que coincide com o nível médio dos mares no oceano não perturbado. A correção ar-livre é dada por: 


$$
\mathrm{C}_{\mathrm{a}}=-\frac{2 \mathrm{~h}}{\mathrm{R}} \mathrm{g}_{0}
$$

onde h é a altitude ortométrica normal à superfície do geóide.

Essa correção leva em conta o fato que g diminui quando o gravímetro é afastado da Terra, e, portanto, calcular os valores correspondentes no geóide é necessário acrescentar a quantidade $2 \mathrm{~h} / \mathrm{R}$. A anomalia ar-livre é definida como:

$$
\Delta \mathrm{g}=\mathrm{g}_{\mathrm{med}}-\mathrm{C}_{\mathrm{a}}-\mathrm{g}_{\text {teor }}
$$

Em gmed já consideramos o efeito da maré, da deriva do gravímetro e a correção de Eötvös, se o gravímetro estiver em movimento. 0 valor de gteor é fornecido por um modelo elipsoidal de referência.

\section{- Correção Bouguer}

A correção Bouguer considera o efeito de atração da massa existente entre o gravímetro e o nível do mar, utilizando um modelo de placa horizontal de extensão infinita e espessura finita h igual à altitude ortométrica da estação gravimétrica no ponto de medida (platô de Bouguer). É dada por:

$$
\mathrm{C}_{\mathrm{b}}=2 \pi \mathrm{G} \rho \mathrm{h}
$$

A anomalia Bouguer é dada por:

$$
\Delta \mathrm{g}=\mathrm{g}_{\mathrm{med}}-\mathrm{C}_{\mathrm{a}}-\mathrm{C}_{\mathrm{b}}-\mathrm{g}_{\text {teor }}
$$

\section{- Correção de terreno}

A correção de terreno considera os desvios entre o platô de Bouguer e a topografia nas vizinhanças da estação. Para efetuar esta correção utilizam-se técnicas numéricas e mapas digitais de topografia. Em escala regional, esta 
correção pode ser negligenciada desde que a topografia seja plana ou moderada. Em escala local, no entanto, ela tem que ser considerada, pois as anomalias envolvidas, neste caso, normalmente são pequenas.

Dá-se o nome de anomalia Bouguer completa à anomalia obtida quando a correção de terreno e a correção do platô para uma calota esférica também são feitas.

\subsection{Isostasia}

Segundo Watts (2001), isostasia é o termo usado para descrever as condições de equilíbrio nas quais a crosta e o manto terrestre tendem a permanecer, na ausência de forças perturbadoras. Os modelos de compensação isostática podem ser locais ou regionais. Os modelos isostáticos de Airy e de Pratt assumem que a topografia é localmente compensada. Já o modelo de VeningMeinesz descreve uma compensação regional, admitindo que as massas topográficas estão localizadas sobre uma placa crustal, que é flexionada devido a esta carga.

\subsubsection{Modelo de Airy}

O modelo de Airy (figura 2) postula uma crosta terrestre fina e sólida, porém pouco resistente, apoiada sobre um substrato de densidade maior que a da crosta (manto). Neste modelo, a topografia é compensada por mudanças de espessura da crosta. Abaixo do alto topográfico, a compensação toma a forma de uma raiz crustal $\left(r_{c}\right)$. Em contraste, baixos topográficos correspondem a uma "anti-raiz" crustal $\left(r_{o}\right)$. A teoria implica que a crosta não possui rigidez, e reage a qualquer magnitude de carga, por menor que seja. 


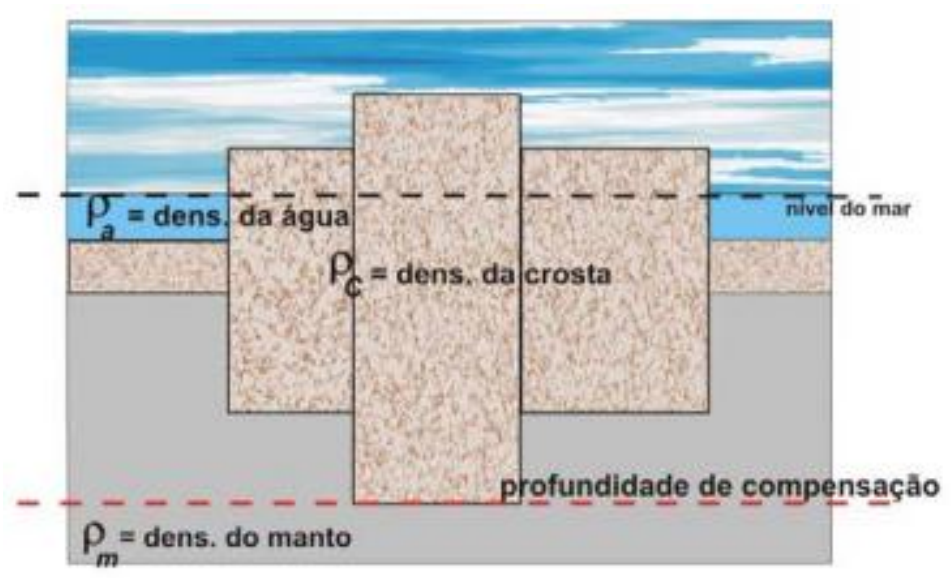

Figura 2: Modelo de isostasia segundo Airy. Figura adaptada de Oliveira (2008).

Em áreas continentais, uma a montanha de altura $\mathrm{h}_{1}$ terá uma raiz dada por:

$$
\mathrm{r}_{\mathrm{c}}=\frac{\mathrm{h}_{1} \rho_{\mathrm{c}}}{\rho_{\mathrm{m}}-\rho_{\mathrm{c}}}
$$

Enquanto que uma feição a uma profundidade d abaixo do nível do mar terá uma "anti-raiz" dada por:

$$
r_{o}=\frac{d\left(\rho_{c}-\rho_{a}\right)}{\rho_{m}-\rho_{c}}
$$

onde $\rho_{\mathrm{c}}, \rho_{\mathrm{m}}, \rho_{\mathrm{a}}$ são as densidades da crosta, do manto e da água, e assumem valores padrões se 2800,3300 , e $1030 \mathrm{~kg} \mathrm{~m}^{-3}$ respectivamente.

A idéia de Airy foi proposta em 1855 e Heiskanen, em 1931, colocou-a em termos matemáticos.

\subsubsection{Modelo de Pratt}

0 modelo de Pratt (figura 3) postula que as massas topográficas, independente da amplitude do relevo, possuem uma mesma profundidade de compensação, porém, nas regiões mais elevadas, sua densidade média é menor. Em cinturões de montanha, por exemplo, a densidade da crosta é menor que em áreas planas. 


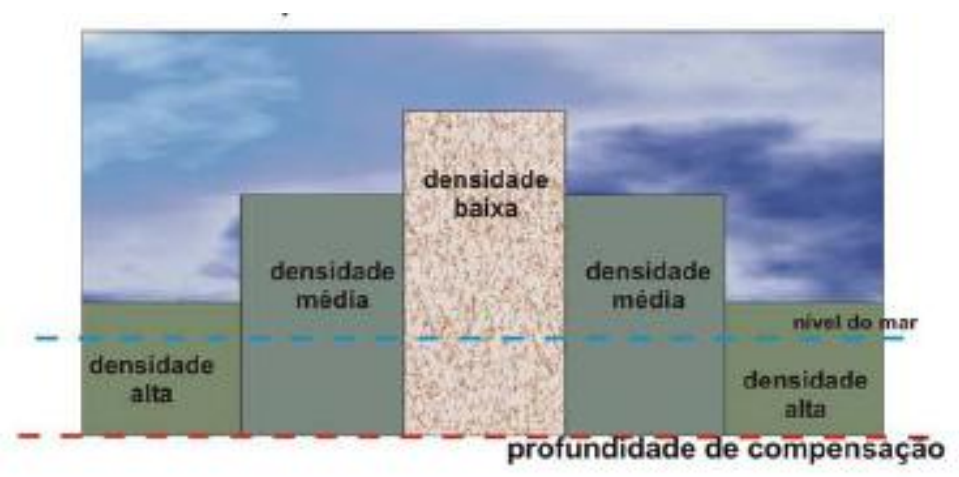

Figura 3: Modelo de isostasia segundo Pratt. Figura adaptada de Oliveira (2008).

Em áreas continentais, uma montanha de altura $\mathrm{h}_{1}$ terá um menor valor de densidade dada por

$$
\rho_{1}=\rho_{\mathrm{c}} \frac{\mathrm{D}_{\mathrm{c}}}{\mathrm{h}_{1}+\mathrm{D}_{\mathrm{c}}}
$$

sendo $\mathrm{D}_{\mathrm{c}}$ a profundidade de compensação, constante neste modelo.

Por outro lado, uma feição a uma profundidade d abaixo do nível do mar terá uma densidade maior dada por:

$$
\rho_{\mathrm{d}}=\frac{\rho_{\mathrm{c}} \mathrm{D}_{\mathrm{c}}-\rho_{\mathrm{a}} d}{\mathrm{D}_{\mathrm{c}}-d}
$$

A idéia de Pratt foi proposta em 1895 e Heiskanen, em 1909, colocou-a em termos matemáticos.

\subsubsection{Modelo de Vening-Meinesz}

O modelo de Vening-Meinesz é baseado principalmente no modelo de Airy e admite que a compensação da superfície terrestre pode não ser necessariamente local. Ele considera a topografia como uma carga sobre a crosta, a qual faz esta curvar, produzindo uma raiz de baixa densidade semelhante à proposta pelo modelo de Airy. A diferença é que neste modelo, a raiz é lateralmente maior, porque a carga é suportada, pelo menos parcialmente, pela rigidez da crosta.

O modelo de flexura de placa fina envolve compensação isostática regional, e tem evoluído a partir do modelo de Vening-Meinesz. 


\subsubsection{Espessura Elástica e Rigidez Flexural}

Na tectônica de placas, a litosfera é uma camada rígida e relativamente fina que flutua sobre o manto. No tempo geológico a litosfera comporta-se elasticamente e o manto reage como um fluido viscoso. Para tempos geológicos muito pequenos ambos se comportam como sólidos elásticos.

Vening-Meinesz introduziu o conceito que a rigidez flexural da litosfera deveria ser levada em consideração em análises isostáticas. Supondo que a placa está em equilíbrio sob a ação de todas as forças, a equação diferencial para a deflexão w(x) de uma placa elástica fina em função da distância horizontal x é

$$
D \frac{d^{4} w}{d x^{4}}=V(x)-H \frac{d^{2} w}{d x^{2}}
$$

sendo $\mathrm{w}(\mathrm{x})$ a deflexão da placa, $\mathrm{V}(\mathrm{x})$ a força vertical, por unidade de comprimento, aplicada à placa, $\mathrm{H}$ a força horizontal constante por unidade de comprimento, e a rigidez flexural da placa, definida como

$$
\mathrm{D}=\frac{\mathrm{ETe}^{3}}{12\left(1-v^{2}\right)}
$$

onde E é o módulo de Young, $v$ é a razão de Poisson (parâmetros elásticos que relacionam esforço e deformação) e Te é a espessura elástica efetiva da placa, que está relacionada ao quanto da placa se comporta de forma elástica. E normalmente varia entre 10 e $100 \mathrm{GPa}, v$ entre 0,1 e 0,4. Para a crosta os valores mais comuns são: $\mathrm{E}=100 \mathrm{GPa}$ e $v=0,25$.

A deflexão da placa depende de suas propriedades, ou seja, quão resistente é o material da placa diante de uma deformação. Valores muito altos de D implicam que a litosfera apresenta forte resistência ao cisalhamento, deformando-se relativamente pouco. Baixos valores de D indicam uma litosfera menos resistente ao cisalhamento, aumentando a deformação sob a carga. No limite em que $\mathrm{D}=0$, a litosfera não apresenta nenhuma resistência e tem-se o modelo de Airy (figura 4). 


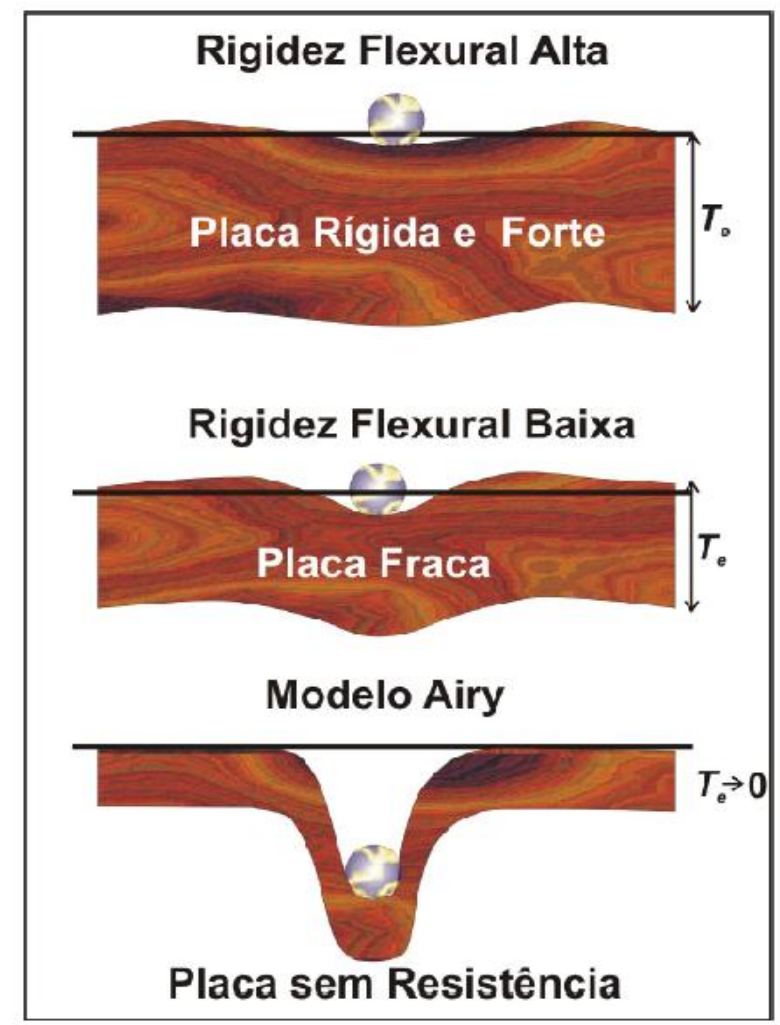

Figura 4: Diferentes comportamentos elástico de uma placa dependendo de sua rigidez flexural. Figura adaptada de Oliveira (2008).

\subsubsection{Estimando o Rigidez Flexural}

A rigidez flexural de uma placa elástica pode ser estimada a partir da equação diferencial de quarta ordem (21), que descreve a flexura de uma placa elástica fina.

Hertz (1884) propôs três soluções diferentes para resolver esta equação para o caso específico de uma placa de gelo flutuando sobre a água. A deflexão da placa foi calculada para uma carga pontual sem levar em consideração os efeitos da aceleração da gravidade. No entanto, aplicando tais soluções a problemas geológicos, os valores flexurais eram muito pequenos comparados às profundidades esperadas da interface crosta-manto (ICM).

Por essa razão, métodos espectrais (admitância e coerência) têm sido usados preferivelmente para a solução da equação de quarta ordem no domínio da frequência (Watts, 1988). 
Os dados utilizados nos cálculos são geralmente o campo gravimétrico, a carga topográfica/batimétrica e as heterogeneidades de densidade na crosta.

No domínio espectral, a admitância e coerência da carga e do campo gravimétrico podem determinadas. A admitância $\mathrm{Z}(\mathrm{k})$ é calculada partir do espectro da topografia e do espectro cruzado da aceleração da gravidade e da topografia em números de onda k com:

$$
\mathrm{Z}(\mathrm{k})=\frac{|\{\mathrm{B}(\overrightarrow{\mathrm{k}}) \mathrm{H}(\overrightarrow{\mathrm{k}}) *\}|}{\{\mathrm{H}(\overrightarrow{\mathrm{k}}) \mathrm{H}(\overrightarrow{\mathrm{k}}) *\}}
$$

sendo $\mathrm{H}(\overrightarrow{\mathrm{k}})$ e $\mathrm{B}(\overrightarrow{\mathrm{k}})$ transformadas de Fourier da topografia e da aceleração da gravidade, respectivamente, $\overrightarrow{\mathrm{k}}=\left(\mathrm{k}_{\mathrm{x}}, \mathrm{k}_{\mathrm{y}}\right)=2 \pi\left(\mathrm{v}_{\mathrm{x}}, \mathrm{v}_{\mathrm{y}}\right)$ o número de onda bidimensional, e $v_{x}$ e $v_{y}$ as frequências ao longo do eixo $\mathrm{x}$ e y. Os colchetes indicam a média sobre uma região anular de largura dk $\mathrm{e}^{*}$ significa o complexo conjugado.

A coerência $\mathrm{Q}(\mathrm{k})$ é computada de uma maneira similar, por:

$$
\mathrm{Q}(\mathrm{k})=\frac{\{\mathrm{B}(\overrightarrow{\mathrm{k}}) \mathrm{H}(\overrightarrow{\mathrm{k}}) *\}^{2}}{\{\mathrm{H}(\overrightarrow{\mathrm{k}}) \mathrm{H}(\overrightarrow{\mathrm{k}}) *\}\{\mathrm{B}(\overrightarrow{\mathrm{k}}) \mathrm{B}(\overrightarrow{\mathrm{k}}) *\}}
$$

A confiabilidade da análise espectral aplicada para o cálculo da rigidez flexural tem sido questionada devido a alguns inconvenientes. 0 primeiro está relacionado ao cálculo inverso da flexura a partir de observações gravimétricas. Neste caso, o método de admitância se torna instável em casos onde há elevações topográficas baixas. Os valores espectrais entram no denominador, podendo gerar problemas numéricos em números de onda em que os coeficientes espectrais são pequenos. 0 segundo inconveniente é referente ao tamanho da janela espacial. Esta, segundo Macario (1995), deve ser grande, com pelo menos $375 \mathrm{~km}$ de comprimento lateral, para gerar resultados confiáveis. Assim, a distribuição da rigidez flexural é estimada apenas grosseiramente, não sendo possível a correlação com feições tectônicas menores.

Algumas desvantagens do método espectral foram superadas, por exemplo, pelo método da convolução proposto por Braitenberg (2002), descrito detalhadamente do capitulo 4. Wienecke (2006) propôs uma solução analítica 
para uma placa elástica (ASEP), usando as três soluções propostas por Hertz (1884).

\subsubsection{ASEP (Solução analítica para uma placa elástica)}

A ASEP resolve uma equação diferencial de quarta ordem para qualquer forma topográfica. A equação foi analiticamente resolvida por Wienecke (2006), e calcula a flexura w de uma placa elástica fina:

$$
\Delta . \Delta w+\frac{1}{\beta^{4}} w=0
$$

Sendo $\Delta$ o operador Laplaciano, que pode ser escrito em coordenadas cartesianas: $\Delta=\frac{\partial^{2}}{\partial x^{2}}+\frac{\partial^{2}}{\partial y^{2}}$ e $\beta$ o parâmetro flexural:

$$
\beta=\sqrt[4]{\frac{D}{\left(\rho_{\mathrm{m}}-\rho_{\mathrm{c}}\right) g}}
$$

Substituindo a rigidez flexural (D) dada pela Eq. 22, tem-se:

$$
\beta=\sqrt[4]{\frac{\mathrm{D}}{\left(\rho_{\mathrm{m}}-\rho_{\mathrm{c}}\right) \mathrm{g}}}=\sqrt[4]{\frac{\mathrm{ET}_{\mathrm{e}}^{3}}{12\left(1-v^{2}\right)} \frac{1}{\left(\rho_{\mathrm{m}}-\rho_{\mathrm{c}}\right) \mathrm{g}}}
$$

As três soluções propostas por Hertz (1884) foram modificadas por Wienecke (2006) a fim de serem aplicadas a uma litosfera elástica. As três soluções encontradas são descritas a seguir.

A primeira solução está no ponto de origem do sistema de coordenadas onde o ponto de carga (P) age. A profundidade máxima da deflexão $\mathrm{w}_{0}$ é expressa por:

$$
\mathrm{W}_{0}=\frac{\mathrm{P}}{8\left(\rho_{\mathrm{m}}-\rho_{\mathrm{c}}\right) \mathrm{g} \beta^{2}}
$$


A segunda solução, chamada de "função logarítmica" é descrita por

$$
\begin{gathered}
\mathrm{w}(\mathrm{x}, \mathrm{y})=\frac{\mathrm{P}}{2 \pi \beta^{2}\left(\rho_{\mathrm{m}}-\rho_{\mathrm{c}}\right) \mathrm{g}} \\
x\left\{\begin{array}{c}
\frac{\left(\mathrm{r}_{\mathrm{x}, \mathrm{y}}\right)^{2}}{2^{2}} \cdot \ln \left(\mathrm{r}_{\mathrm{x}, \mathrm{y}}\right)-\frac{\left(\mathrm{r}_{\mathrm{x}, \mathrm{y}}\right)^{6}}{2^{2} \cdot 4^{2} \cdot 6^{2}} \cdot\left(\ln \left(\mathrm{r}_{\mathrm{x}, \mathrm{y}}\right)-\frac{5}{6}\right)+\cdots \\
+\frac{\pi}{4}\left(1-\frac{\left(\mathrm{r}_{\mathrm{x}, \mathrm{y}}\right)^{4}}{2^{2} \cdot 4^{2}}+\frac{\left(\mathrm{r}_{\mathrm{x}, \mathrm{y}}\right)^{4}}{2^{2} \cdot 4^{2} \cdot 6^{2} \cdot 8^{2}}-\cdots\right) \\
\ldots-1 \cdot 1159 \cdot\left(\frac{\left(\mathrm{r}_{\mathrm{x}, \mathrm{y}}\right)^{2}}{2^{2}}-\frac{\left(\mathrm{r}_{\mathrm{x}, \mathrm{y}}\right)^{6}}{2^{2} \cdot 4^{2} \cdot 6^{2}}+\cdots\right)
\end{array}\right\}
\end{gathered}
$$

Sendo o raio $\mathrm{r}_{\mathrm{x}, \mathrm{y}}$ a distância radial normalizada a partir do ponto de origem

$$
r_{x, y}=\frac{\sqrt{x^{2}+y^{2}}}{\beta}
$$

A terceira solução para a deflexão, chamada de "função seno" é descrita como

$$
\begin{gathered}
w(\mathrm{x}, \mathrm{y})=\frac{\mathrm{P}}{8\left(\rho_{\mathrm{m}}-\rho_{\mathrm{c}}\right) \mathrm{g} \beta^{2}} \sqrt{\frac{\pi}{2}} \frac{\mathrm{e}^{-\left(\mathrm{r}_{\mathrm{x}, \mathrm{y}}\right) \sqrt{\frac{1}{2}}}}{\sqrt{\left(\mathrm{r}_{\mathrm{x}, \mathrm{y}}\right)}} \\
\mathrm{x}\left\{\sin \left[\left(\mathrm{r}_{\mathrm{x}, \mathrm{y}}\right) \sqrt{\frac{1}{2}}+\frac{\pi}{8}\right]-\frac{1}{8\left(\mathrm{r}_{\mathrm{x}, \mathrm{y}}\right)} \sin \left[\left(\mathrm{r}_{\mathrm{x}, \mathrm{y}}\right) \sqrt{\frac{1}{2}}+\frac{3 \pi}{8}\right]+\cdots\right\}
\end{gathered}
$$

As três funções foram combinadas a fim de alcançar uma solução analítica para o cálculo da rigidez flexural. Investigações realizadas por Wienecke (2006) mostraram que a função logarítmica é apropriada apenas para pequenos valores do raio $\mathrm{r}_{\mathrm{x}, \mathrm{y}}$. No entanto, os valores de deflexão produzidos pela função seno são subestimados apenas para pequenos valores de $r_{x, y}$. Sendo assim, deve-se trocar de função analítica para função seno na distância $r(x, y)=2 \beta$.

0 aparecimento da primeira ombreira (bulge) em uma distância x pode ser calculado através da equação (Hertz 1884):

$$
x_{\text {"bulge" }}=\beta .3,89
$$


De acordo com Hertz (1884), a deflexão resulta na ombreira $w(x$ "bulge" $)=$ $0 \mathrm{~km}$ e à medida que vai aumentando a distância radial, a deflexão se torna positiva. Wienecke (2006) encontrou que tal afirmação é valida apenas para a função seno (figura 5).

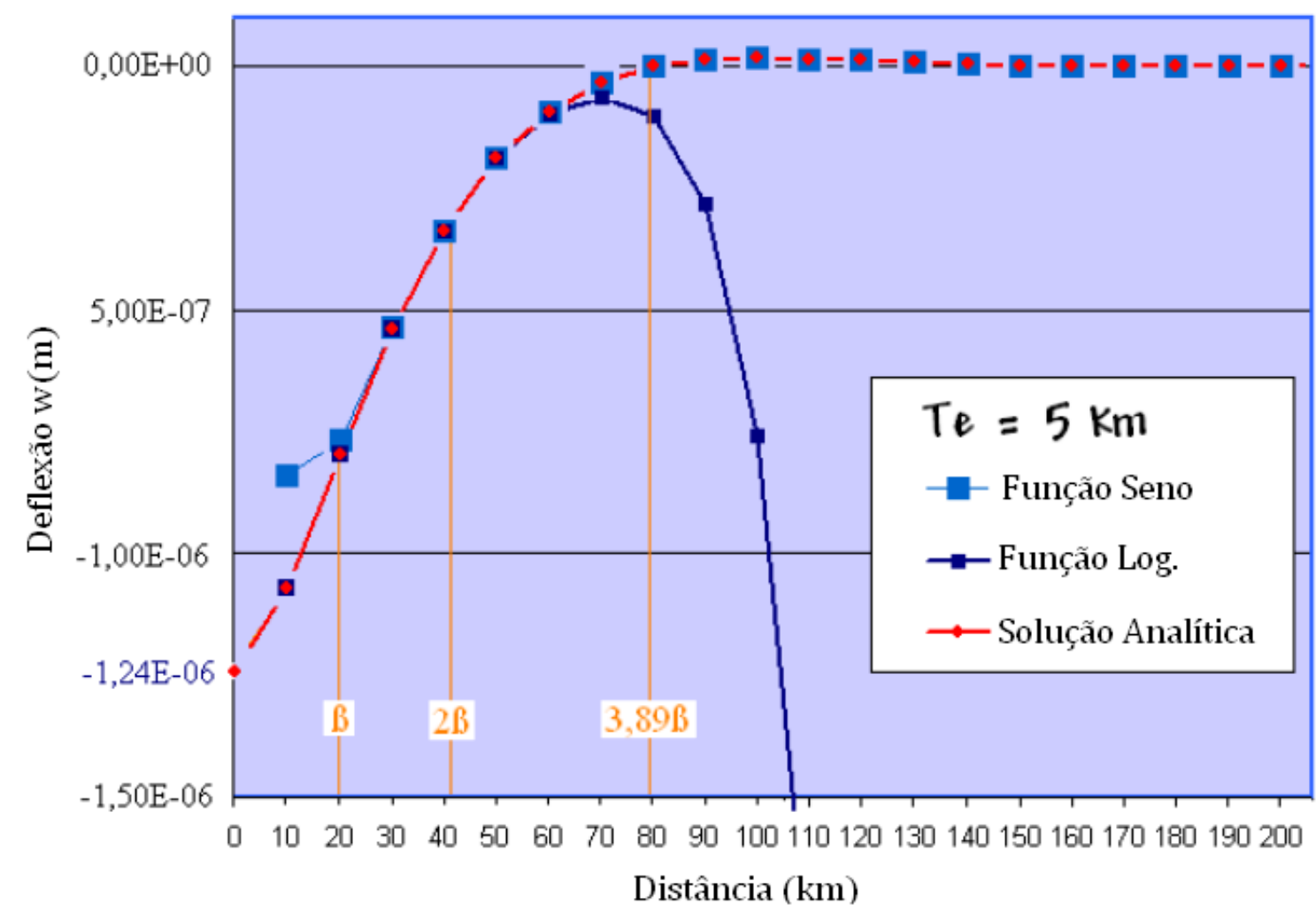

Figura 5: Adaptada de Wienecke (2006). Como exemplo, Wienecke calculou a solução analítica para uma placa elástica (ASEP) para um ponto de carga com $\mathrm{h}=1 \mathrm{~km}, \mathrm{D}=1.11 .10^{21} \mathrm{Nm}, \mathrm{g}=9.81 \mathrm{~ms}^{-2} \mathrm{e}$ densidades $\rho_{\mathrm{m}}=3500 \mathrm{~kg} \mathrm{~m}^{-3} \mathrm{e} \rho_{\mathrm{c}}=2700 \mathrm{~kg} \mathrm{~m}^{-3}$. A ASEP consiste de três soluções diferentes em dependência do parâmetro flexural $\beta$ : (a)solução para o ponto de origem, (b) função logarítmica e (c) função seno. As soluções são mostradas em um perfil na direção x (então, $r(x, y)$ corresponde a x neste caso). Como no ponto $2 \beta$ a função logarítmica e seno tem o mesmo valor de deflexão $\mathrm{w}$, a ASEP consiste de uma função logarítmica para o raio $\mathrm{r}(\mathrm{x}, \mathrm{y}) \leq 2 \beta$ a então muda para função seno para $r(x, y)>2 \beta$.

A fim de acelerar os cálculos, a função analítica deve ser interrompida em uma certa distância. Tendo em vista o fato de que o valor de deflexão deve alcançar o zero antes de a função ser cortada, esta deve ser considerada dentro da distância $x_{\text {"bulge" }}=\beta \cdot 3,89$ Esta distância será chamada durante o presente trabalho de "raio de convolução", e será utilizada a abordagem de convolução descrita por Braitenberg (2006). 


\section{Capítulo 2}

\section{Introdução}

0 conhecimento do embasamento oceânico é de grande importância em diversas aplicações na área de geociências. Sua estrutura é composta principalmente por rochas ígneas e metamórficas e representa a situação tectônica e a história de uma determinada região.

O fundo oceânico sofre um constante processo de sedimentação. Em algumas áreas, a cobertura de sedimentos pode ocultar feições tectônicas do embasamento como lineamentos, blocos crustais inclinados, cordilheiras e eixos de espalhamento. 0 conhecimento dessas estruturas pode ser extremamente útil em estudos geofísicos que visam investigar as estruturas da crosta. Por exemplo, em situações onde campanhas de coleta de dados geofísicos são realizadas ao longo de perfis, o ideal é traçá-los ortogonalmente aos lineamentos. Como o embasamento do fundo oceânico ainda não foi globalmente cartografado, grandes erros podem ser gerados durante a locação desses perfis de coleta de dados.

Segundo Braitenberg et al. (2006), os elementos responsáveis pela composição estrutural do embasamento podem ser úteis em diversos estudos, como por exemplo na determinação da densidade lateral ou variações da espessura da litosfera através do princípio do balanço hidrostático e o campo gravimétrico observado. Neste caso é necessário estimar a carga da crosta, que é determinada pela profundidade do embasamento, profundidade oceânica, espessura crustal e suas respectivas densidades (Ebbing et al., 2006).

Obter dados de gravidade através de altimetria por satélite pode ser um método rápido para avaliar a estrutura sedimentar do fundo oceânico, devido a distribuição global e de boa qualidade deste tipo de dado (Woodward \& Wood, 2000).

Em áreas oceânicas a componente de curto comprimento de onda do sinal observado geralmente está correlacionada com a batimetria. Isto foi usado em trabalhos pretéritos como de Smith \& Sandwell (1997) e Sandwel \& Smith (2001) para criar modelos de batimetria a partir de dados de gravidade. 
Vários trabalhos são encontrados na literatura onde aspectos do fundo oceânico são investigados através de dados de satélite. Smith \& Sandwell (1997) integraram dados de navio com dados de altimetria por satélites para construir um mapa da topografia dos oceanos. Ramillien \& Cazenave (1996) usaram dados in situ obtidos do NGDC e dados do ERS-1 GEODETIC MISSION para computarem globalmente a batimetria dos oceanos. Calmant \& Baudry (1996) mostraram em seu estudo diferentes técnicas para modelos batimétricos realizados a partir de dados de altimetria por satélite.

Neste trabalho utilizamos o sinal gravimétrico completo para encontrarmos as estruturas do embasamento da Bacia de Santos, de forma diferente dos trabalhos citados. Onde o embasamento apresenta uma cobertura sedimentar, a anomalia gravimétrica pode conter sinal de alta freqüência correspondente à morfologia do embasamento enterrado. Portanto, a anomalia gravimétrica utilizada neste estudo é livre do sinal correspondente à cobertura sedimentar.

$\mathrm{Na}$ crosta oceânica existem três descontinuidades de densidade predominantes: i) a superfície da água, que marca a transição da atmosfera para a água; ii) o fundo oceânico, delimitando a transição da água para um material sólido, geralmente os sedimentos e iii) embasamento, marcando a transição dos sedimentos para rocha consolidada. Na nomenclatura utilizada neste trabalho, a batimetria corresponde ao fundo oceânico e as ondulações do embasamento correspondem à topografia do embasamento. Os mapeamentos do fundo oceânico realizados a bordo de navios cartografam exclusivamente a batimetria. 0 fundo oceânico coincide com a topografia do embasamento apenas em regiões onde não há cobertura de sedimentos.

Para estudos geológicos, o conhecimento da topografia do embasamento sob uma cobertura de sedimento é muito importante para o estudo de feições oceânicas como eixos de espalhamento, cordilheiras, fossas e blocos crustais inclinados.

A interpretação do campo gravimétrico referente ao embasamento é importante para a interpretação com dados sísmicos ou em áreas onde tais dados são escassos ou indisponíveis. Isto ocorre na Bacia de Santos, que, devido ao seu alto interesse exploratório, não permite a disponibilização de grande quantidade de informações. 
No presente trabalho, através da análise combinada de dados gravimétricos, modelo batimétrico, modelo de espessura sedimentar e espessura da crosta, pretende-se determinar a estrutura do embasamento oceânico na Bacia de Santos. Trabalhos como o de Braitenberg et al. (2006) utilizaram estes dados e metodologia e determinaram com sucesso a estrutura do embasamento oceânico do Mar da China, e os autores sugerem que o estudo seja globalmente ampliado.

A hipótese científica do presente estudo é a de que feições tectônicas podem estar sendo ocultadas pelo pacote sedimentar na região Bacia de Santos, e, para que sejam estudadas é preciso ter o conhecimento da topografia do embasamento, ou seja, o subsolo que está sob esta camada de sedimentos.

\subsection{Objetivos}

O objetivo geral do presente trabalho é determinar a profundidade da ICM (Interface Crosta-Manto) e as estruturas do embasamento oceânico na região de estudo através da análise combinada de dados de anomalia gravimétrica, modelo batimétrico, modelo de espessura sedimentar e espessura da crosta.

Os objetivos específicos são:

- Modelar as variações da profundidade da ICM com base na análise espectral do campo de gravidade observada;

- Modelar as variações da profundidade da ICM com base na teoria de deformação flexural;

- Isolar a anomalia gravitacional observada a partir do sinal de gravidade da ICM e dos sedimentos, obtendo o campo de gravidade residual;

- Calcular a topografia do embasamento a partir da inversão do campo de gravidade residual assim obtido. 


\section{Capítulo 3}

\section{Dados}

Este estudo é baseado em dados gravimétricos, de batimetria, informações sobre a espessura crustal e a espessura sedimentar na região de estudo, a Bacia de Santos.

\subsection{Bacia de Santos}

A Bacia de Santos está situada na região sudeste da margem continental brasileira, entre os paralelos $23^{\circ} 00 \mathrm{~S}$ e $28^{\circ} 00^{\prime} \mathrm{S}$, até a cota batimétrica de $3.000 \mathrm{~m}$ (Figura 6). Sua área possui cerca de $350000 \mathrm{~km}^{2}$, abrangendo os litorais dos Estados do Rio de Janeiro, São Paulo, Paraná e Santa Catarina (Moreira et al. 2007).

A Bacia de Santos é uma bacia de margem passiva e tem sua origem associada aos primeiros pulsos tectônicos que ocasionaram a ruptura do continente Gondwana, no Neocimoniano, resultando na abertura do Oceano Atlântico Sul e abertura dos continentes africano e americano (Caldas \& Zalán, 2009).

Segundo Mio et al. (2006), a Bacia de Santos foi formada a partir de processos de rifteamento durante a separação afroamericana, no Mesozóico. A acumulação de sedimentos ocorreu inicialmente em condições flúvio-lacustres, passando posteriormente por um estágio de bacia evaporítica e evoluindo para uma bacia de margem passiva. Estes acontecimentos podem ser relatados como as principais fases evolutivas da Bacia: rifte, transição e margem passiva.

Segundo Mio et al. (2006), a fase rifte é composta por um magmatismo basal recoberto por uma seqüência depositada em ambiente flúvio-lacustre, composta por folhelhos, carbonatos e depósitos grossos associados a leques aluviais. A fase de transição é composta por uma espessa seção de rochas evaporíticas, depositadas durante o Aptiano em um ambiente marinho restrito, com contribuição de depósitos típicos de ambiente sabkha. Sobre os evaporitos da 
fase de transição instalou-se, durante o Albiano inferior, uma ampla plataforma carbonática, bordejada por sistemas de leques aluviais, iniciando a fase de margem passiva na bacia que perdura até hoje.

A evolução estrutural da bacia é influenciada por heterogeneidades que afetam tanto a crosta quanto o manto, que compreendem zonas de sutura entre blocos continentais, cinturões de dobramento e cavalgamento, zonas de cisalhamento e enxames de diques máficos. Estas descontinuidades controlaram o arcabouço estrutural do embasamento da Bacia de Santos através da reativação de estruturas durante o processo de estiramento e abertura (Mio, 2005).

Durante o presente trabalho, todos os dados foram processados para uma área maior que a Bacia de Santos, por dois fatores: a ausência de dados de refração sísmica disponíveis na região estrita da Bacia e para uma melhor visualização dos resultados.

\section{Batimetria}

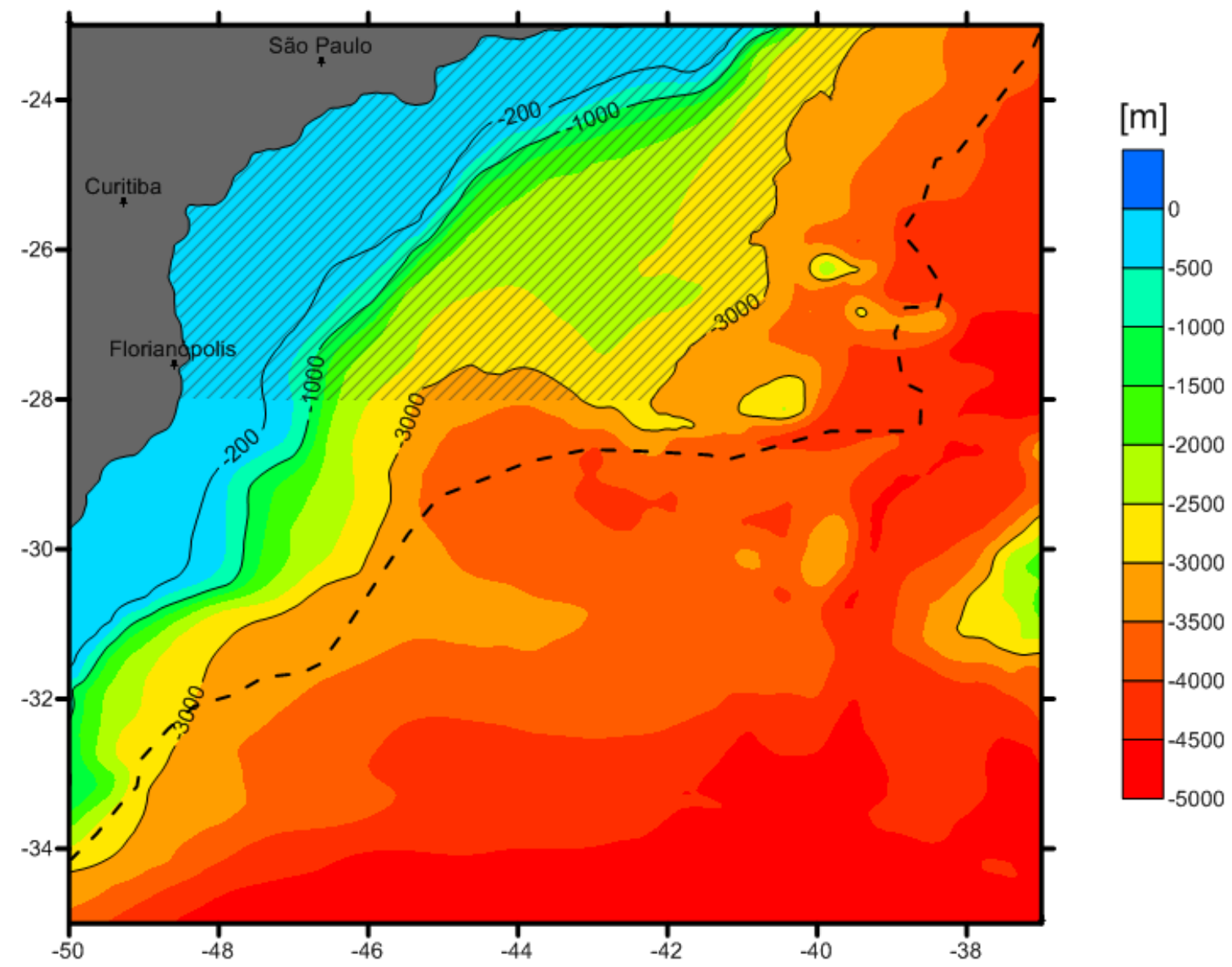

Figura 6: Dados batimétricos fornecidos pela GEBCO. A região hachurada (listras) representa a área da Bacia de Santos, delimitada segundo Moreira (2007). 0 limite crustal, segundo Cainelli \& Moriak (1998) é representado pela linha tracejada. Estão representadas também as isolinhas batimétricas referentes às profundidades 200, 100 e $3000 \mathrm{~m}$. 


\subsection{Dados gravimétricos}

Os dados de anomalia da gravidade utilizados estão disponíveis no trabalho de Molina (2009) (figura 7) e foram calculados utilizando dados de missões geodésicas de diversos satélites e geofísica marinha presentes na região do Atlântico Sul.

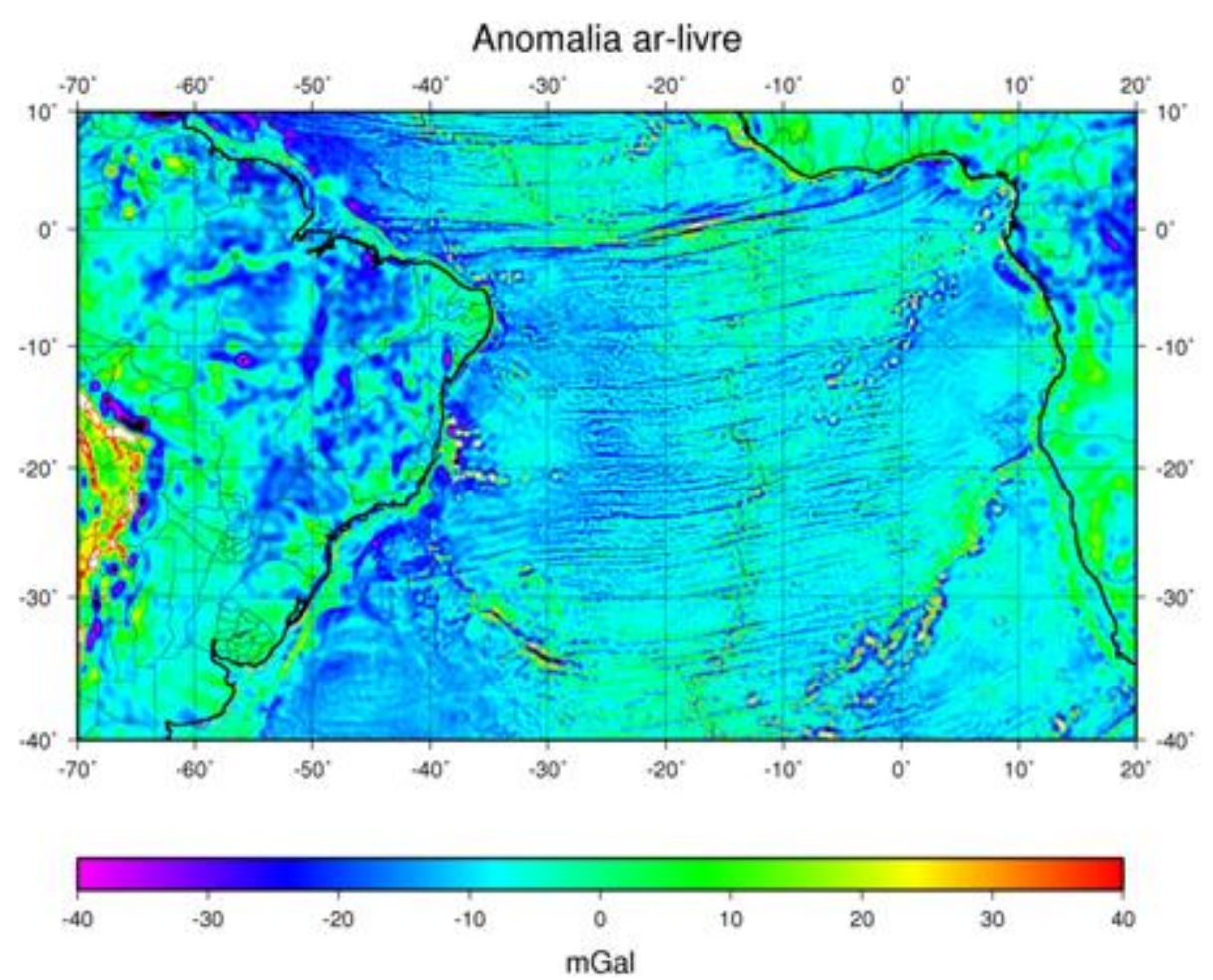

Figura 7: Anomalia ar-livre determinada a partir de dados de altimetria por satélite e geofísica marinha (Molina, 2009).

Os dados de gravimetria marinha utilizados no trabalho de Molina (2009) envolvem os cruzeiros obtidos a partir do banco de dados de Geofísica Marinha do U. S. National Geophysical Data Center e os cruzeiros referentes ao projeto EQUANT I e EQUANT II. Dados adicionais do LEPLAC foram utilizados para avaliação do modelo calculado. Os dados de altimetria por satélite são provenientes das missões geodésicas dos satélites ERS-1, GEOSAT e SEASAT.

O trabalho utiliza a derivada direcional ao longo das trilhas de satélite calculados a partir das alturas da superfície do mar e dados de gravimetria marinha para a estimativa da altura geoidal e anomalia ar-livre na superfície dos oceanos utilizando a colocação por mínimos quadrados. 0 modelo foi elaborado com uma resolução espacial de 2 × 2 arc min. 


\subsection{Modelo de Espessura Sedimentar}

0 modelo de espessura sedimentar (figura 8) foi retirado do "Total Sediment Thickness of the World's Oceans and Marginal Seas, World Data Center for Marine Geology and Geophysics, Boulder" (Divins, D.L). Os dados digitais de espessura sedimentar foram compilados pela "National Geophysical Data Center" (NGDC) da NOAA (National Oceanic and Atmospheric Administration) e possuem resolução de 5 x 5 arc min. Os dados de espessura sedimentar foram compilados a partir de três principais fontes: (i) Mapas de Isópacas previamente publicados, (ii) Resultados de perfuração oceânica, fornecidos por ambos os projetos "Ocean Drilling Program" (ODP) e "Deep Sea Drilling Project" (DSDP); (iii) perfis de sísmica de reflexão arquivados pela NGDC.

Para o Atlântico Sul, os mapas de isópacas foram digitalizados por Dennis Hayes do Lamont-Doherty Earth Observatory. Os dados digitalizados foram convertidos em grade na NGDC usando o algoritmo de splines sob tensão de Smith e Wessel (1990).

Os valores são em metros e representam a profundidade do embasamento acústico, definido como o refletor observável mais profundo nos perfis de sísmica de reflexão, que pode não representar a base dos sedimentos. Estes dados têm como objetivo fornecer um valor mínimo para a espessura dos sedimentos em uma área geográfica particular. 
Total Sediment Thickness of the World's Oceans \& Marginal Seas

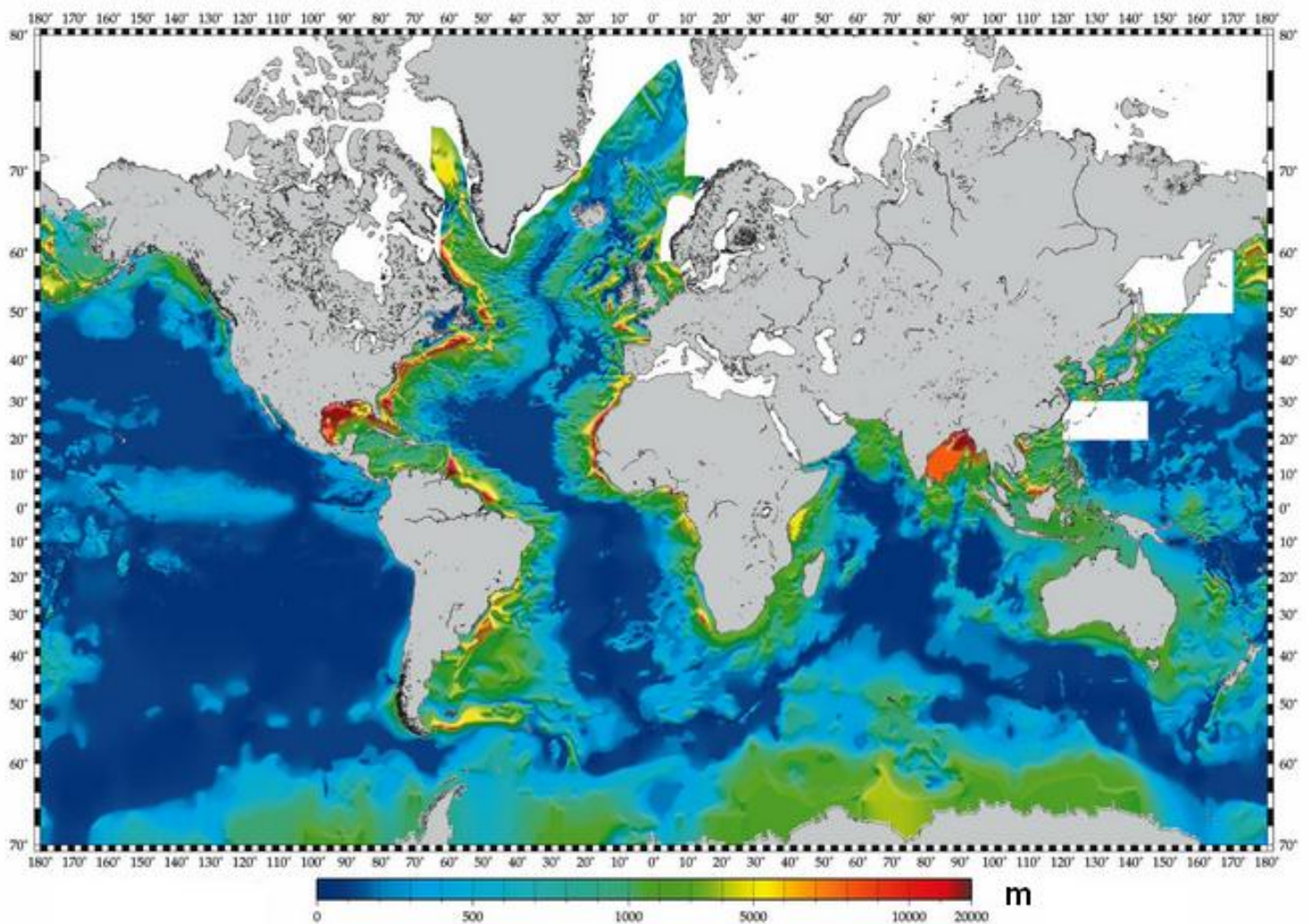

Figura 8: Modelo de espessura sedimentar. Fonte: Divins, D.L., NGDC Total Sediment Thickness of the World's Oceans \& Marginal Seas, http://www.ngdc.noaa.gov/mgg/sedthick/sedthick.html. (site consultado em mar/2011).

Como o modelo representa apenas a espessura da camada sedimentar, dados complementares como densidade e porosidade foram obtidos do "Deep Sea Drilling Project" (DSDP), projeto internacional iniciado em 1968 para perfuração e investigação do oceano profundo a bordo do navio Glomar Challenger.

Para obter os dados para o presente trabalho foi utilizada a leg 39, site 356, correspondente à latitude -28.2870 e longitude -41.0880 (figura 9). A perfuração neste local atingiu 741 metros de profundidade e os resultados da análise, disponíveis no NGDC, fornecem dados geoquímicos, geofísicos e biológicos. Maiores detalhes podem ser encontrados em Supko (1997). 


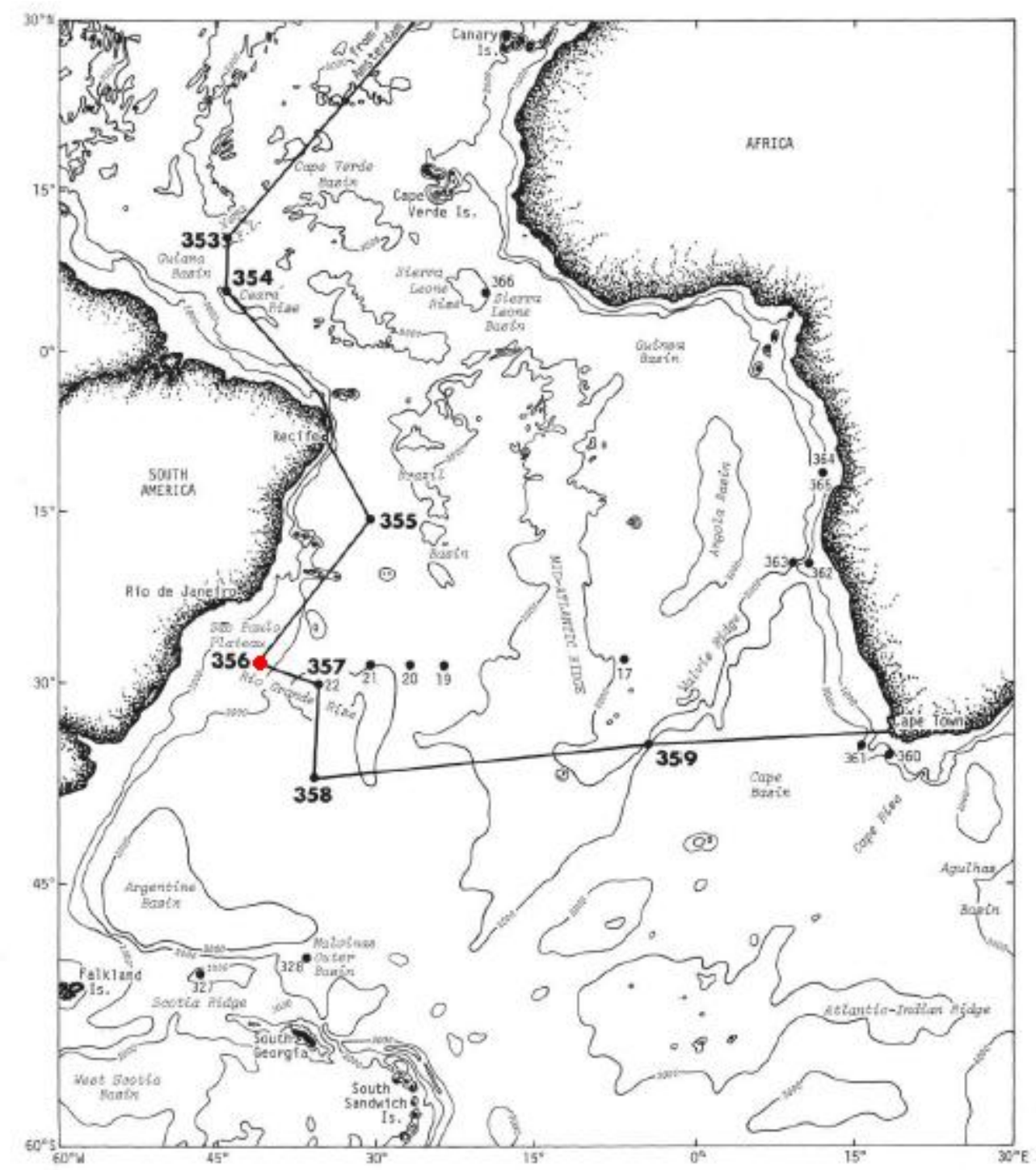

Figura 9: Rota do Glomar Challenger durante perfurações da leg 39. Em vermelho, a localização do ponto utilizado para este trabalho. Figura Adaptada de Supko (1997).

\subsection{Dados Batimétricos}

Os dados batimétricos utilizados foram extraídos da GEBCO (figura 10). A grade utilizada corresponde a um intervalo de $1 \mathrm{arc} \min$ (GEBCO One Minute Grid). Os dados são baseados em contornos batimétricos contidos no GEBCO Digital Atlas (GDA), mantido pelo British Oceanographic Data Centre (BODC) sobre os cuidados da International Hydrographic Organization (IHO) e da Intergovernmental Oceanographic Commission (IOC) da UNESCO. 


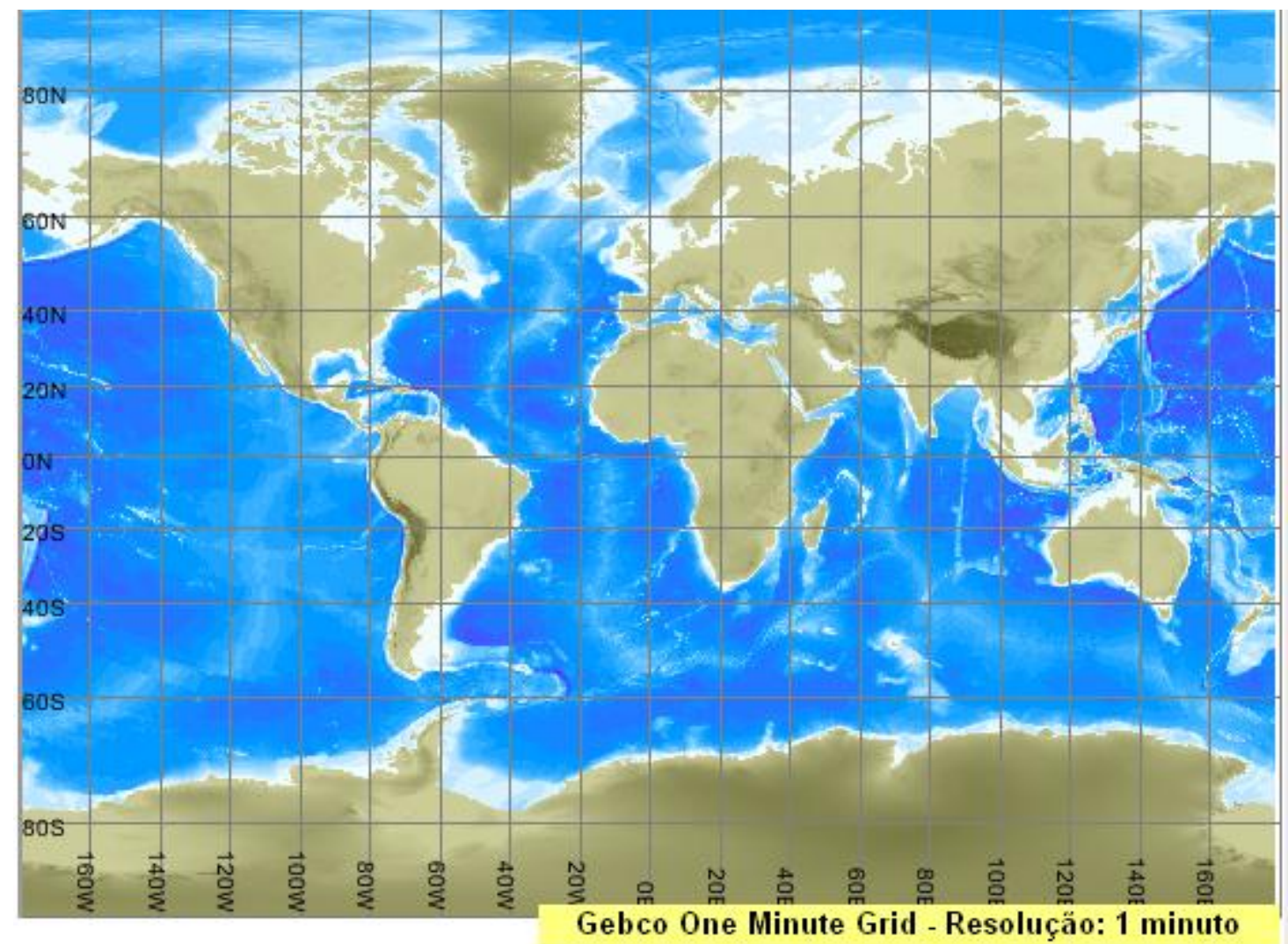

Figura 10: Dados batimétricos do GEBCO. Fonte: www.gebconet. Site consultado em $\operatorname{mar} / 2011$.

\subsection{Dados de Espessura Crustal}

Os dados de espessura crustal foram retirados do trabalho de Leyden (1971) e Zalán (2011).

Os dados obtidos de Leyden (1971) são provenientes de 33 perfis de sísmica de refração registrados ao longo de duas linhas entre Punta Del Este e Rio Grande, realizados em junho de 1960. Ao todo, para este trabalho, 16 valores de espessura crustal foram utilizados. Estes valores são mostrados na figura 11.

Aparentemente, estes eram os únicos dados de espessura crustal obtidos por sísmica de refração disponíveis publicamente. Valores de espessura crustal obtidos por outros métodos podem ser encontrados na literatura, porém a partir de testes realizados durante este trabalho, nenhum destes dados apresentava localização, resolução e conteúdo apropriado.

Onze valores adicionais foram recentemente encontrados em Zalán (2011) (Figura 11). Tais valores são resultados da interpretação de 12000 km de seções 
sísmicas 2D adquiridas pelo ION-GTX, acopladas, linha por linha, com dados de gravimetria e magnetometria e integrados com valores regionais disponíveis no banco de dados da Petrobrás.

\section{Valores de Espessura Crustal}

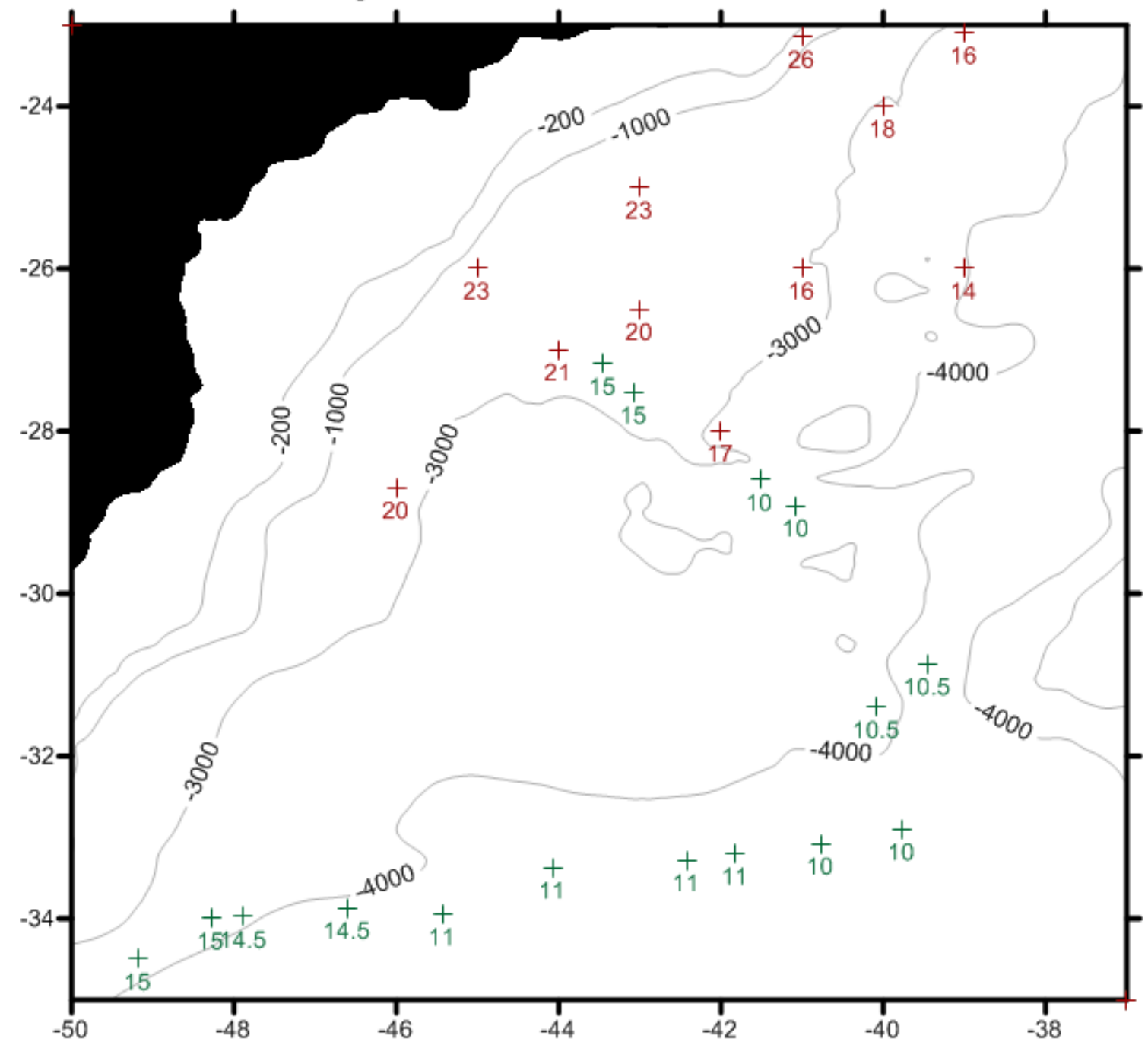

Figura 11: Mapa batimétrico com valores de espessura crustal, em metros. Em vermelho, dados referentes à Zalán (2011) e em verde, relativos a Leyden (1971). 


\section{Capítulo 4}

\section{Metodologia}

Modelos batimétricos formulados a partir do curto comprimento de onda do campo gravimétrico têm sido úteis em estudos onde não existem dados obtidos diretamente ou mesmo em áreas onde estes dados não estão disponíveis publicamente e normalmente oferecem informações sobre o topo da camada sedimentar. Neste trabalho o objetivo é encontrar estruturas do embasamento, que podem estar sendo ocultadas pela camada sedimentar. A fim de alcançar tal objetivo, este estudo se baseou na metodologia proposta por Braitenberg et al. (2006), que faz uso do sinal gravimétrico completo e combina inversão gravimétrica com análise flexural para esta análise.

0 ponto inicial para utilizar o método é a base de dados contendo observações de anomalia da gravidade, estimativa da espessura crustal obtidas através de investigações sísmicas, modelo de espessura sedimentar e modelo batimétrico. As etapas da aplicação do método neste estudo estão descritas a seguir.

\subsection{Etapa 1}

A primeira parte do trabalho modela as variações da ICM a partir da inversão do campo gravimétrico.

Os dados de anomalia ar-livre (Molina, 2009) foram corrigidos para obterse a anomalia Bouguer. O campo gravimétrico assim obtido foi então corrigido para remover o efeito da cobertura sedimentar. O efeito gravimétrico da camada sedimentar pode ser calculado pelo algoritmo de Parker (1972), que expande o campo de gravidade gerado pela camada de descontinuidade em série até ordem 5. O cálculo pode ser realizado com um contraste de densidade constante para toda a descontinuidade, porém, para considerar a situação mais próxima da real a compactação sedimentar com a profundidade deve ser considerada. Para isso, utilizou-se um modelo de compactação sedimentar descrito por Sclater \& Christie 
(1980), baseado em uma redução exponencial da porosidade com a profundidade. Segundo esses autores, a densidade em função da profundidade abaixo do fundo oceânico (z) é calculada a partir da relação

$$
\rho(z)=\rho_{\mathrm{f}} \varphi_{0} \mathrm{e}^{-\frac{\mathrm{z}}{\mathrm{d}}}+\rho_{\mathrm{g}}\left(1-\varphi_{0} \mathrm{e}^{-\frac{\mathrm{z}}{\mathrm{d}}}\right)
$$

sendo:

$\rho_{\mathrm{f}}=$ Densidade do fluído

$\rho_{\mathrm{g}}=$ Densidade da rocha/grão

$\varphi_{0}=$ Porosidade inicial dos sedimentos

$\mathrm{d}=$ Parâmetro de decaimento

O efeito gravimétrico dos sedimentos foi então calculado aplicando esse modelo para uma série de camadas finas (10 m de espessura), com densidade lateral variável, descritas pela equação (33).

Os valores de densidade e porosidade inicial utilizados são provenientes do Deep Sea Drilling Project (DSDP) e correspondem a $2750 \mathrm{~kg} / \mathrm{m}^{3}$ e 0.66 respectivamente. A densidade do fluído é padrão, com o valor de $1030 \mathrm{~kg} / \mathrm{m}^{3}$ e o parâmetro de decaimento foi determinado no presente trabalho através da calibração dos dados do DSDP e encontrado para $1.4 \mathrm{~km}$.

Após o cálculo do efeito da cobertura sedimentar, o campo corrigido (resultante da subtração do efeito gravitacional dos sedimentos da anomalia Bouguer) foi invertido através do Modelo de Inversão proposto por Braitenberg \& Zadro (1999).

\subsubsection{Modelo de Inversão Gravimétrica Iterativo}

A metodologia proposta por Braitenberg \& Zadro (1999) é uma solução iterativa que alterna a lei de continuação para baixo com calculo direto do campo gravimétrico referente ao modelo. 
Sendo $\mathrm{g}_{0}(\mathrm{x}, \mathrm{y})$ a anomalia Bouguer, $d$ a profundidade de referência e $\mathrm{r}(\mathrm{x}, \mathrm{y})$ a oscilação da interface desejada, definida como o desvio a partir da profundidade $d$, e sendo $\mathrm{g}_{\mathrm{d}}(\mathrm{x}, \mathrm{y})$ o campo continuado para baixo, para a profundidade $d$, tomando-se a transformada de Fourier do campo gravimétrico, tem-se

$$
\begin{gathered}
g_{d}\left(k_{x}, k_{y}\right)=e^{d} g_{0}\left(k_{x} k_{y}\right) \\
\gamma=\sqrt{k^{2}{ }_{x}+k^{2}{ }_{y}}
\end{gathered}
$$

sendo $\mathrm{k}_{\mathrm{x}}, \mathrm{k}_{\mathrm{y}}$ números de onda ao longo do eixo de coordenadas.

Admitindo que o campo gravimétrico é gerado por uma lâmina de massa localizada na profundidade $d$, a densidade superficial da lâmina de massa $\sigma(\mathrm{x}, \mathrm{y})$ é dada por:

$$
\sigma(x, y)=\frac{1}{2 \pi G} g_{d}(x, y)=\frac{1}{2 \pi G} F^{-1}\left[g_{d}\left(k_{x}, k_{y}\right)\right]
$$

sendo $\mathrm{FT}^{-1}$ a Transformada Inversa de Fourier e G a constante gravitacional.

A lâmina de massa com densidade superficial horizontalmente variável é interpretada como a interface oscilante que separa duas camadas com um contraste de densidade $\Delta \rho$. A amplitude de oscilação da interface é dada por

$$
r_{1}(x, y)=\frac{1}{\Delta \rho} \sigma(x, y)
$$

Deve-se notar que o campo gravimétrico gerado pela interface coincide com o campo $\mathrm{g}_{0}(\mathrm{x}, \mathrm{y})$ apenas em primeira aproximação. Neste método é realizada uma aproximação da interface por meio de uma série de prismas retangulares e é calculado o campo gravimétrico aplicando o algoritmo descrito por Nagy (1966). 0 campo gravimétrico residual $\delta g_{1}(x, y)$ é definido como a diferença entre o campo observado $\left(g_{0}(x, y)\right)$ e o campo $\left(g_{1}(x, y)\right)$ gerado pela série de prismas 


$$
\delta g_{1}(x, y)=g_{0}(x, y)-g_{1}(x, y)
$$

O campo residual é continuado para baixo e a correção introduzida na densidade de superfície da lâmina massa é obtida pela Eq. 35. A correção afeta a amplitude de oscilação da interface de densidade de acordo com a Eq. 36. 0 procedimento é repetido iterativamente, obtendo a cada nova iteração $(\mathrm{k})$ o campo gravimétrico residual $\delta g_{k}(x, y)$ e a amplitude de oscilação da interface $r_{k}(x, y)$.

O número padrão de iterações utilizado por Braitenberg \& Zadro (1999) é 3, e o mesmo foi utilizado neste trabalho, gerando resultados bastante satisfatórios.

\subsection{Etapa 2}

Esta etapa envolve a flexura da placa litosférica, um meio independente para determinar as ondulações da ICM, permitindo que a confiabilidade dos dados obtidos na etapa 1 seja checada. A análise flexural é feita com base na metodologia introduzida por Braitenberg et al. (2002, 2003).

0 modelo de flexura de placa fina prevê que as camadas mais externas da terra respondam às cargas a longo prazo ( $>1 \mathrm{Myr})$ similarmente a uma placa elástica fina sobre um fluído viscoso. As cargas são compostas da soma da carga topográfica e intracrustal (referente aos sedimentos). Esta carga tem valores negativos para a situação deste trabalho, porque o preenchimento das bacias com água faz com que fiquem menos densas em relação à crosta de referência. A flexura $w(\vec{r})$ de uma placa carregada pela carga $h(\vec{r})$, no espaço de frequência, é, segundo Watts (2001) e Turcotte et al. (1982)

$$
\mathrm{W}(\overrightarrow{\mathrm{k}})=\frac{\rho_{\mathrm{c}}}{\rho_{\mathrm{m}}-\rho_{\mathrm{c}}+\frac{\mathrm{D}}{\mathrm{g}}|\overrightarrow{\mathrm{k}}|^{4}} \mathrm{H}(\overrightarrow{\mathrm{k}})
$$

Onde $\vec{r}=(x, y), W(\vec{k})$ é a transformada de Fourier da flexura $w(\vec{r})$ da placa, $H(\vec{k})$ é a transformada de Fourier da topografia, $\rho_{c}, \rho_{m}$ são as densidades da crosta e do manto, respectivamente, $\mathrm{g}$ a aceleração média da gravidade, $\overrightarrow{\mathrm{k}}=\mathrm{k}_{\mathrm{x}}, \mathrm{k}_{\mathrm{y}}=2 \pi\left(\mathrm{v}_{\mathrm{x}}, \mathrm{v}_{\mathrm{y}}\right)$ 
o número de onda bidimensional, $\mathrm{v}_{\mathrm{x}}, \mathrm{v}_{\mathrm{y}}$ frequências ao longo do eixo $\mathrm{x}$ e $\mathrm{y}$, respectivamente e D é a rigidez flexural da placa, que caracteriza a resposta da litosfera aos seus carregamentos (Karner \& Watts, 1982) e é descrita pela equação

$$
\mathrm{D}=\frac{\mathrm{ETe}^{3}}{12\left(1-v^{2}\right)}
$$

com

$\mathrm{E}=$ Módulo de Young

$v=$ Razão de Poisson

$\mathrm{Te}=$ espessura elástica efetiva

Tomando a transformada inversa de Fourier da Eq. 38, a relação entre as duas quantidades é dada no espaço pela relação

$$
w(\vec{r})=s(\vec{r}) * h(\vec{r})
$$

que descreve o produto de convolução da carga $h(\overrightarrow{\mathrm{r}})$ com a função resposta flexural para uma carga pontual $s(\overrightarrow{\mathrm{r}})$.

No modelo de flexura de placa fina, é geralmente admitido que a flexura $\mathrm{w}(\overrightarrow{\mathrm{r}})$ é aproximadamente igual aos desvios de nivelamento da ICM.

Para cada nó da grade de carga topográfica, uma curva de resposta flexural é calculada com a ASEP, conforme descrito no item 1.2.6. Cada nó da grade é definido pelos pares de coordenadas $(\mathrm{x}, \mathrm{y})$ em uma altura (z). Essa altura é usada, com a densidade e aceleração da gravidade g, para definir o ponto de carga. Cada valor da grade é uma carga distribuída "retangularmente".

Um ponto de carga, entretanto, pode ser considerado uma carga retangular relacionada a uma unidade de área. Assim, a ASEP deve ser normalizada para cada valor do nó da grade, com $A=d x$.dy, onde $d x$ é a distância na direção $x$ e dy na direção y. Este método foi testado em Wienecke (2006).

Usando uma série de funções resposta para uma carga flexural pontual na convolução, cada uma correspondendo a um valor de Te entre 0 - 110km, com intervalos de 1 - 10km, é obtida a ondulação da flexura da ICM correspondente. 
Para este trabalho, preparou-se um conjunto de curvas de resposta flexural referente a valores de Te entre 0 e $25 \mathrm{~km}$ em intervalos de $1 \mathrm{~km}$.

Para evitar efeitos de borda, os dados de entrada referentes à carga topográfica devem ter uma área maior em relação à esperada para o dado de saída, ou seja, a área de estudo, devido ao valor de raio de convolução, definido pela equação 32. Fora da área definida pelo raio de convolução, a deflexão da placa causada pela carga é insignificante. Neste trabalho, o raio de convolução, que varia em função da espessura elástica e das densidades da crosta e do manto, ficou entre 25 e $284 \mathrm{~km}$. Maiores valores de espessura elástica requerem maiores valores de raio de convolução (Braitenberg , 2006). Uma discussão sobre a escolha do raio de convolução pode ser encontrada em Wienecke (2006).

Para calcular as variações espaciais da Te, o erro RMS (root mean square) entre a ICM observada e as ondulações da flexura da ICM pode ser determinado em janelas de comprimentos laterais L. A melhor Te invertida para uma janela é aquela que minimiza o erro RMS, e, portanto, atinge a aproximação de melhor ajuste da ICM observada.

\subsection{Etapa 3}

Nesta etapa, o efeito gravimétrico da ICM encontrada na etapa 2 é calculado utilizando-se um contraste de densidade constante ao longo da ICM, aplicando o algoritmo Parker (1972).

O objetivo deste procedimento é isolar a anomalia de gravidade observada do sinal de gravidade da ICM e dos sedimentos:

$$
\mathrm{g}_{\text {res }}=\mathrm{g}_{\mathrm{obs}}-\mathrm{g}_{\mathrm{CMI}}-\mathrm{g}_{\mathrm{sed}}
$$

O campo residual ( $g_{\text {res }}$ ) assim obtido pode então ser invertido para o cálculo da topografia do embasamento, que é o objetivo da próxima etapa. 


\subsection{Etapa 4}

O último passo consiste da inversão do campo $\mathrm{g}_{\text {res }}$ a partir do Modelo Inverso Iterativo com Vínculos. 0 procedimento resulta na topografia do embasamento.

O desenvolvimento da metodologia foi realizado com o auxílio do software LithoFLEX (Braitenberg et al., 2007), que, por sua aplicação direta no problema investigado no presente trabalho, será brevemente descrito a seguir.

O LithoFLEX é uma ferramenta de trabalho extremamente útil para interpretação de dados de anomalia de gravidade em regiões oceânicas e em áreas continentais. A ferramenta combina a modelagem direta e inversão de dados gravimétricos com a investigação do estado isostático.

Uma das situações em que o LithoFLEX pode ser aplicado inclui o estudo e a caracterização do embasamento através da inversão do campo de gravidade. Estudos investigando áreas oceânicas distintas como o East Barents Sea e o South China Sea utilizando esse software estão descritos em Braitenberg et al. (2007).

O software LithoFLEX dispõe de ferramentas com as seguintes funções:

A) Cálculos de anomalia de gravidade direta:

- Cálculo do efeito da anomalia da gravidade de uma camada de descontinuidade

- Cálculo do efeito da anomalia da gravidade dos sedimentos

- Inversão de dados gravimétricos

B) Cálculos Isostáticos

- Flexura direta

- Inversão da espessura elástica efetiva (Te)

C) Ferramentas extras

- Cálculo de topografia equivalente: ferramenta onde podem ser estimadas as cargas para cálculos flexurais, expressos pela topografia equivalente.

- Topografia sintética: permite que uma topografia sintética seja criada a partir de dados aleatórios. 


\section{Capítulo 5}

\section{Resultados}

A topografia do embasamento é calculada seguindo as quatro etapas descritas anteriormente. A etapa A1 envolve corrigir o campo gravimétrico para o efeito da cobertura sedimentar. 0 modelo de espessura sedimentar fornecido pela NOAA (Figura 12) consiste apenas na espessura sedimentar. Dados de densidade e porosidade obtidos por medição direta foram retirados do Deep Sea Drilling Project (Figura 7).

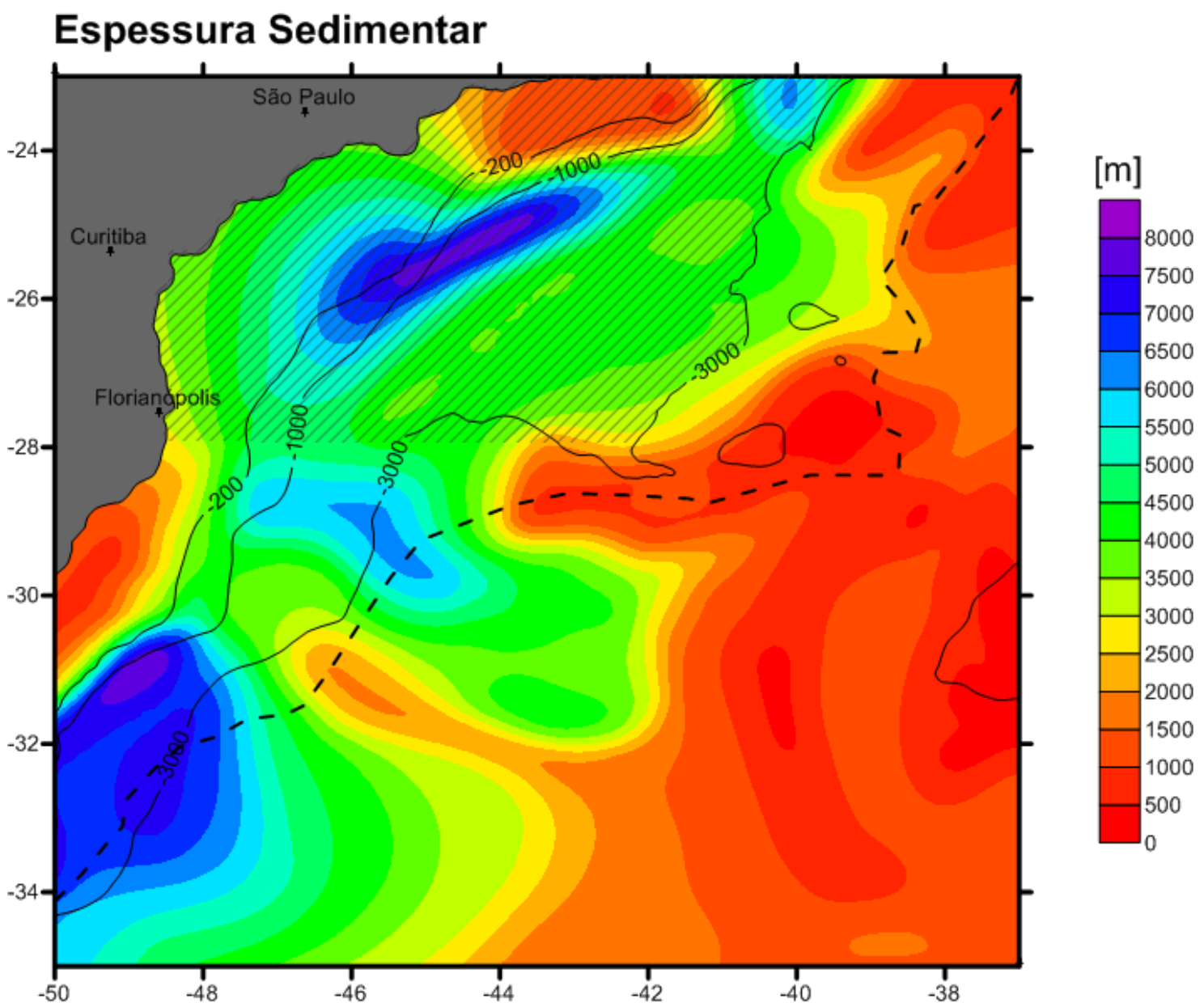

Figura 12: Modelo de espessura sedimentar obtido pela NGDC. A região hachurada (listras) representa a área da Bacia de Santos, delimitada segundo Moreira (2007). 0 limite crustal, segundo Cainelli \& Moriak (1999) é representado pela linha tracejada. Estão representadas também As isolinhas batimétricas referentes às profundidades 200, 1000 e $3000 \mathrm{~m}$. 
O efeito gravimétrico dos sedimentos é calculado utilizando o modelo de Sclater \& Christie (1980) em uma série de camadas finas (10 metros de espessura) com densidade lateral variável, descrito pela equação 33. Este efeito é mostrado na figura 13.

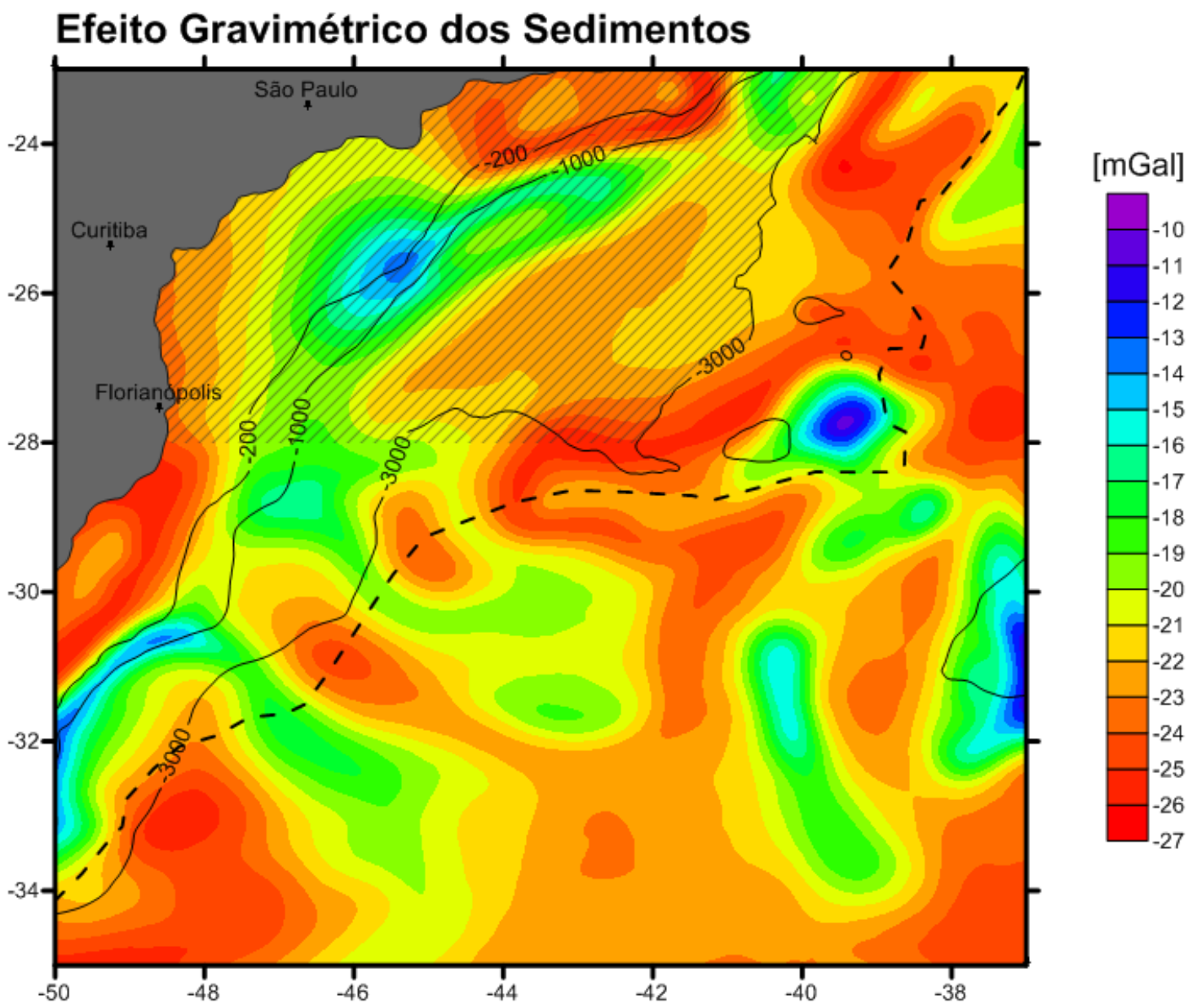

Figura 13: Campo gravimétrico referente ao pacote sedimentar. A região hachurada (listras) representa a área da Bacia de Santos, delimitada segundo Moreira (2007). 0 limite crustal, segundo Cainelli \& Moriak (1999) é representado pela linha tracejada. Estão representadas também As isolinhas batimétricas referentes às profundidades 200, 1000 e $3000 \mathrm{~m}$.

A camada de sedimentos contribui no sinal gravimétrico na ordem de aproximadamente -10 a -30 mGal. Na área delimitada como Bacia de Santos, a contribuição é em torno de -12 mGal (região azul). Este valor vai aumentando em um padrão circular, chegando a valores de $-27 \mathrm{mGal}$ nos extremos da Bacia, ou seja, próximo à costa e próximo a cota batimétrica de $3000 \mathrm{~m}$.

Para a obtenção da profundidade da ICM a contribuição dos sedimentos no sinal gravimétrico é, então, subtraída da anomalia Bouguer (figura 14). 0 campo resultante desta subtração (figura 15) é utilizado na inversão. 


\section{Anomalia Bouguer}

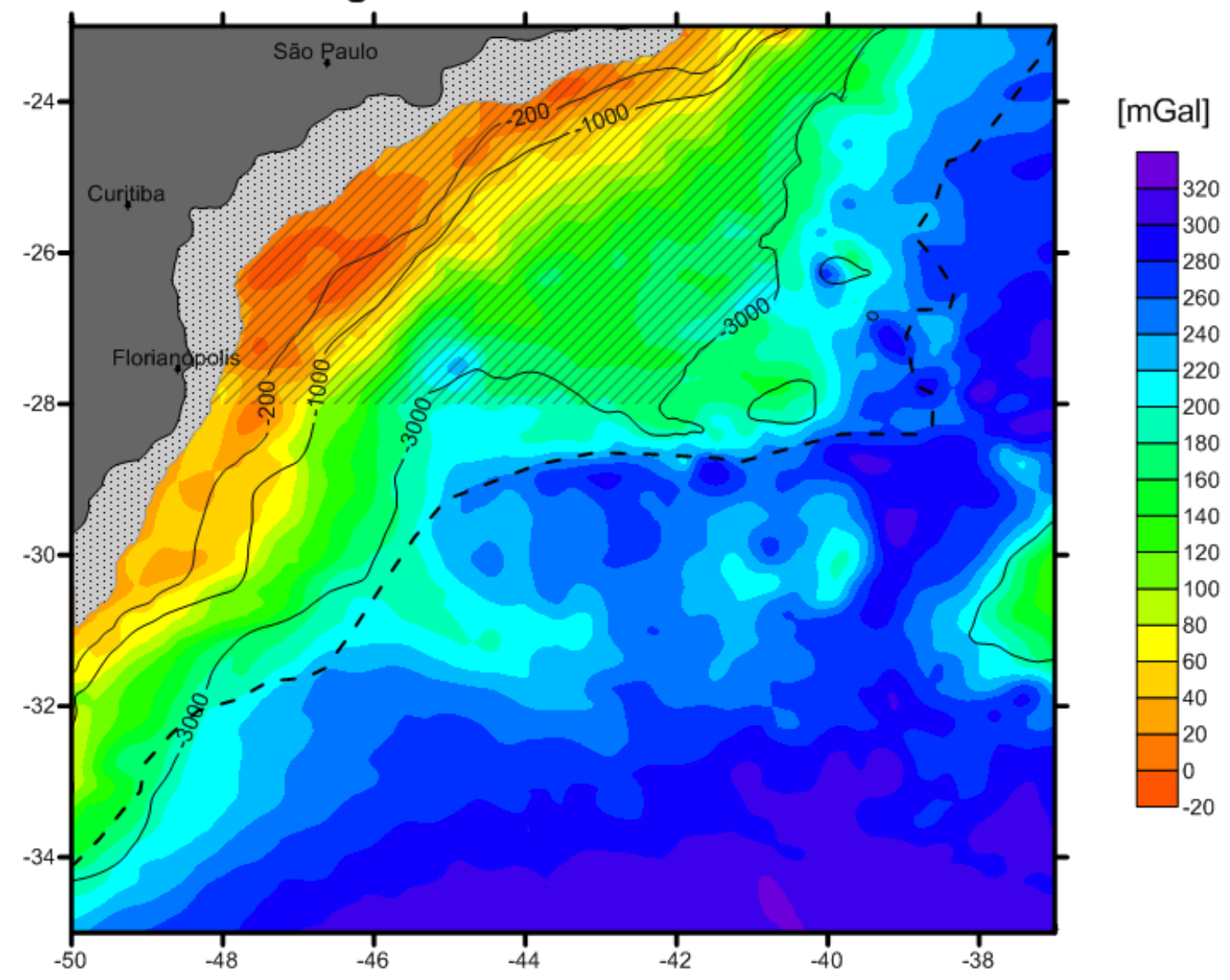

Figura 14: Anomalia Bouguer (Molina, 2009). As regiões hachuradas (listras e pontilhados) representam, respectivamente, a área da Bacia de Santos, delimitada segundo Moreira (2007) e a área onde os dados gravimétricos não são confiáveis. O limite crustal, segundo Cainelli \& Moriak (1999) é representado pela linha tracejada. Estão representadas também As isolinhas batimétricas referentes às profundidades 200, 1000 e $3000 \mathrm{~m}$

Os valores de Anomalia Bouguer para a área da Bacia de Santos são da ordem de 0 a $180 \mathrm{mGal}$. Valores próximos da costa (em torno da cota batimétrica de $85 \mathrm{~m}$ ) apresentam efeito de borda e não são considerados confiáveis, por isso, durante este trabalho, esses valores serão desconsiderados. Todos os dados influenciados pelo campo gravimétrico serão representados pela área hachurada em cinza.

Os valores de anomalia Bouguer aumentam à medida que se afastam da costa e atingem seu máximo dentro da Bacia, próximo à cota batimétrica de $3000 \mathrm{~m}$. Esses valores continuam aumentando progressivamente e atingem aproximadamente 320 mGal (área em roxo) nos extremos da região investigada.

O campo gravimétrico corrigido, sem o sinal da cobertura sedimentar, é mostrado na figura 15. 


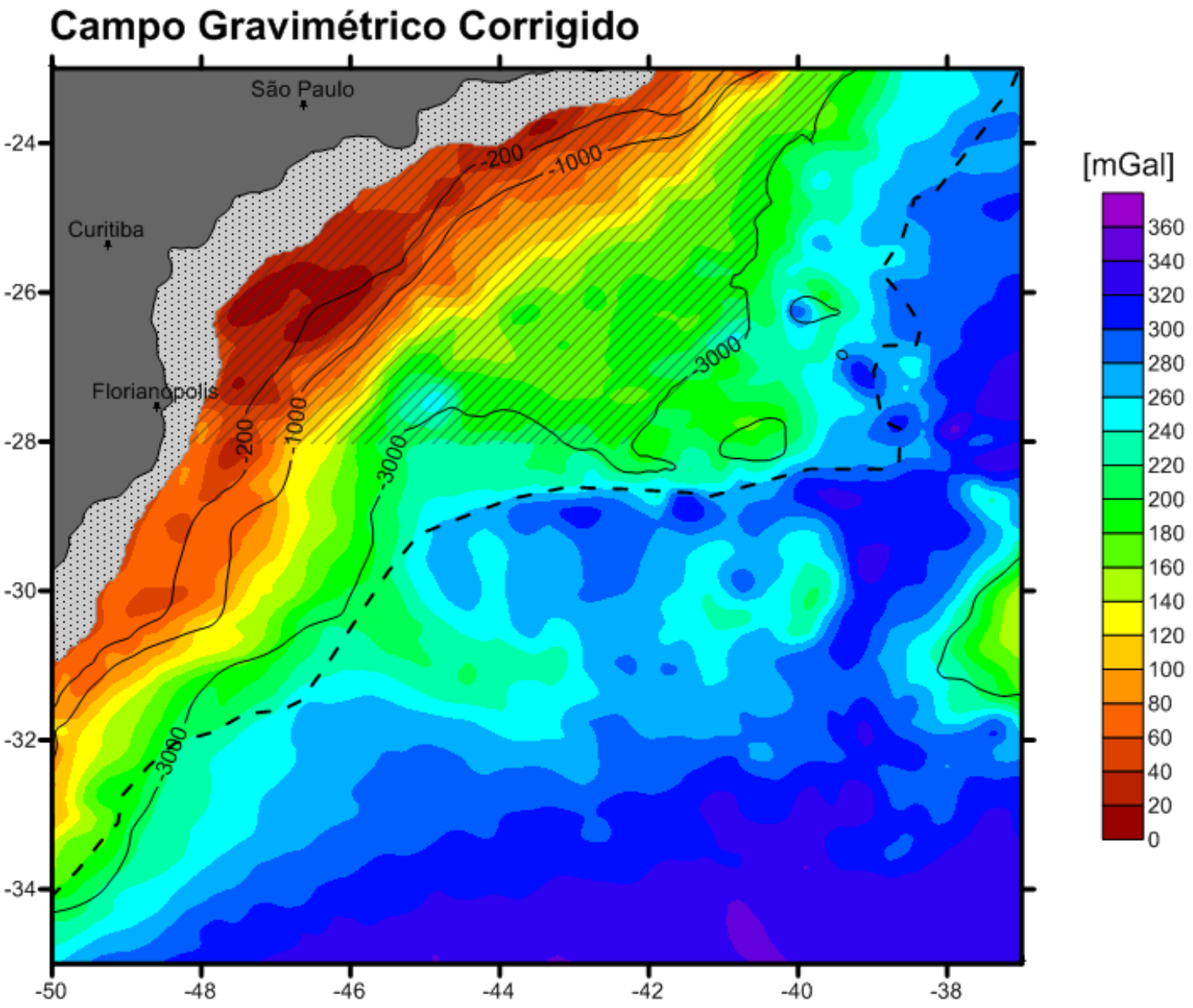

Figura 15: Campo gravimétrico corrigido, ou seja, sem o sinal do efeito gravimétrico gerado pelo pacote sedimentar. As regiões hachuradas (listras e pontilhados) representam, respectivamente, a área da Bacia de Santos, delimitada segundo Moreira (2007) e área onde os dados gravimétricos não são confiáveis. Estão representadas também As isolinhas batimétricas referentes às profundidades 200, 1000 e $3000 \mathrm{~m}$.

Segundo Blakely (1995) geralmente a componente de longo comprimento de onda é gerada pelas ondulações da ICM e a componente de curto comprimento de onda é gerada pelas massas superficiais. Isso não significa que as massas superficiais não contribuam para a parte de longo comprimento de onda, mas a maior contribuição certamente se dá no longo comprimento de onda. Durante este trabalho, admitimos que as ondulações da ICM são geradas exclusivamente pela parte do longo comprimento de onda. Para a inversão, o comprimento de onda de corte foi estimado a partir do decaimento do espectro de amplitude do campo gravimétrico (Russo \& Speed, 1994) e o valor encontrado foi de $115 \mathrm{~km}$ (Figura 16).

O campo gravimétrico é invertido segundo o Modelo de Inversão Gravimétrica Iterativo, descrito por Braitenberg \& Zadro (1999), para um contraste de densidade 
lateralmente variável entre a crosta e o manto. Estes valores foram retirados do modelo CRUST 2.0 (Figura 17).

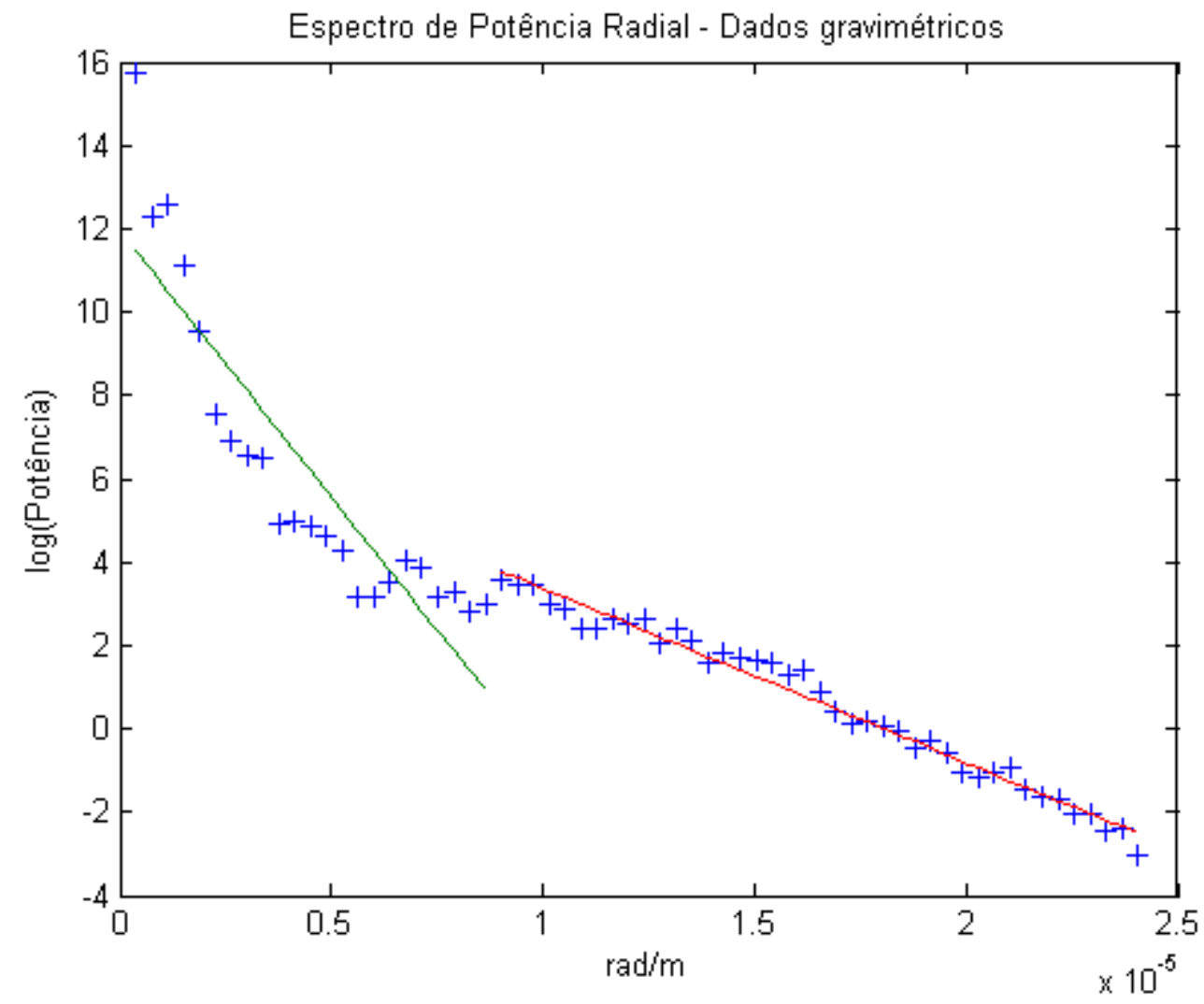

Figura 16: Gráfico do espectro de potência radial do campo gravimétrico. 0 ajuste mostrado em verde fornece um comprimento de onda de corte de $115 \mathrm{~km}$ a ser utilizado na inversão dos dados. 


\section{Contraste de Densidade}

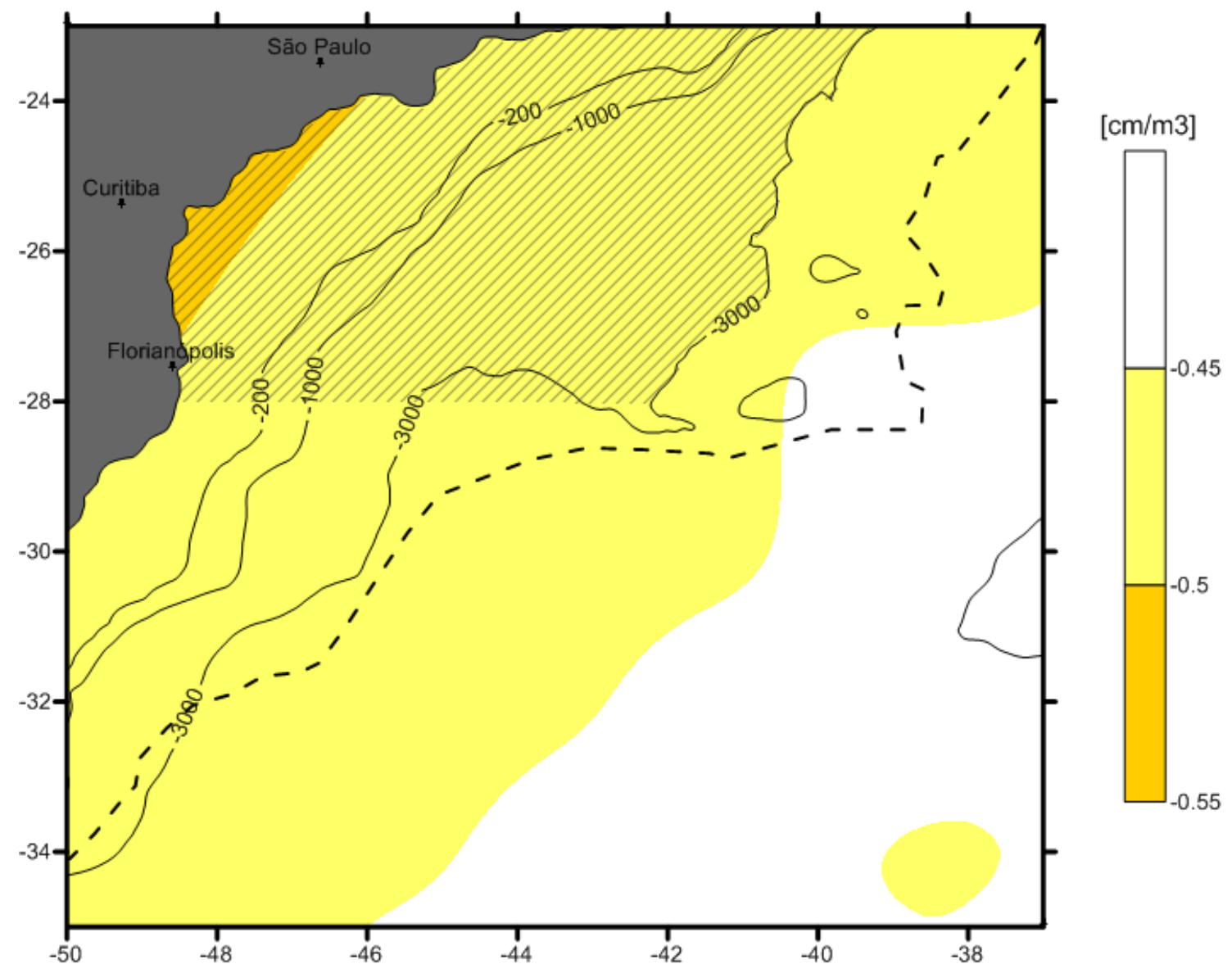

Figura 17: Modelo de contraste de densidade entre a crosta e o manto. Os valores foram obtidos do CRUST2.0. A região hachurada (listras) representa a área da Bacia de Santos, delimitada segundo Moreira (2007). 0 limite crustal, segundo Cainelli \& Moriak (1999) é representado pela linha tracejada. Estão representadas também As isolinhas batimétricas referentes às profundidades 200, 1000 e $3000 \mathrm{~m}$.

Nota-se que o contraste de densidade entre a crosta e o manto é praticamente constante na área da Bacia de Santos, com valores em torno de -0.5 $\mathrm{kg} / \mathrm{m}^{3}$.

O processo de inversão é realizado para uma série de valores de profundidades de referência variando entre 20 e $30 \mathrm{~km}$. 0 erro RMS é calculado entre os valores obtidos por inversão e vínculos sísmicos. Uma parte dos vínculos, obtidos por sísmica de refração, foram retirados de Leyden (1971). Tais valores não estavam localizados na Bacia de Santos e por isso, a área de estudo teve que ser estendida. Outra parte dos vínculos, obtidos a partir de uma análise combinada de dados sísmicos, gravimétricos e magnetométricos, foi retirada de Zálan, (2011). 
Na figura 18 os valores marcados em preto correspondem aos valores de espessura Crustal referentes a Leyden (1971) e os valores marcados em vermelho são referentes a Zalán (2011).

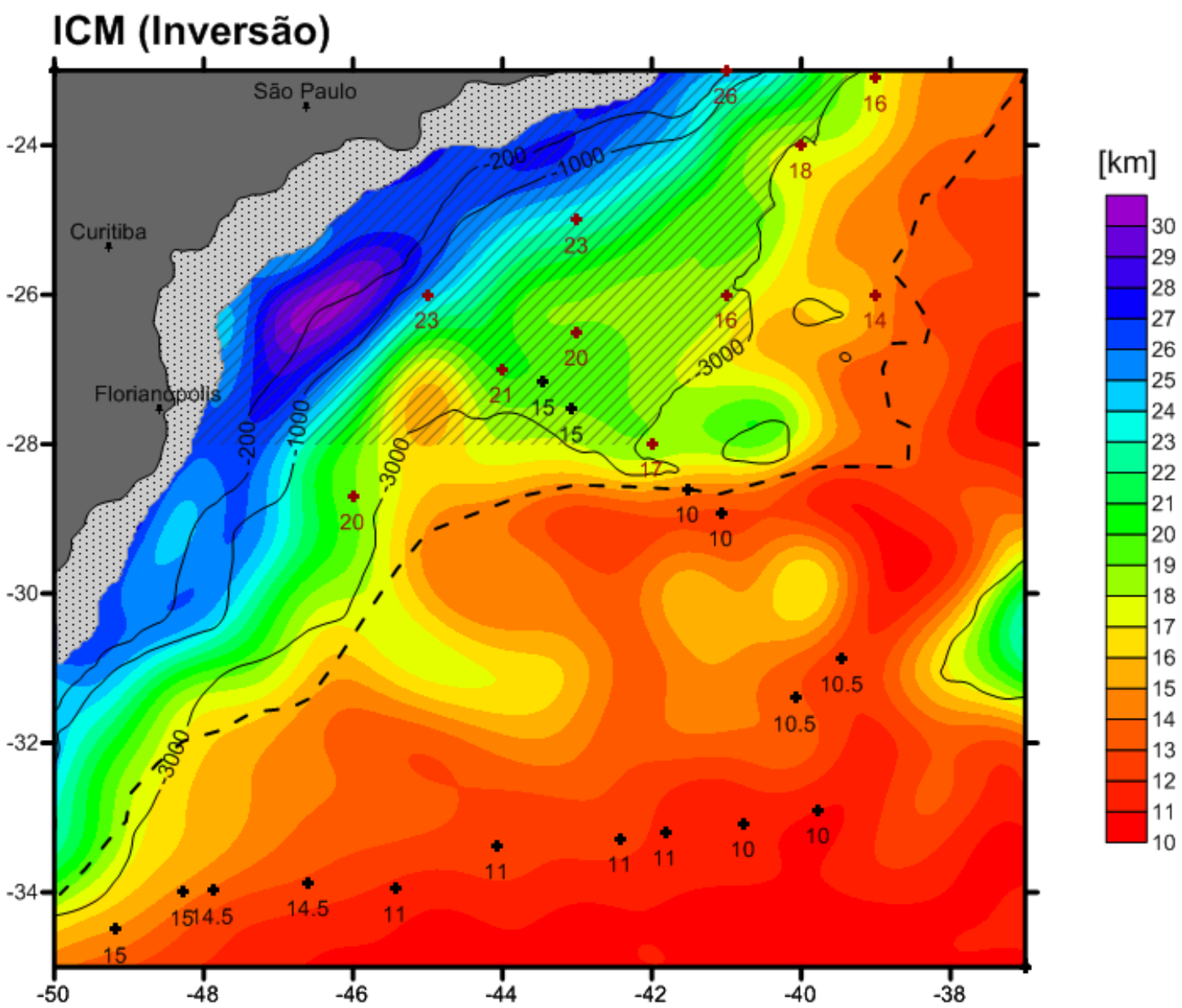

Figura 18: Mapa da Interface Crosta Manto (ICM) obtida a partir da inversão do campo gravimétrico. Os valores marcados em vermelho são vínculos de Zalán (2011) e em preto, vínculos de Leyden (1971). As regiões hachuradas (listras e pontilhados) representam, respectivamente, a área da Bacia de Santos, delimitada segundo Moreira (2007) e área onde os dados gravimétricos não são confiáveis. 0 limite crustal, segundo Cainelli \& Moriak (1999) é representado pela linha tracejada. Estão representadas também As isolinhas batimétricas referentes às profundidades 200, 1000 e $3000 \mathrm{~m}$.

Após realizados os testes com valores de profundidade de referência variável, a profundidade de $28.7 \mathrm{~km}$ com um erro RMS de aproximadamente 1.9 $\mathrm{km}$ foi a que forneceu o melhor resultado.

A tabela 1 mostra as coordenadas dos vínculos, seus respectivos valores e a diferença entre os valores obtidos por inversão do campo gravimétrico e aqueles obtidos por refração sísmica. Essa diferença, apresentada na coluna 5, é representada na figura 19. 


\begin{tabular}{|c|c|c|c|c|c|}
\hline \multirow[t]{2}{*}{ Ponto } & \multirow[t]{2}{*}{ Longitude } & \multirow[t]{2}{*}{ Latitude } & \multirow{2}{*}{\multicolumn{2}{|c|}{ Vínculo }} & Valor \\
\hline & & & & & $\begin{array}{l}\text { inversão } \\
\text { vínculo }(\mathrm{km})\end{array}$ \\
\hline $1 \mathrm{~L}$ & -49.18 & -34.5 & & 15 & 0.07 \\
\hline $2 \mathrm{~L}$ & -48.28 & -34 & & 15 & 0.37 \\
\hline $3 \mathrm{~L}$ & -47.88 & -33.98 & & 14.5 & 0.63 \\
\hline $4 \mathrm{~L}$ & -46.6 & -33.87 & & 14.5 & 1.67 \\
\hline $5 \mathrm{~L}$ & -45.43 & -33.95 & & 11 & -0.76 \\
\hline $6 \mathrm{~L}$ & -44.07 & -33.38 & & 11 & -1.41 \\
\hline 7L & -42.42 & -33.28 & & 11 & -1.32 \\
\hline $8 \mathrm{~L}$ & -41.82 & -33.2 & & 11 & -0.71 \\
\hline 9L & -40.77 & -33.08 & & 10 & -1.25 \\
\hline 10L & -39.77 & -32.9 & & 10 & -1 \\
\hline $11 \mathrm{~L}$ & -40.08 & -31.4 & & 10.5 & -2.7 \\
\hline $12 \mathrm{~L}$ & -39.45 & -30.87 & & 10.5 & -1.8 \\
\hline 13L & -41.52 & -28.6 & & 11 & -3.6 \\
\hline 14L & -41.07 & -28.92 & & 11 & -1.87 \\
\hline $15 \mathrm{~L}$ & -43.45 & -27.17 & & 15 & -4.72 \\
\hline $16 \mathrm{~L}$ & -43.07 & -27.53 & & 15 & -4 \\
\hline $1 \mathrm{Z}$ & -39 & -23.1 & & 16 & -1.48 \\
\hline $2 \mathrm{Z}$ & -41 & -23.15 & & 26 & 1.94 \\
\hline $3 Z$ & -40 & -24 & & 18 & 0.12 \\
\hline $4 \mathrm{Z}$ & -43 & -25 & & 23 & -0.09 \\
\hline $5 Z$ & -45 & -26 & & 23 & -1.72 \\
\hline $6 \mathrm{Z}$ & -44 & -27 & & 21 & 0.83 \\
\hline $7 \mathrm{Z}$ & -41 & -26 & & 16 & -2.36 \\
\hline $8 \mathrm{Z}$ & -42 & -28 & & 17 & -1.79 \\
\hline $9 \mathrm{Z}$ & -46 & -28.7 & & 20 & 0.84 \\
\hline $10 \mathrm{Z}$ & -43 & -26.5 & & 20 & 0.8 \\
\hline $11 Z$ & -39 & -26 & & 14 & -0.94 \\
\hline
\end{tabular}

Tabela 1: Coordenadas geográficas, vínculos e diferença de valores entre os dados obtidos por inversão do campo gravimétrico e os dados fornecidos pelos vínculos utilizados. Os pontos representados com a letra "L" referem-se aos à Leyden (1971) e os pontos representados com a letra "Z" referem-se à Zalán (2011). Os valores negativos da última coluna significam quem os valores da ICM obtida por inversão são menores que os valores utilizados como vínculos. 
Os valores da 5a coluna na tabela são negativos quando a profundidade da ICM obtida por inversão gravimétrica é menor do que a profundidade utilizada como vínculo.

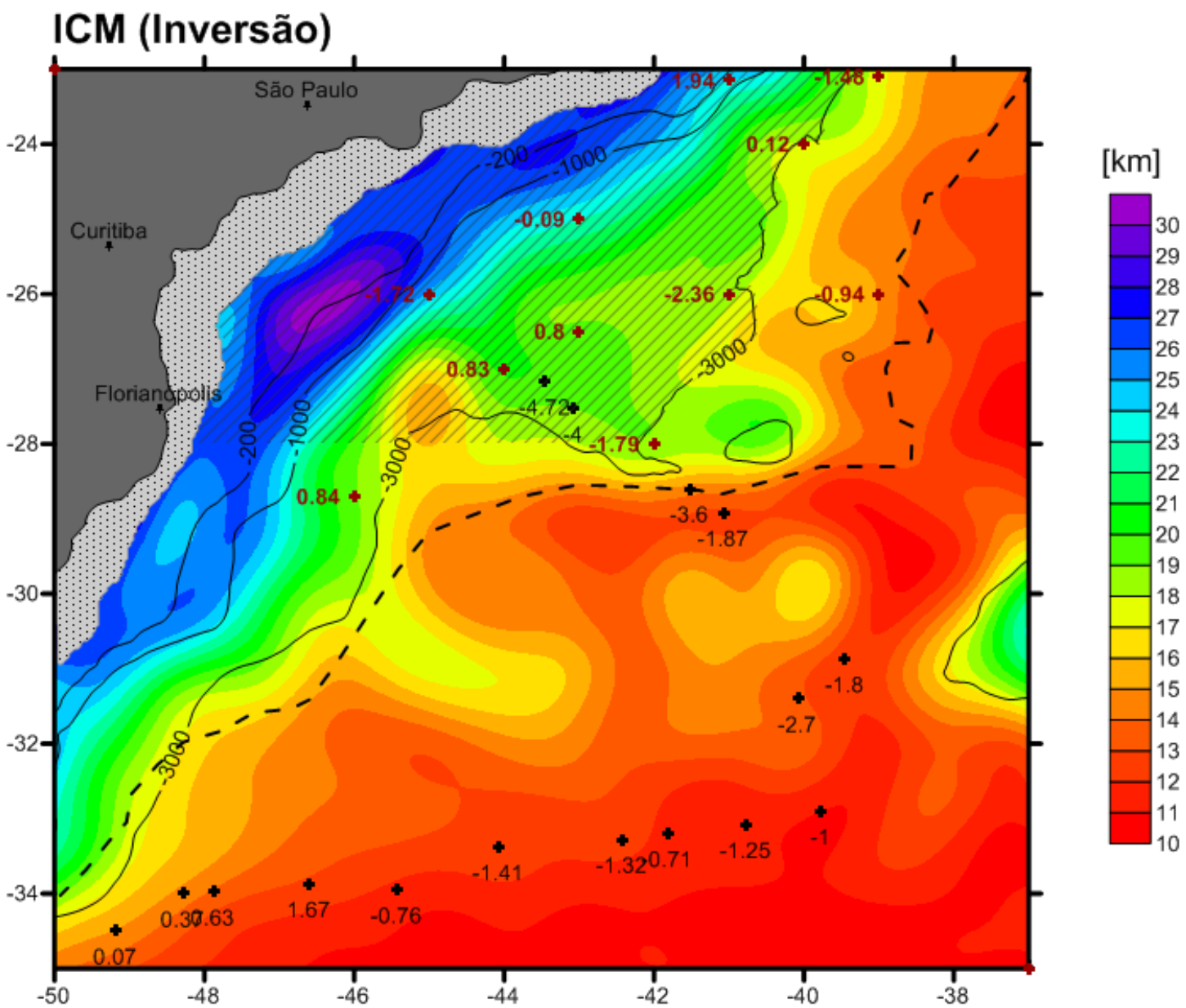

Figura 19: Mapa da Interface Crosta Manto (ICM) obtida a partir da inversão do campo gravimétrico. Os valores marcados em vermelho representam a diferença entre a ICM gravimétrica e os vínculos de Zalán (2011) e em preto, a diferença entre a ICM gravimétrica e os vínculos de Leyden (1971). As regiões hachuradas (listras e pontilhados) representam, respectivamente, a área da Bacia de Santos, delimitada segundo Moreira (2007) e área onde os dados gravimétricos não são confiáveis. O limite crustal, segundo Cainelli \& Moriak (1999) é representado pela linha tracejada. Estão representadas também As isolinhas batimétricas referentes às profundidades 200, 1000 e $3000 \mathrm{~m}$ :

No geral, a diferença entre os dados obtidos por inversão do campo gravimétrico e dos vínculos é pequena, sendo menor que dois $\mathrm{km}$ em quase todos os pontos. Valores maiores são encontrados próximo ao limite entre as crostas continental e oceânica, correspondendo aos pontos 13L $(-3.6 \mathrm{~km})$ e $15 \mathrm{~L}(-4.72$ $\mathrm{km})$. Outro valor consideravelmente maior é encontrado no extremo leste da bacia, correspondente ao ponto $7 \mathrm{Z}(-2.36 \mathrm{~km})$. 
Essa pequena diferença encontrada foi resultado de inúmeros testes realizados durante o processo de inversão a fim de alcançar-um menor erro RMS que ficou em $1.9 \mathrm{~km}$.

Finalizada a primeira etapa do trabalho e obtida a profundidade da ICM para a área de estudo, pode-se prosseguir para a etapa 2, que consiste em estimar a ICM por meio de outra metodologia, a análise flexural, para validar os resultados obtidos pela etapa1.

O primeiro passo envolve calcular a topografia equivalente. Segundo Kumar et al. (2011), a topografia equivalente é a profundidade que a crosta assume na ausência de gelo ou água, e sob condições isostáticas, dada por:

$$
\mathrm{h}(\mathrm{x})=\frac{\rho_{\mathrm{c}}-\rho_{\mathrm{w}}}{\rho_{\mathrm{c}}} d
$$

Sendo $\mathrm{h}(\mathrm{x})$ é a topografia equivalente, $d$ a batimetria em metros, $\rho_{\mathrm{c}}$ e $\rho_{\mathrm{w}}$ as densidades da crosta e da água, respectivamente.

A topografia equivalente calculada para a região de estudo é mostrada na figura 20 .

Observa-se que os valores calculados variam de $-200 \mathrm{~m}$ a $-3200 \mathrm{~m}$, sendo que dentro da área da Bacia de Santos, esses valores vão de -200 m na região que margeia o continente até aproximadamente $-2000 \mathrm{~m}$ em quase todo o extremo leste da Bacia.

Estes valores apresentam sinal negativo, porque em áreas oceânicas a carga é negativa, já que as bacias preenchidas por água são menos densas que a crosta de referência.

O segundo passo envolve calcula a flexura w(r) com base no modelo de flexura de placa fina. 


\section{Topografia Equivalente}

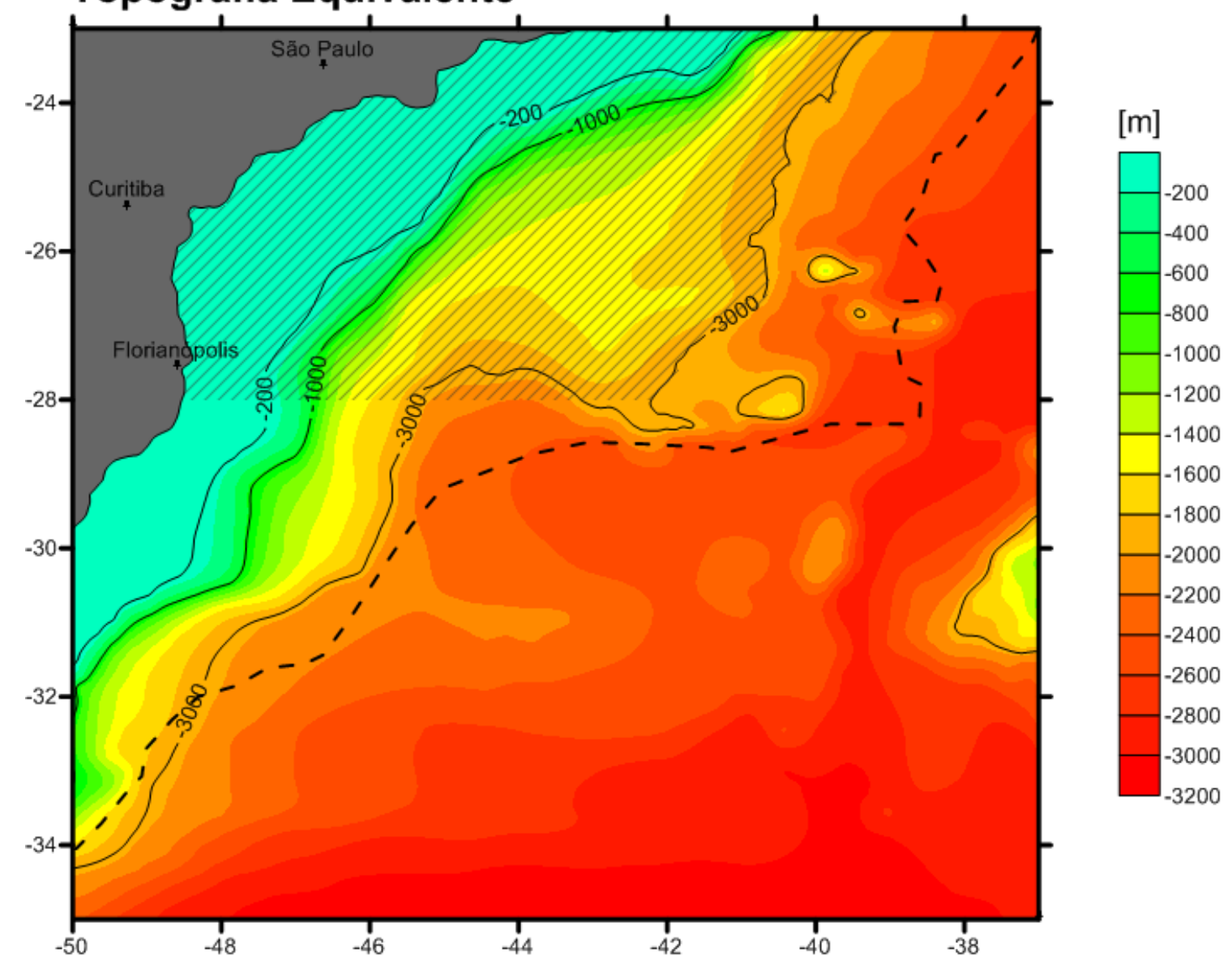

Figura 20: Valores em metros da topografia equivalente (carga crustal) na área de estudo. A região hachurada (listras) representa a área da Bacia de Santos, delimitada segundo Moreira (2007). 0 limite crustal, segundo Cainelli \& Moriak (1999) é representado pela linha tracejada. Estão representadas também As isolinhas batimétricas referentes às profundidades 200,1000 e $3000 \mathrm{~m}$.

A rigidez flexural é calculada utilizando uma janela média corrente de comprimento de $100 \mathrm{~km}$, com deslocamento de $20 \mathrm{~km}$. Valores padrões serão adotados para o Módulo de Young $(\mathrm{E}=100 \mathrm{GPa})$, para a razão de Poisson $\mathbf{v}=0.25 \mathrm{e}$ aceleração da gravidade $\left(9.81 \mathrm{~m} / \mathrm{s}^{2}\right)$. Os valores de densidade do manto (3370 $\left.\mathrm{kg} / \mathrm{m}^{3}\right)$ e densidade da crosta $\left(2880 \mathrm{~kg} / \mathrm{m}^{3}\right)$ são valores médios obtidos do modelo de densidade CRUST 2.0. A espessura elástica (Te) varia de 1 à $25 \mathrm{~km}$. Tais valores devem estar de acordo com a reologia local e são baseados em Tassara et al. (2007).

A ICM obtida por análise flexural é mostrada na Figura 21. Os valores de espessura crustal variam de 11 a $30 \mathrm{~km}$. Dentro da Bacia, os valores próximos à costa são de 30 km e chegam A 18 KM próximos da cota batimétrica de 3000m. 
Considerando a área da Bacia definida por Moreira (2007) e admitindo o limite entra a crosta oceânica e a crosta continental definido por Cainelli \& Moriak (1998), a Bacia de Santos possui sua área total sobre a crosta continental, o que explica os altos valores de espessura crustal obtidos dentro da sua área.

No limite entre a as duas crostas o valor da espessura crustal é de aproximadamente $16 \mathrm{~km}$. 0 afinamento da crosta oceânica atinge $11 \mathrm{~km}$ no extremo leste da área total estudada (em vermelho). Um espessamento aparece em aproximadamente nas coordenadas $31 \mathrm{~S}$ - 37W, mostrando o início da elevação do Rio Grande.

Os valores obtidos por análise flexural estão em concordância com a ICM gravimétrica, como pode ser visto na figura 22 , que mostra a diferença entre as duas ICM. No geral, a diferença é pequena, variando de 2,5 a $3 \mathrm{~km}$. Os valores positivos representam uma ICM flexural mais rasa que a ICM gravimétrica.

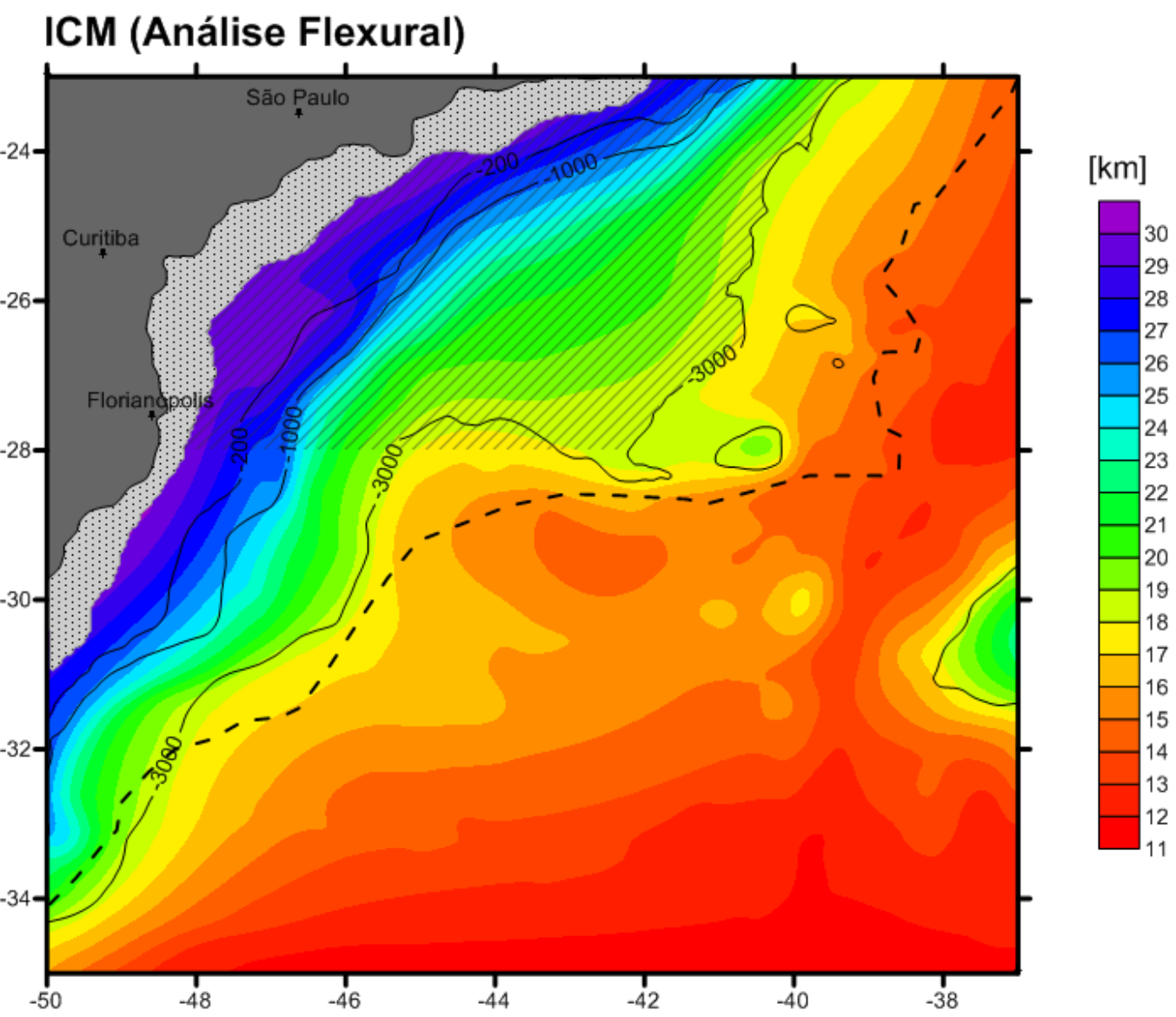

Figura 21: Mapa da Interface Crosta Manto (ICM) obtida a partir de análise flexural. As regiões hachuradas (listras e pontilhados) representam, respectivamente, a área da Bacia de Santos, delimitada segundo Moreira (2007) e área onde os dados gravimétricos não são confiáveis. 0 limite crustal, segundo Cainelli \& Moriak (1999) é representado pela linha tracejada. Estão representadas também As isolinhas batimétricas referentes às profundidades 200,1000 e $3000 \mathrm{~m}$. 
Os maiores valores estão próximos à área onde os resultados não são confiáveis (hachurada em cinza, na figura) e podem representar, ao menos em parte, influência desses dados. Essas diferenças serão discutidas no próximo capítulo.

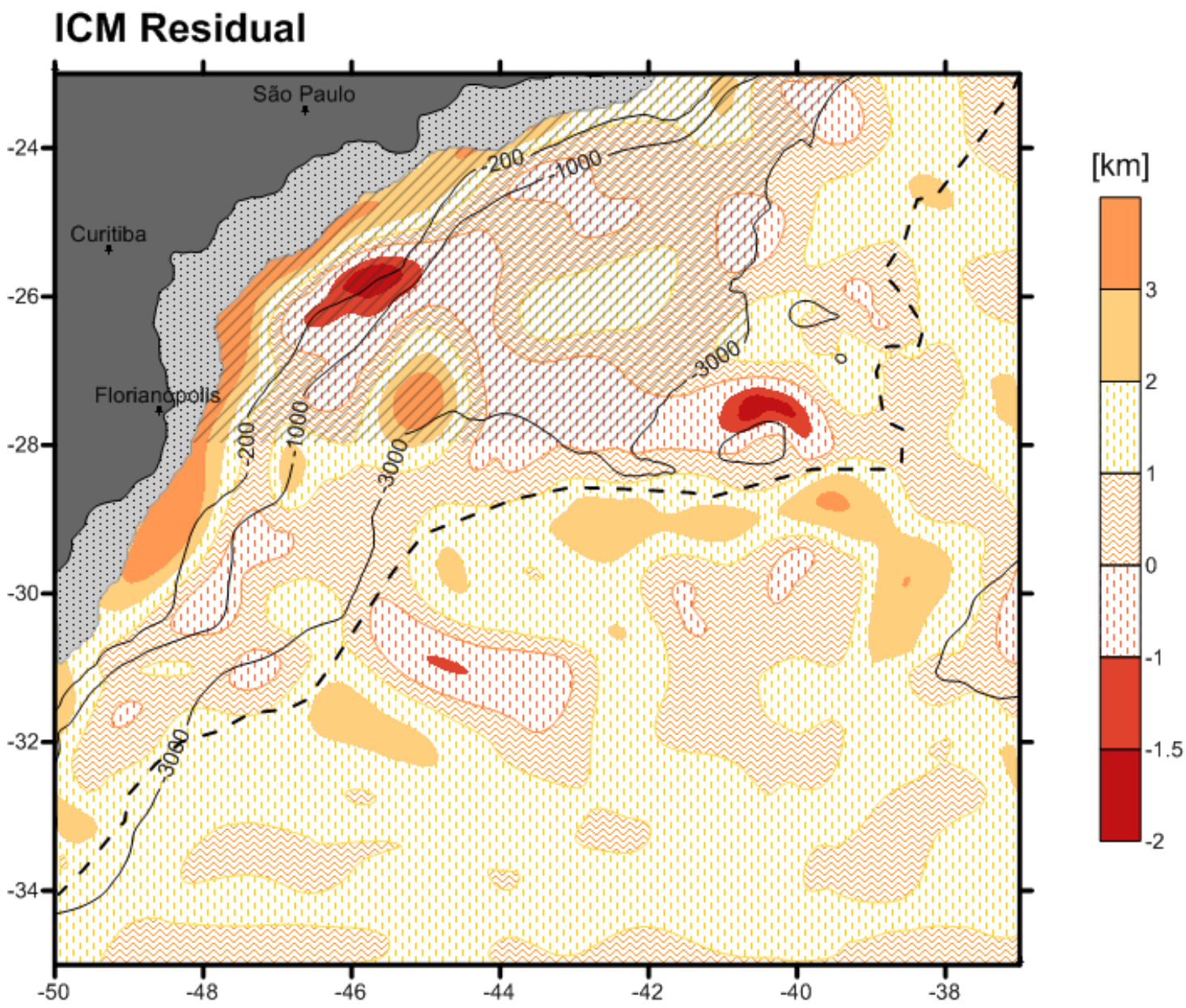

Figura 22: Diferença entre valores de profundidade obtidos por inversão do campo gravimétrico e por análise flexural. Valores positivos representam uma ICM flexural mais rasa que a ICM gravimétrica. Valores negativos representam uma ICM flexural mais profunda que a ICM gravimétrica. As regiões hachuradas (listras e pontilhados) representam, respectivamente, a área da Bacia de Santos, delimitada segundo Moreira (2007) e área onde os dados gravimétricos não são confiáveis. 0 limite crustal, segundo Cainelli \& Moriak (1999) é representado pela linha tracejada. Estão representadas também As isolinhas batimétricas referentes às profundidades 200, 1000 e $3000 \mathrm{~m}$.

Na próxima etapa o efeito gravimétrico da ICM é calculado pelo método de Parker, 1972 (Figura 23). Como a metodologia proposta por este estudo é baseada em um modelo físico completo, a interface utilizada para este cálculo foi a interface obtida por análise flexural (Figura 21). 
O sinal da ICM assim obtido é da ordem de 0 a $340 \mathrm{mGal}$. Na área da Bacia de Santos, o sinal é aproximadamente nulo na região que margeia a costa, aumentando à medida que dela se afasta. Entre a cota batimétrica de $1000 \mathrm{~m}$ e $3000 \mathrm{~m}$ o sinal gravimétrico aumenta gradativamente de aproximadamente 80 mGal até $200 \mathrm{mGal}$. (Figura 22). Passando o limite da Bacia, o sinal gravimétrico chega até $340 \mathrm{mGal}$, com exceção de uma região onde o sinal é menor, referente ao início da elevação de Rio Grande.

\section{Efeito Gravimétrico da ICM}

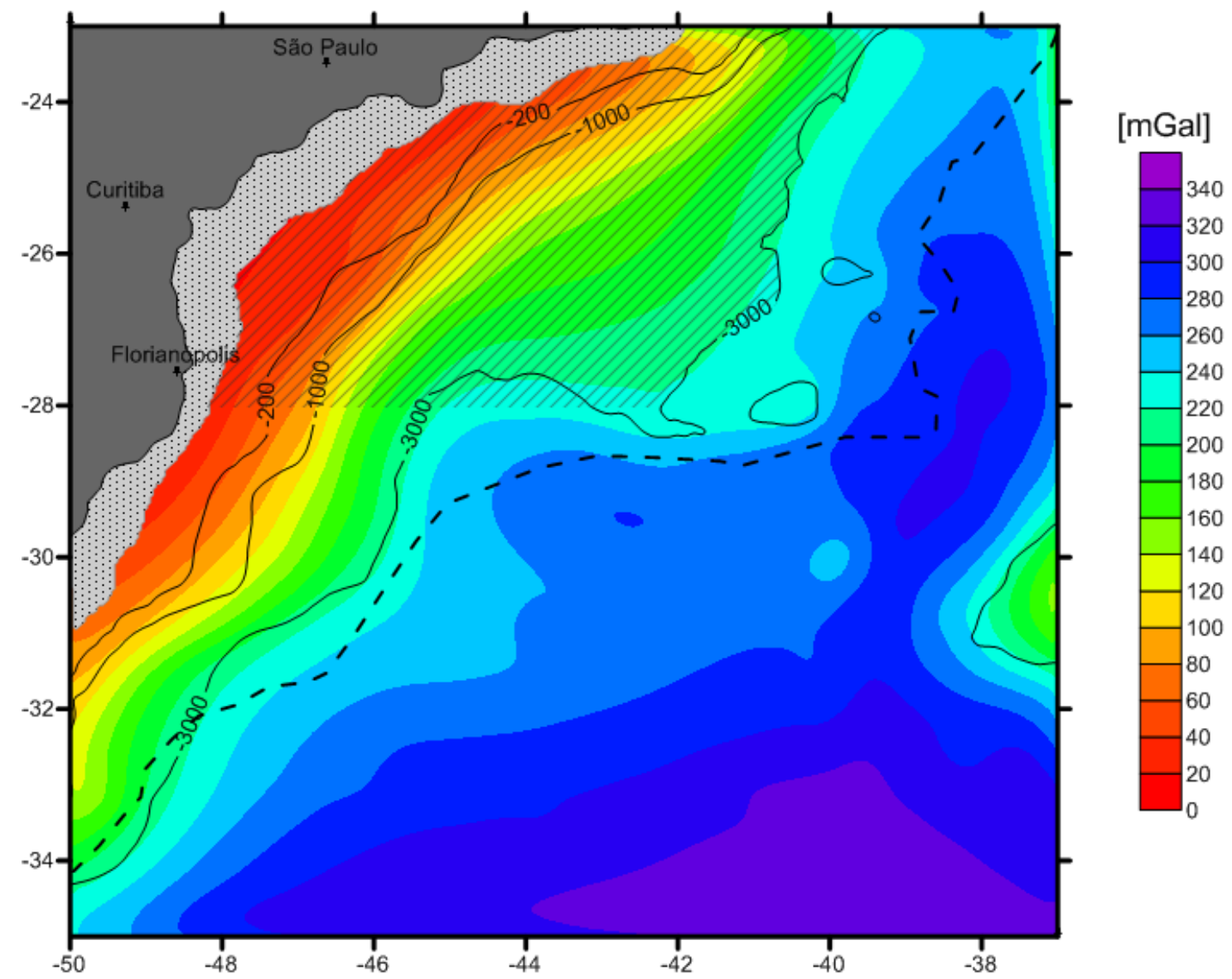

Figura 23: Efeito gravimétrico da Interface ICM calculado segundo Parker (1972). As regiões hachuradas (listras e pontilhados) representam, respectivamente, a área da Bacia de Santos, delimitada segundo Moreira (2007) e área onde os dados gravimétricos não são confiáveis. 0 limite crustal, segundo Cainelli \& Moriak (1999) é representado pela linha tracejada. Estão representadas também As isolinhas batimétricas referentes às profundidades 200,1000 e $3000 \mathrm{~m}$. 
Após o cálculo do sinal gravimétrico produzido pelo pacote sedimentar e do sinal gravimétrico produzido pela ICM, é possível subtrair da anomalia observada ambos os sinais, resultando no campo residual referente ao embasamento (equação 41).

Este campo, chamado de campo gravimétrico residual (gres), é mostrado na figura 24 e será invertido na última etapa deste trabalho.

O campo gravimétrico residual mostra anomalias entre -50 e $+40 \mathrm{mGal}$.

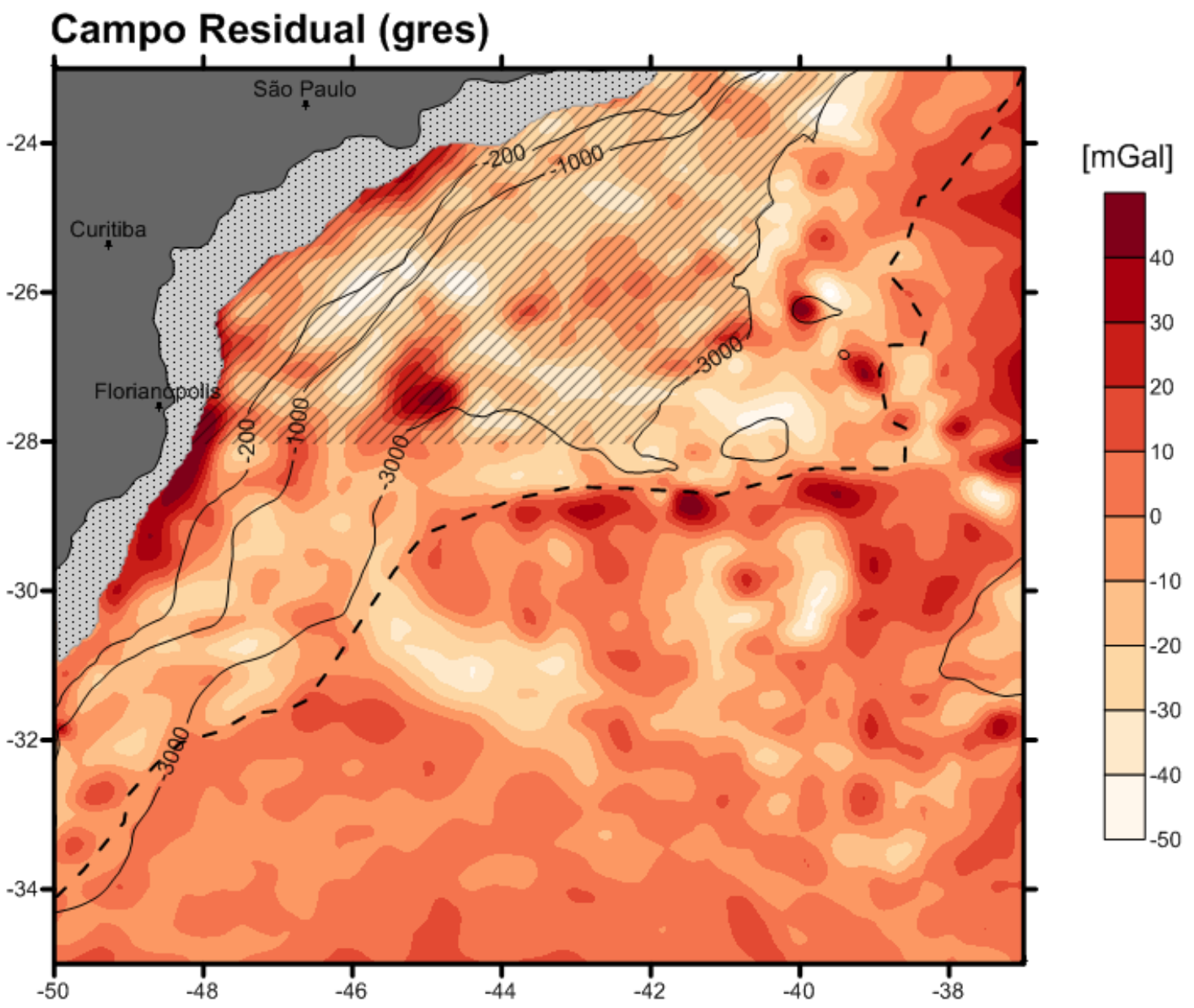

Figura 24: Campo gravimétrico residual $\left(\mathrm{g}_{\mathrm{res}}=\mathrm{g}_{\mathrm{obs}}-\mathrm{g}_{\mathrm{CMI}}-\mathrm{g}_{\mathrm{sed}}\right)$. As regiões hachuradas (listras e pontilhados) representam, respectivamente, a área da Bacia de Santos, delimitada segundo Moreira (2007) e área onde os dados gravimétricos não são confiáveis. 0 limite crustal, segundo Cainelli \& Moriak (1999) é representado pela linha tracejada. Estão representadas também As isolinhas batimétricas referentes às profundidades 200, 1000 e 3000 m.

Esses altos e baixos gravimétricos representam as estruturas do embasamento que estão enterradas sobre o pacote sedimentar da Bacia. Para delinear tais estruturas, o campo gravimétrico residual (gres) deve ser invertido 
com o Modelo de Inversão Gravimétrica Iterativo, descrito por Braitenberg \& Zadro (1999).

Para a inversão do campo residual, foi utilizado um contraste de densidade constante, de $1570 \mathrm{~kg} / \mathrm{m}^{3}$, referente ao contraste de densidade entre a crosta superior $\left(2600 \mathrm{~kg} / \mathrm{m}^{3}\right)$ e a água $\left(1030 \mathrm{~kg} / \mathrm{m}^{3}\right) .0$ valor referente à crosta superior foi escolhido utilizando os dados do modelo CRUST 2.0. Durante a inversão, todos os comprimentos de onda foram levados em consideração. Segundo Hwang (1999), o processo de inversão pode ser feito para uma única profundidade de referência, que vai ser definida como o nível zero.

0 termo embasamento utilizado neste trabalho refere-se à superfície física que se encontra abaixo da camada sedimentar. Os dados de espessura sedimentar utilizados neste trabalho representam a profundidade do embasamento acústico, definido como sendo o refletor observável mais profundo nos perfis de sísmica de reflexão e que pode não representar necessariamente a base dos sedimentos. 0 resultado final deste trabalho corresponde a base dos sedimentos e será chamado de embasamento gravimétrico.

As figuras 26 e 27 representam topografia do embasamento gravimétrico, representada em forma de mapa de contorno e superfície 3D, respectivamente. Pode-se observar depressões que chegam a 700m de profundidade. $\mathrm{Na}$ área da Bacia de Santos os valores são bem variáveis, apresentando feições de profundidade indo de 0 até $700 \mathrm{~m}$. 


\section{Embasamento}

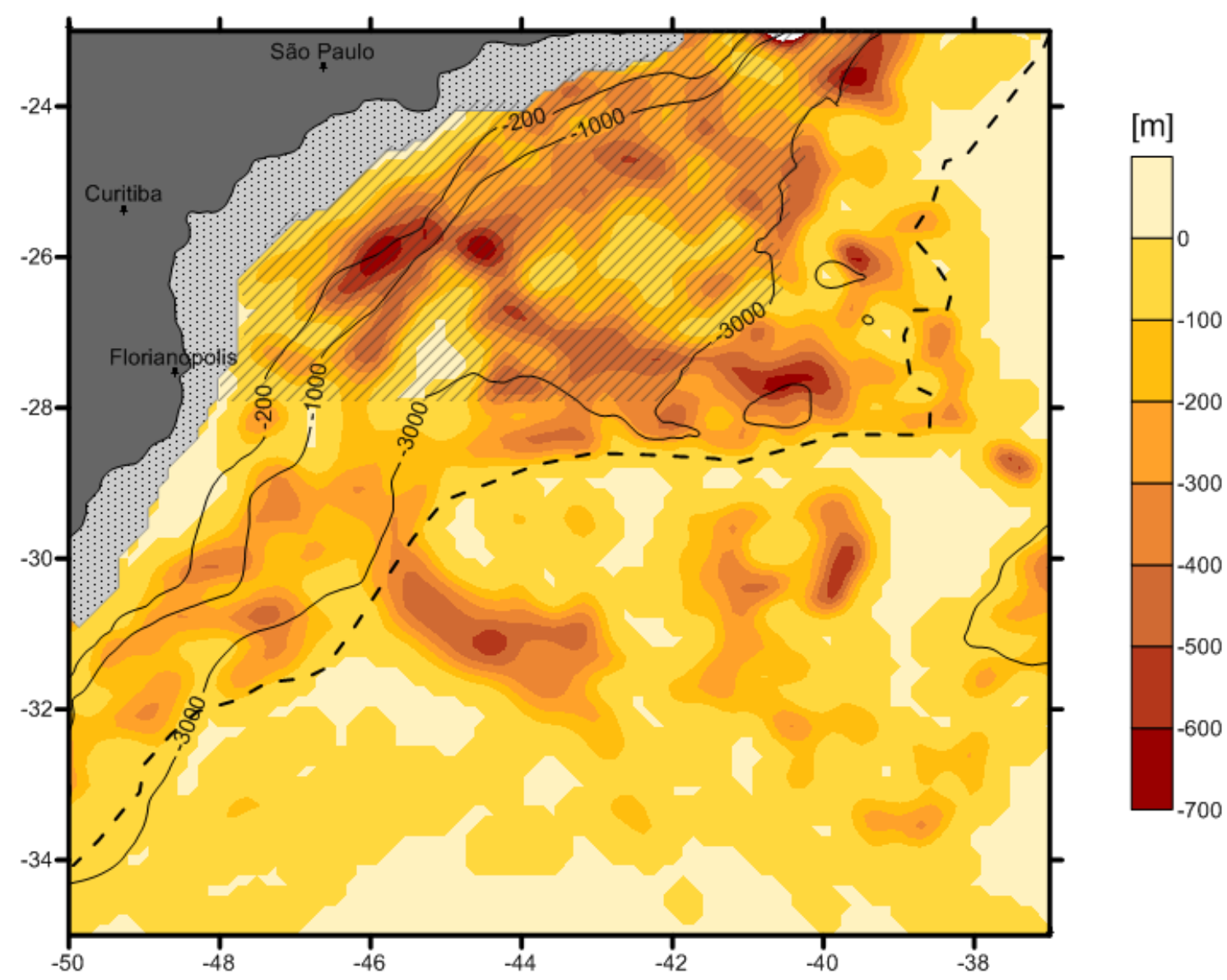

Figura 25: Estruturas do embasamento. As regiões hachuradas (listras e pontilhados) representam, respectivamente, a área da Bacia de Santos, delimitada segundo Moreira (2007) e área onde os dados gravimétricos não são confiáveis. O limite crustal, segundo Cainelli \& Moriak (1999) é representado pela linha tracejada. Estão representadas também As isolinhas batimétricas referentes às profundidades 200,1000 e $3000 \mathrm{~m}$. 


\section{Embasamento}

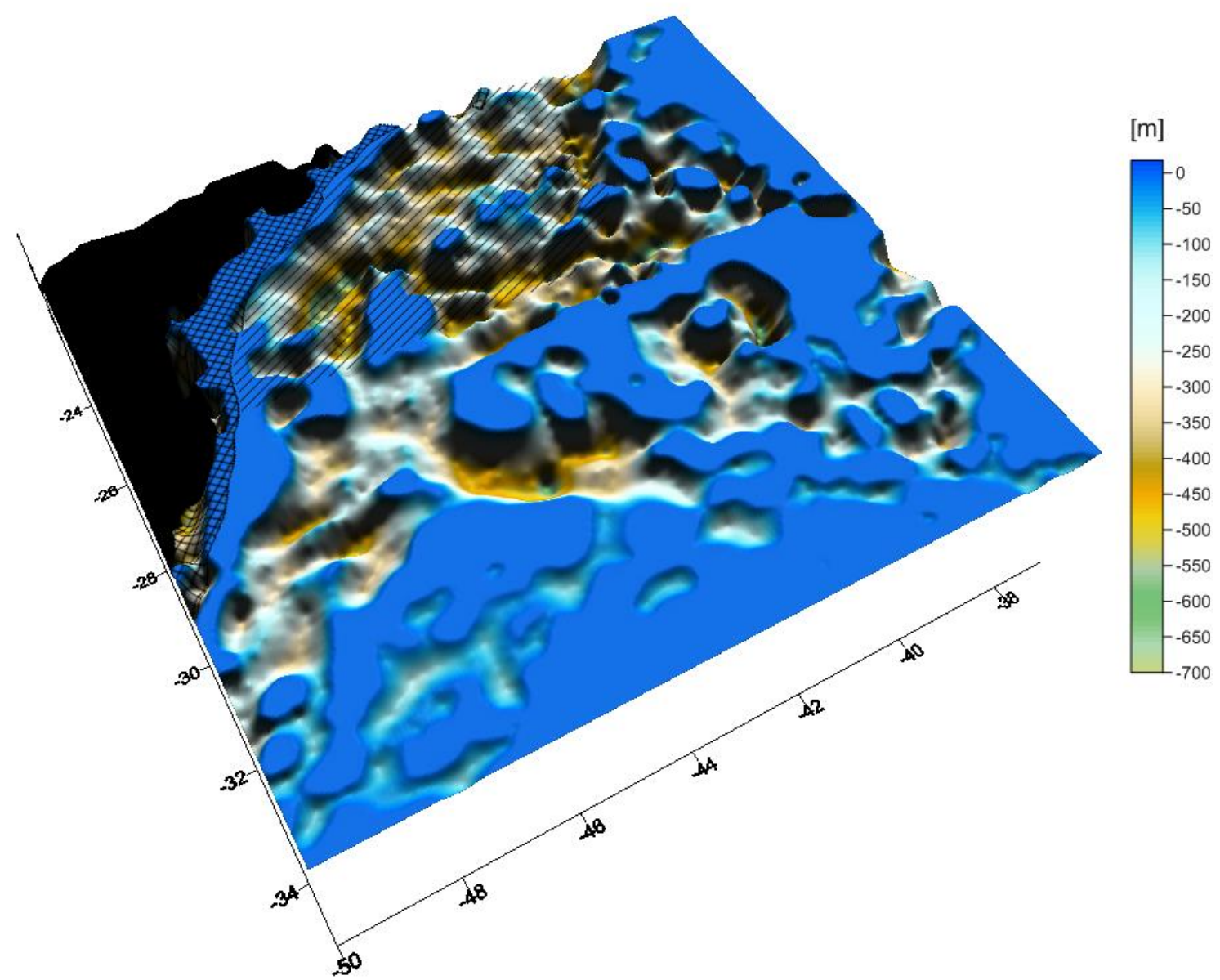

Figura 26: Estruturas do Embasamento representadas em 3D. As regiões hachuradas (listras e quadriculado) representam, respectivamente, a área da Bacia de Santos, delimitada segundo Moreira (2007) e área onde os dados gravimétricos não são confiáveis.

Para fornecer outras formas de visualizar os resultados, profundidade do embasamento é mostrada em mapas 3D em duas projeções distintas: perspectiva (figura 27) e ortogonal (figura 28). Esta profundidade corresponde à somatória das interfaces: batimetria (figura 6), espessura sedimentar (figura 12) e embasamento (figura 26).

Os mesmos valores são representados (figura 29) em forma de mapa de contorno. Os valores variam de 1500 a 10500 metros. Dentro da área da Bacia de Santos, podemos ver valores mais rasos (próximos à Costa, ao Norte da Bacia) e valores mais profundos, na ordem de 10500 metros na região mais ao centro, representados em vermelho.

Os resultados obtidos neste capítulo serão discutidos detalhadamente no capítulo a seguir. 


\section{Profundidade do Embasamento}

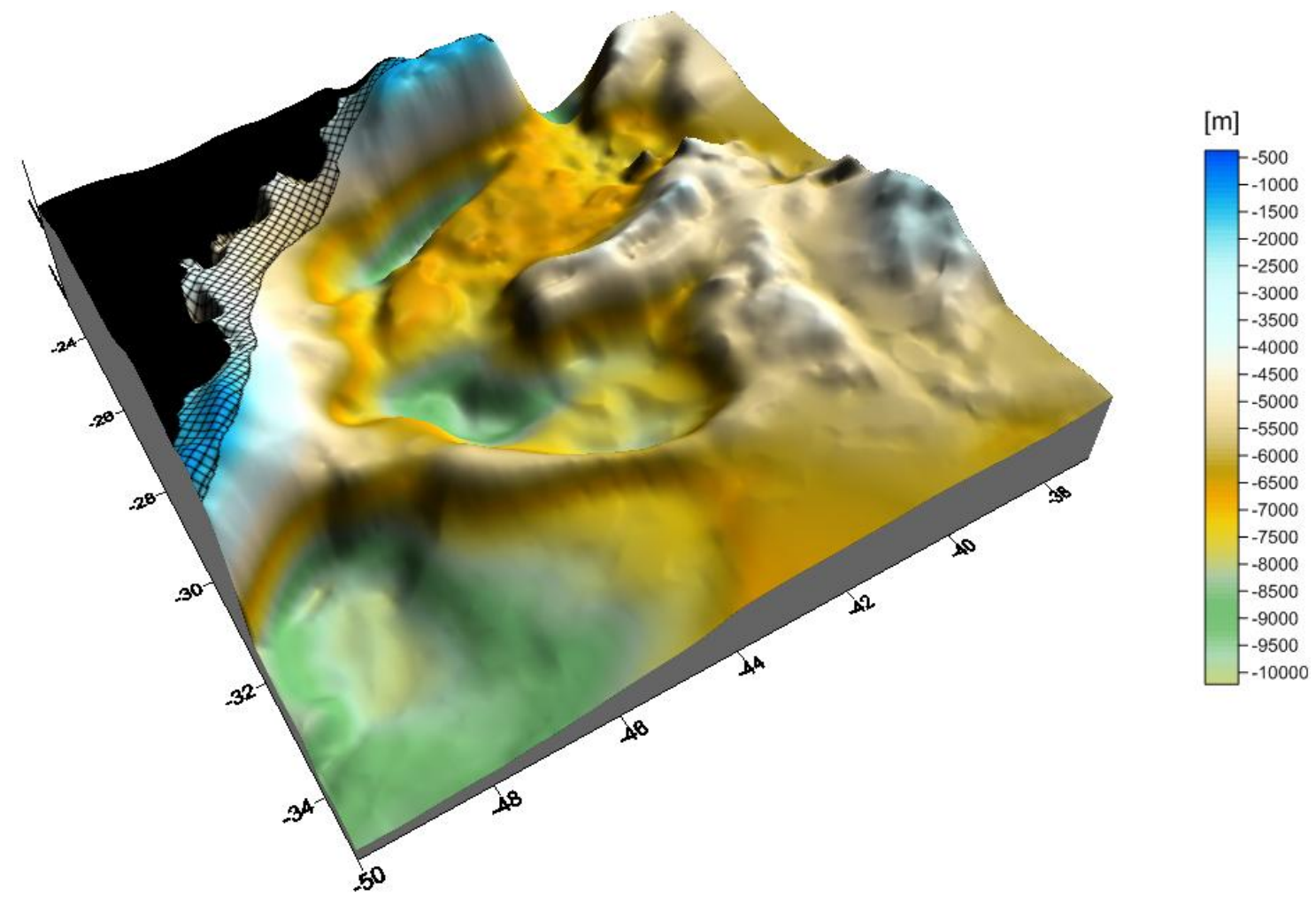

Figura 27: Profundidade do embasamento representada em perspectiva. A região hachurada (quadriculada) representa a área onde os dados gravimétricos não são confiáveis.

\section{Profundidade do Embasamento}
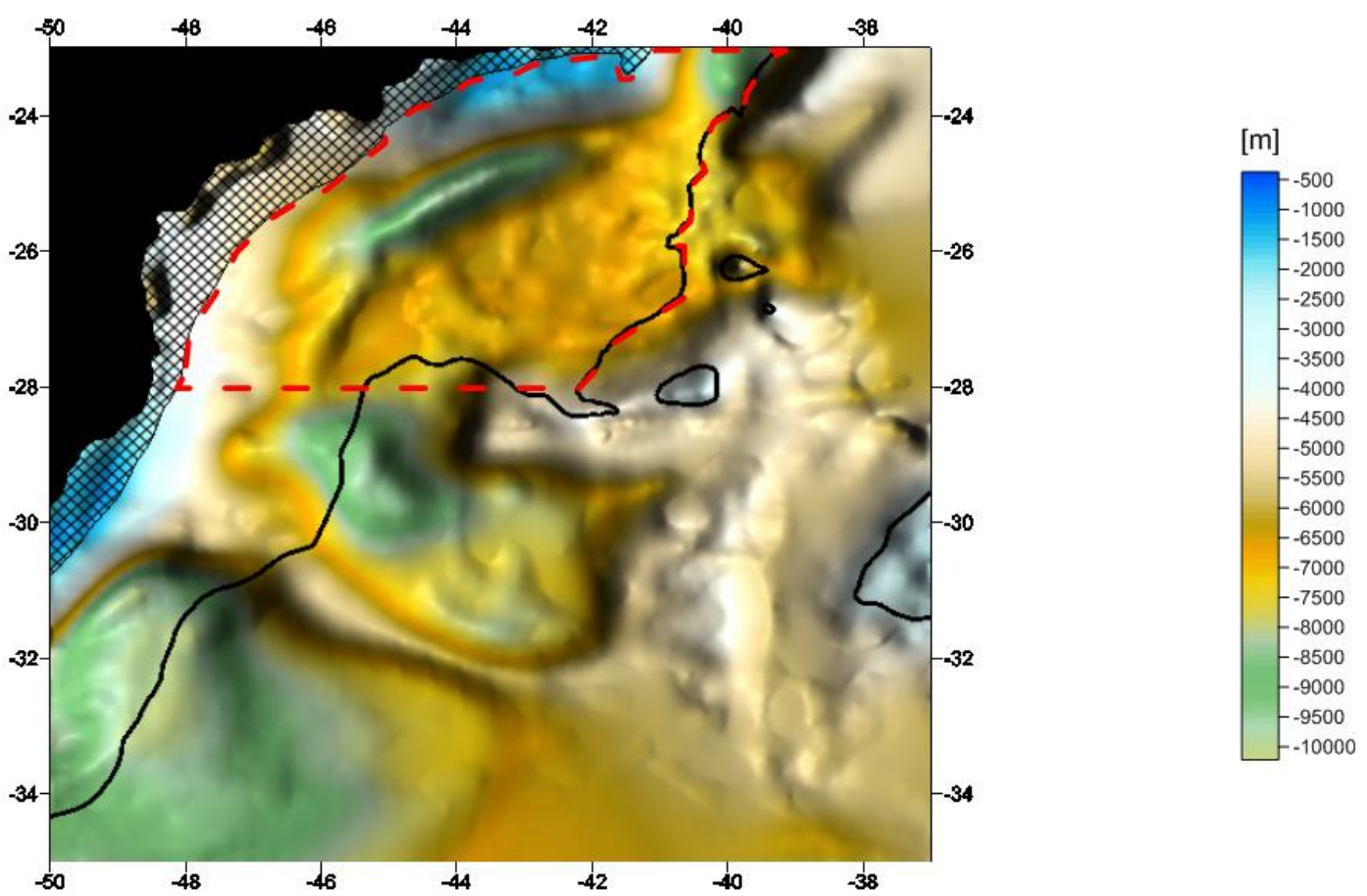

Figura 28: Profundidade do embasamento representada em projeção ortográfica. A região hachurada (quadriculada) representa a área onde os dados gravimétricos não são confiáveis. A 
região delimitada pelo tracejado vermelho representa a área da Bacia de Santos segundo Moreira (2007).

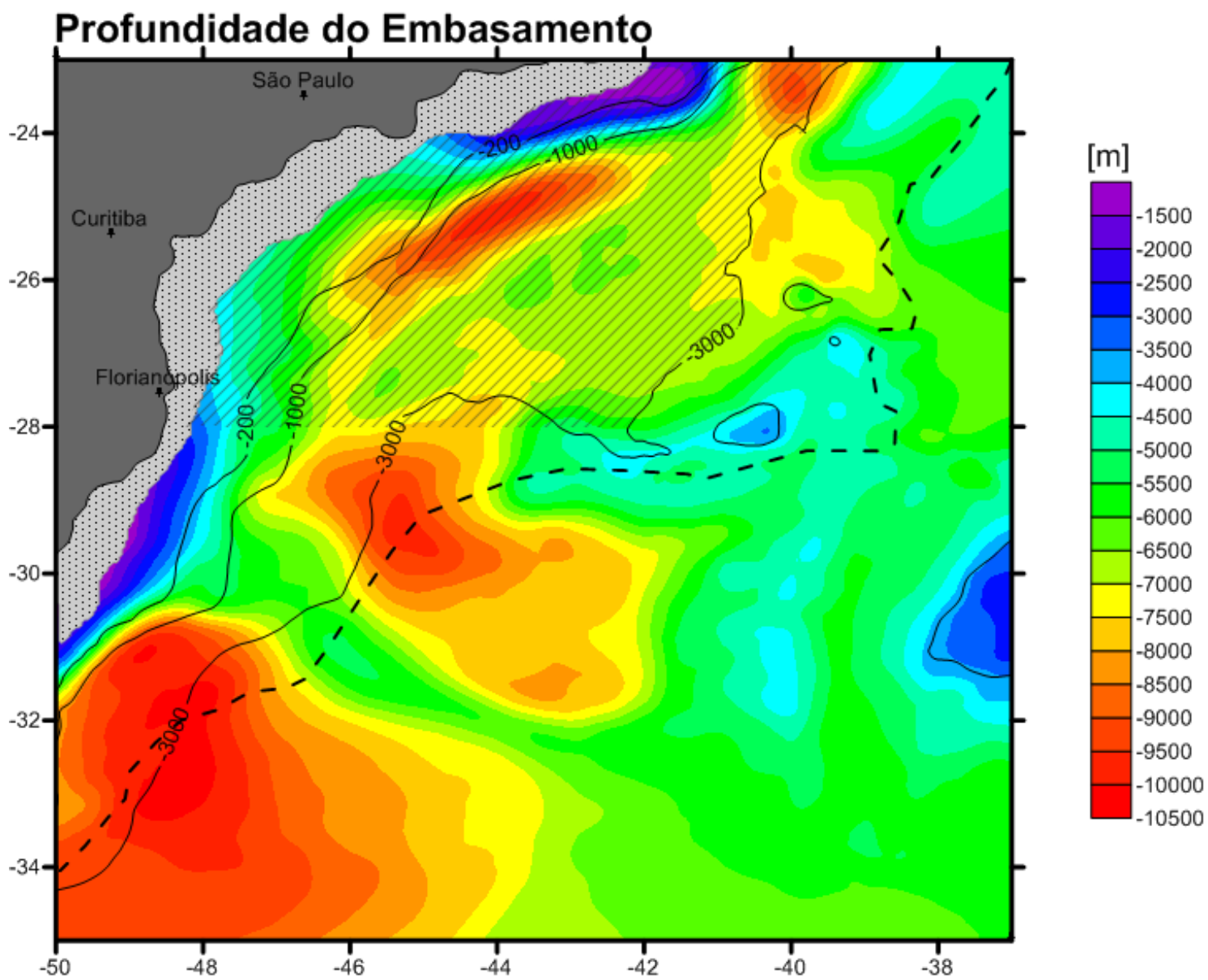

Figura 29: Profundidade do embasamento. As regiões hachuradas (listras e pontilhados) representam, respectivamente, a área da Bacia de Santos, delimitada segundo Moreira (2007) e área onde os dados gravimétricos não são confiáveis. 0 limite crustal, segundo Cainelli \& Moriak (1999) é representado pela linha tracejada. Estão representadas também As isolinhas batimétricas referentes às profundidades 200,1000 e $3000 \mathrm{~m}$. 


\section{Capítulo 6}

\section{Discussão}

Neste trabalho o sinal gravimétrico foi usado para calcular a topografia do embasamento oceânico na região da Bacia de Santos. A metodologia considerou dados de espessura crustal obtidas por sísmica, dados de testemunhos de sondagem obtidos pelo projeto DSDP, um modelo de espessura sedimentar e o modelo físico de análise flexural, e foi realizada em etapas que envolveram a modelagem da profundidade da ICM com base na análise espectral do campo gravimétrico observado e também com base na teoria da isostasia flexural, a estimativa do efeito da camada sedimentar e da interface ICM no sinal gravimétrico, para o cálculo do campo residual referente ao embasamento, e a obtenção das feições do embasamento a partir da inversão do campo gravimétrico residual.

A precisão do modelo desenvolvido neste trabalho depende diretamente dos dados de anomalia gravimétrica utilizados como base para os cálculos. A componente de longo comprimento de onda destes dados depende principalmente do efeito gravimétrico da camada de sedimentos e da ICM. A precisão dos dados gravimétricos utilizados neste trabalho é consideravelmente alta, estimada entre 2.6 e 3.0 mGal.

0 modelo de espessura sedimentar da NGDC utilizado neste trabalho apresenta uma resolução de 5 × 5 arc min, e foi escolhido por ter apresentado bons resultados em outras aplicações da presente metodologia (Braitenberg, 2006).

A profundidade do embasamento (figuras 27 e 28) é fortemente dependente do modelo de espessura sedimentar e possíveis erros neste modelo podem afetar diretamente os resultados finais deste trabalho.

As feições do embasamento, segundo Braitenberg (2006), poderiam ser calculadas a partir de dados gravimétricos sem levar em consideração o pacote sedimentar em regiões onde não existem informações sobre o mesmo. Porém, como a área de estudo é uma bacia sedimentar, que em certos locais apresenta 
quilômetros de espessura de sedimentos, é de fundamental importância considerar, na pior das hipóteses, uma estimativa da contribuição do pacote sedimentar no sinal gravimétrico.

Para o cálculo do efeito gravimétrico do pacote sedimentar (figura 13), a fim de ser o mais realista possível, foi considerada a compactação sedimentar com a profundidade. Para isso foi utilizado o modelo de Sclatter \& Christie (1980) (equação 23). Os parâmetros definidos para os cálculos são provenientes do Deep Sea Drilling Project (DSDP).

Este efeito, depois de calculado, foi subtraído da anomalia Bouguer para que fosse realizada a inversão dos dados e o cálculo da ICM.

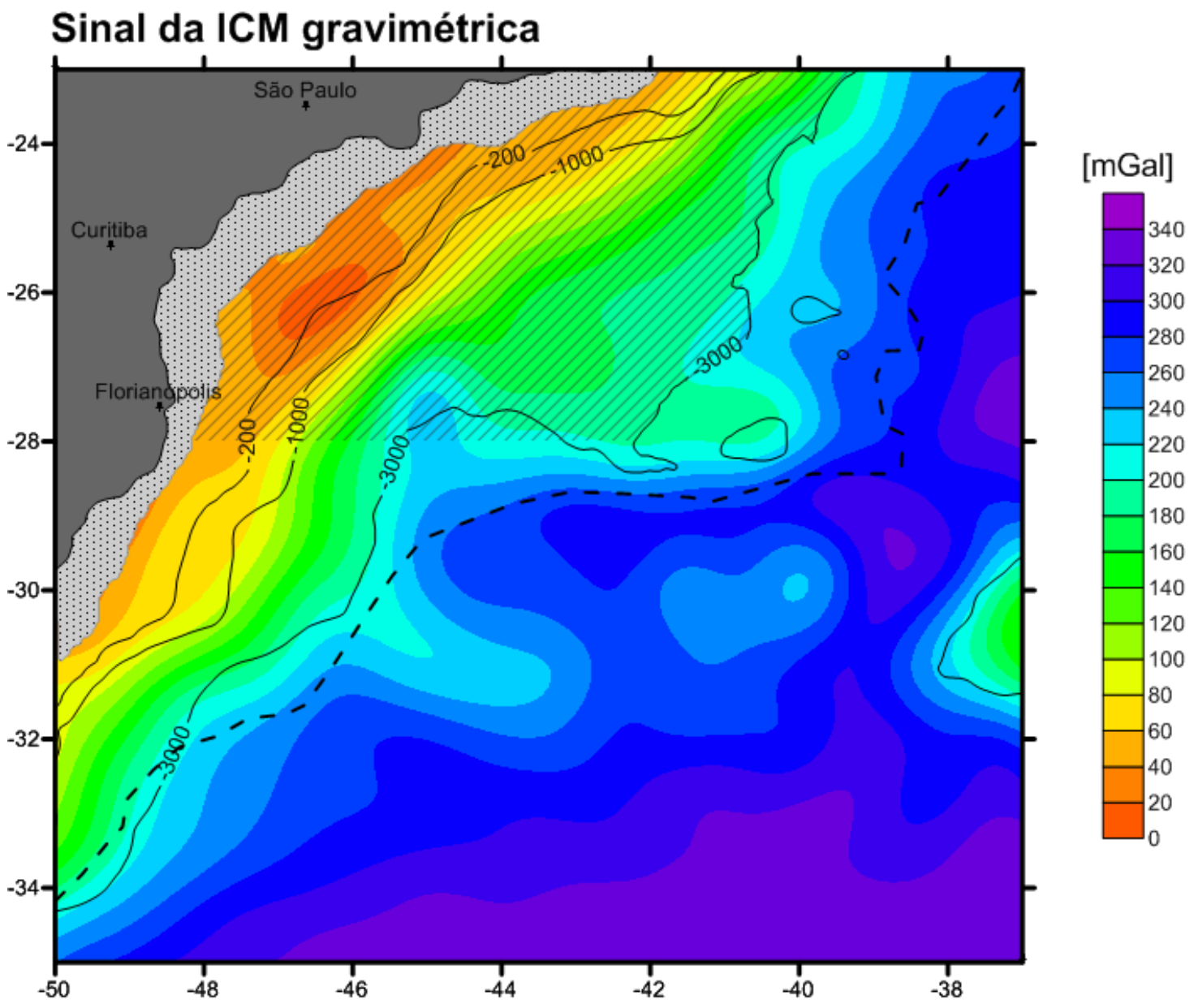

Figura 30: Sinal Gravimétrico da ICM obtida através da inversão do campo gravimétrico. As regiões hachuradas (listras e pontilhados) representam, respectivamente, a área da Bacia de Santos, delimitada segundo Moreira (2007) e área onde os dados gravimétricos não são confiáveis. 0 limite crustal, segundo Cainelli \& Moriak (1999) é representado pela linha tracejada. As isolinhas batimétricas referente às profundidades 200, 1000 e 3000 são mostradas.

O efeito gravimétrico da ICM assim calculada (figura 30) foi comparado com os dados gravimétricos de entrada para analisar os resultados do modelo obtido. A 
diferença entre o dado gravimétrico original e o efeito gravimétrico da ICM calculada é apresentada na figura 31.

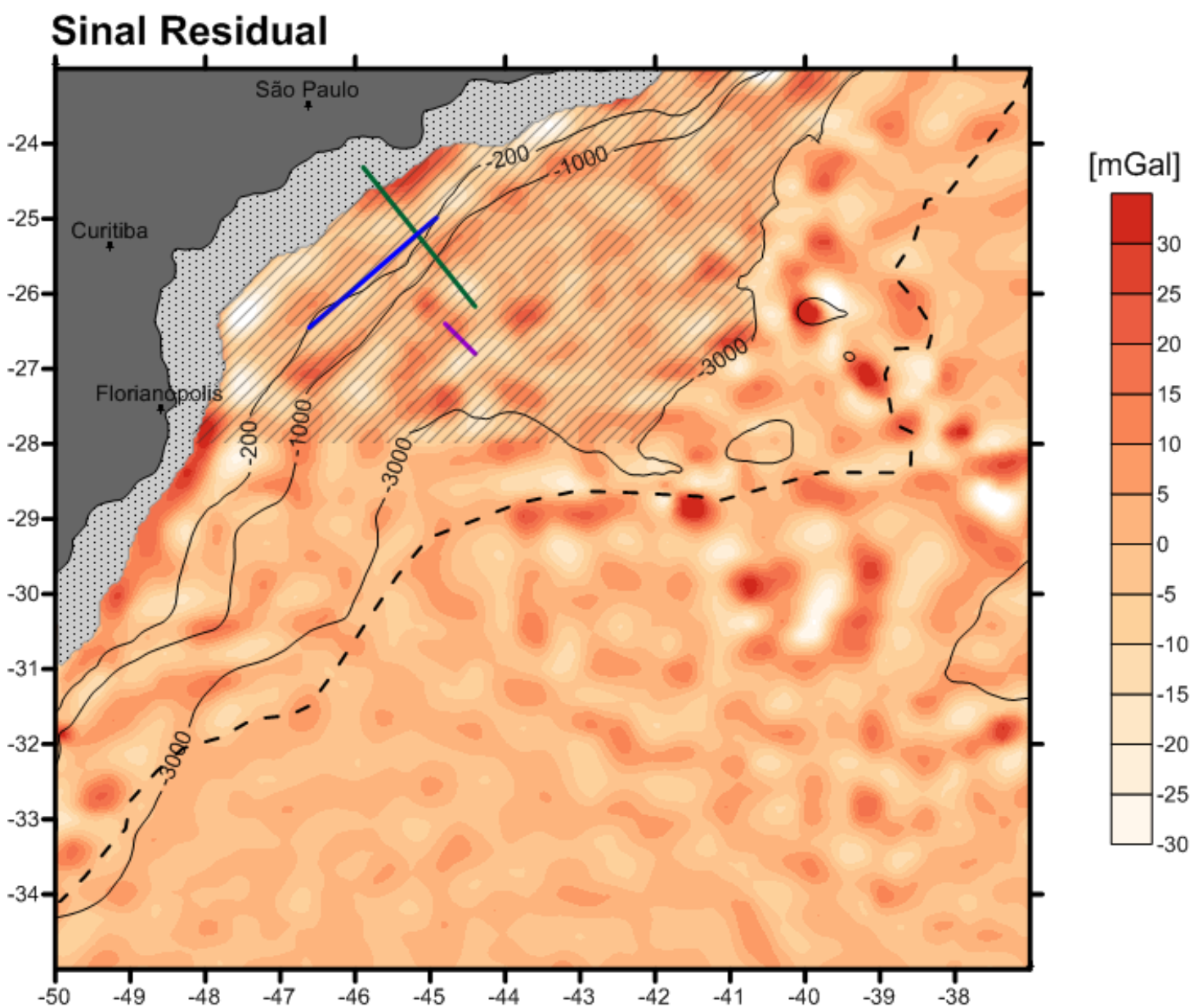

Figura 31: Diferença entre o campo gravimétrico utilizado como dado de entrada e o campo referente à ICM gravimétrica. Os traços coloridos representam perfis sísmicos. As regiões hachuradas (listras e pontilhados) representam, respectivamente, a área da Bacia de Santos, delimitada segundo Moreira (2007) e área onde os dados gravimétricos não são confiáveis. 0 limite crustal, segundo Cainelli \& Moriak (1999) é representado pela linha tracejada. As isolinhas batimétricas referente às profundidades 200, 1000 e 3000 são mostradas.

Como se pode observar, alguns valores residuais são encontrados dentro da bacia, com predominância na ordem de 10 a $20 \mathrm{mGal}$. Como foi utilizada apenas a parte de longo comprimento de onda durante o processo de inversão, esses valores podem estar tanto refletindo a parte de curto comprimento de onda presentes nos dados originais quanto às incertezas do modelo calculado.

Um dos resultados parciais deste trabalho, obtido nas etapas 1 e 2 , é referente às ondulações da ICM, que obedecem a teoria da isostasia flexural e concordam com a ICM gravimétrica vinculada a dados sísmicos. 
Após extensivos testes com os parâmetros na primeira etapa da metodologia, optou-se por utilizar valores de contraste de densidade entre a crosta e o manto variáveis para a área. A metodologia permite que este processo seja feito também para um único valor de contraste de densidade, mas neste trabalho os melhores resultados foram obtidos para uma variação lateral de densidades, pelos motivos explicados a seguir.

A princípio, durante a inversão do campo gravimétrico corrigido na etapa 1, o processo de inversão foi realizado para diferentes valores de contraste de densidade e profundidade, variando-se estes parâmetros entre os valores de 300$700 \mathrm{~km} / \mathrm{m} 3$ e $20-30 \mathrm{~km}$, respectivamente.

A partir desses resultados, calculou-se o erro RMS entre os dados obtidos para cada dupla de valores e os vínculos sísmicos disponíveis. 0 mesmo foi feito para valores de contraste de densidade lateralmente variável, obtidos a partir do CRUST 2.0, variando-se apenas o valor da profundidade de referência. Os melhores resultados, correspondentes ao menor erro RMS $(1.9 \mathrm{~km})$, foram encontrados para a profundidade de referência $28.7 \mathrm{~km}$ e para o contraste de densidade variável, apresentado na figura 18.

O outro fator para a escolha de uma variação lateral do contraste de densidades está relacionado à área estudada. Como pode-se ver em todos os mapas apresentados, a área de estudo envolve tanto crosta oceânica quanto crosta continental, o que não permite o uso de um valor de contraste de densidade constante.

As ondulações da ICM obtidas por análise flexural na etapa 2, quando comparadas às da ICM gravimétrica, mostraram, no geral, valores de espessura crustal que vão desde aproximadamente $30 \mathrm{~km}$ até $11 \mathrm{~km}$ (figura 21). A diferença entre as duas ICMs é apresentada na figura 22.

Os valores negativos representam uma ICM flexural mais profunda que a ICM gravimétrica. A diferença máxima negativa é de $2 \mathrm{~km}$ e aparece em evidência em duas áreas, uma dentro e outra bem próxima ao limite leste da bacia. A maior diferença positiva é de aproximadamente $3 \mathrm{~km}$ e está no limite sul da Bacia, próximo à cota batimétrica de $3000 \mathrm{~m}$. Os demais valores positivos, por estarem próximos à área onde os dados não são confiáveis, não serão discutidos neste trabalho. 
Umas das possíveis interpretações para essa diferença entre as ICMs seria a presença de feições de curto/médio comprimento de onda que podem estar presentes no sinal da anomalia gravimétrica e não no resultado da análise flexural. Tal possibilidade parece poder ser descartada por dois motivos principais: durante a inversão, a parte de curto comprimento de onda foi removida, e, portanto, não deveria estar gerando esta diferença; além disso, pode-se pensar que as feições que aparecem nos dados de anomalia gravimétrica poderiam não aparecer durante a análise flexural se tais feições estivessem sobre uma região da crosta com rigidez flexural, suficiente para comportá-las sem deformação. Para verificar este segundo argumento, foi realizada a análise dos valores de espessura elástica obtidos na etapa 2 (figura 32). As áreas circuladas representam as maiores diferenças encontradas entre a profundidade da ICM gravimétrica e da ICM flexural.

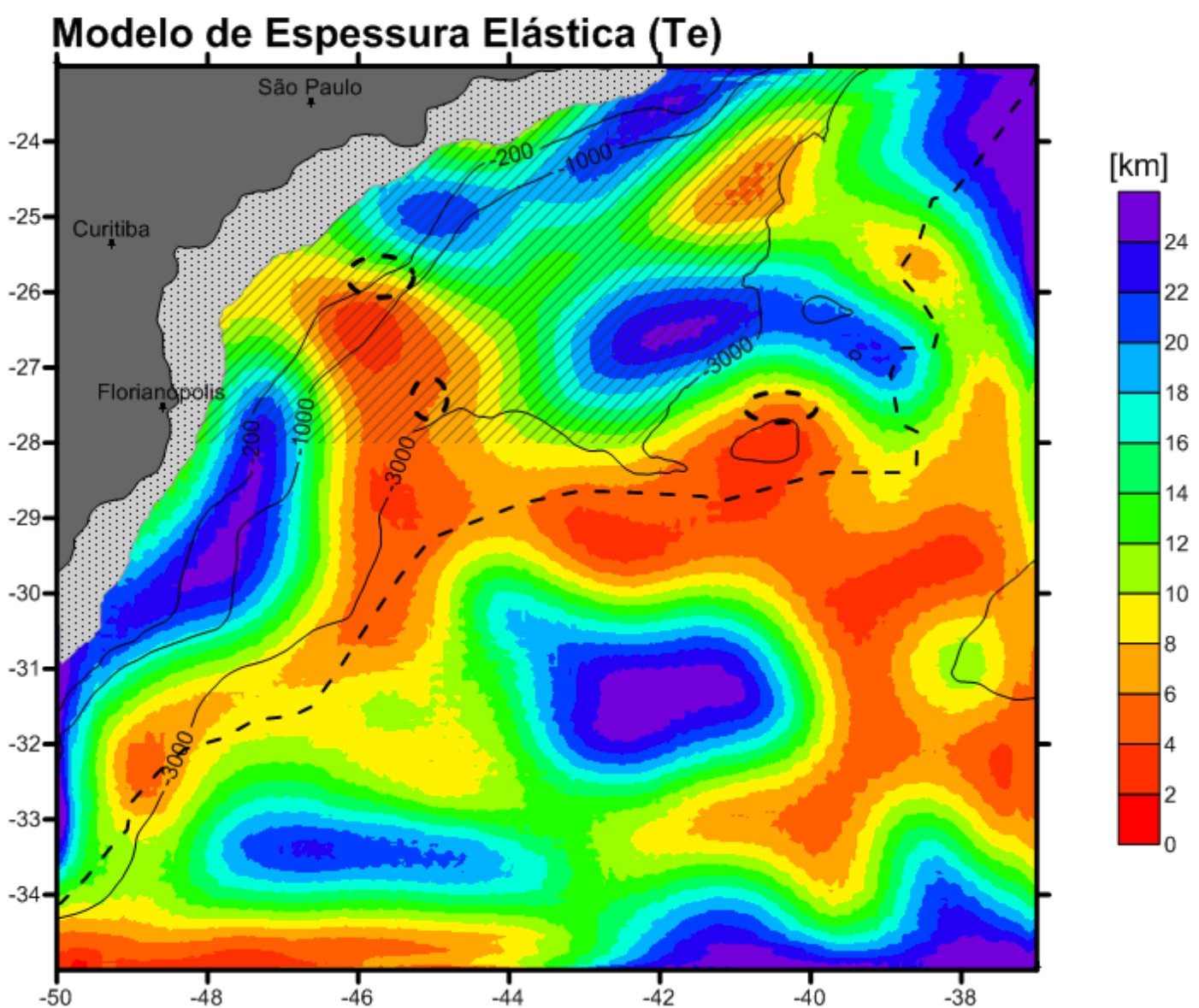

Figura 32: Modelo de espessura elástica. A região hachuradas (listras e pontilhados) representa, respectivamente, a área da Bacia de Santos, delimitada segundo Moreira (2007) e área onde os dados gravimétricos não são confiáveis. O limite crustal, segundo Cainelli \& Moriak (1999) é representado pela linha tracejada. As isolinhas batimétricas referente às profundidades 200, $1000 \mathrm{e}$ 3000 são mostradas. 
Observa-se no mapa que os valores de espessura elástica sob as áreas de maior diferença entre as ICMs são baixas, com predominância entre 4 e 6 km, indicando uma baixa rigidez flexural na região.

A partir dessa análise pode-se postular que as diferenças possivelmente têm outra fonte, e podem estar relacionadas ao contexto geológico complexo na região, como por exemplo, intrusões de domos salinos na Bacia de Santos.

Um levantamento bibliográfico foi realizado a fim de confirmar e relatar a presença dessas anomalias na Bacia de Santos. Trabalhos como Miesling et al. (2001), Izeli (2008), Caldas \& Zalán (2009) e Souza et al. (2009) interpretaram em perfis sísmicos a presença de domos salinos na região, o que permite aceitar a interpretação proposta neste trabalho.

Como exemplo, a figura 33 traz dois perfis sísmicos na região provenientes do Banco de Dados de Exploração e Produção (BDEP), administrados pela Agência Nacional do Petróleo (ANP), que foram interpretados por Souza et al (2009), mostrando muralhas e diápiros de sal. A localização dos perfis é dada na figura 31. 0 primeiro é referente ao perfil traçado em azul naquela figura, e o segundo, em verde.
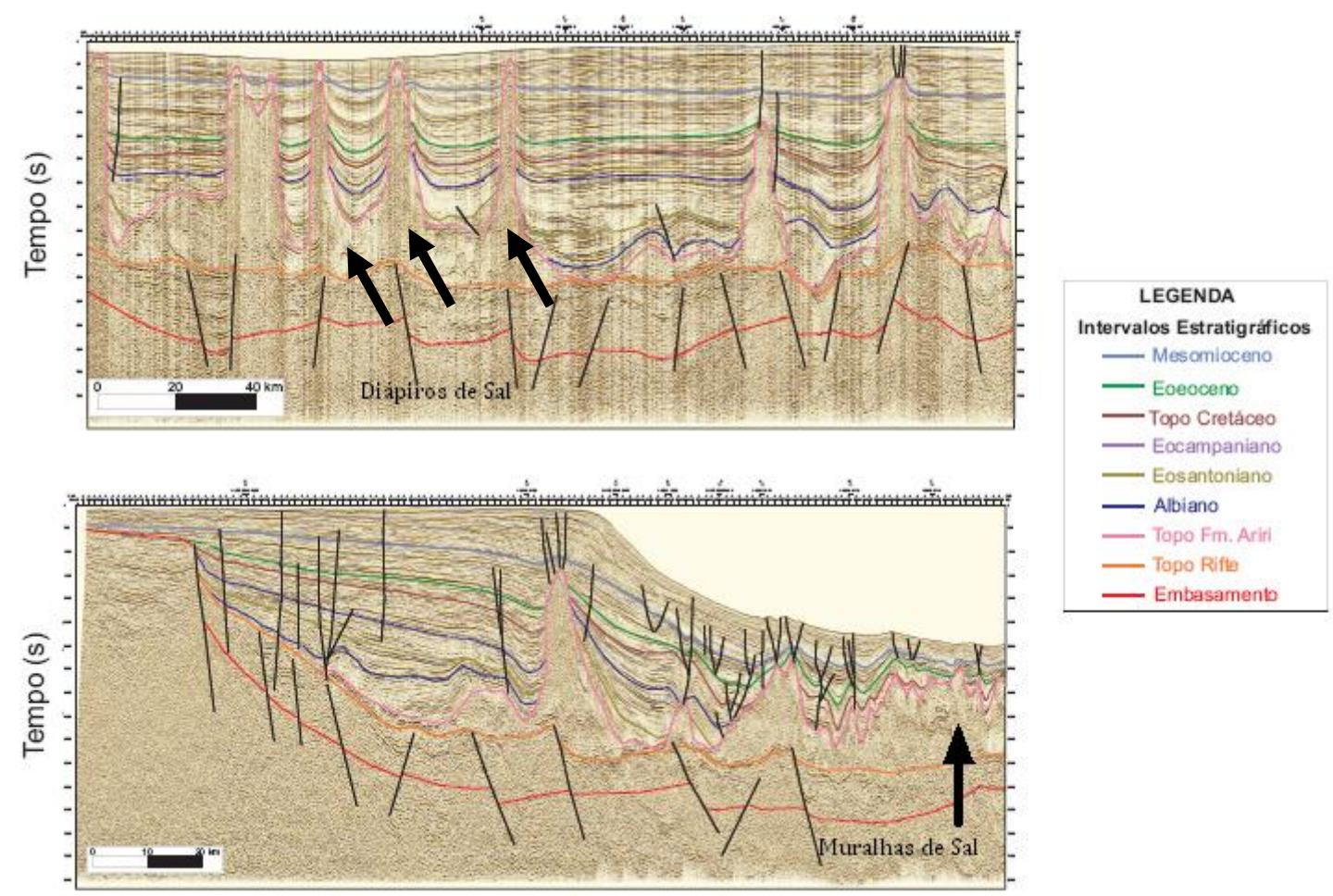

Figura 33: Perfis sísmicos na Bacia de Santos. As setas pretas indicam diápiros e muralhas de sal. Figura adaptada de Souza et al. (2009). 
0 perfil apresentado na figura 34 é proveniente do trabalho de Miesling et al. (2001) e está representado no mapa da figura 31 pela linha em roxo.

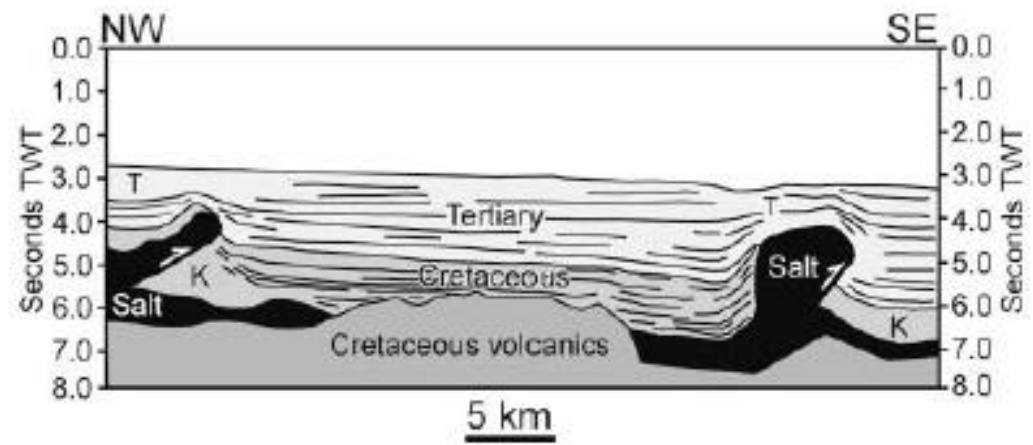

Figura 34: Perfil sísmico na Bacia de Santos. Figura adaptada de Miesling et al. (2001).

As ondulações da ICM assim encontradas foram utilizadas para calcular o seu efeito gravimétrico. Este efeito e o efeito dos sedimentos foram subtraídos da anomalia Bouguer, resultando no campo gravimétrico residual a ser invertido na última etapa. Essa inversão do campo residual resultou nas estruturas do embasamento apresentadas na figura 35.

Analisando o campo gravimétrico residual utilizado para inversão do embasamento (figura 24), pode-se ver uma faixa de anomalias positivas começando na cota batimétrica $3000 \mathrm{~m}$, com direção noroeste (NW). Essas anomalias foram discutidas em trabalhos como o de Demercian, L.S., (1996) e Meisling et al. (2001).

Segundo Meisling et al. (2001), essas anomalias gravimétricas positivas, quando analisadas juntamente à perfis sísmicos regionais, podem ser interpretadas como rochas vulcânicas, em algumas situações sobrepostas por finas camadas de evaporitos Aptianos, cujas fácies são bem acamadadas e interpretadas como anidrido.

Segundo este autor, essas anticlinais foram cordilheiras de terrenos altos durante a deposição de evaporitos. Ao longo dessas cordilheiras, a atividade vulcânica continuou durante e após o Aptiano, mobilizando os evaporitos e combinando-os com depósitos vulcanoclásticos. 


\section{Embasamento}

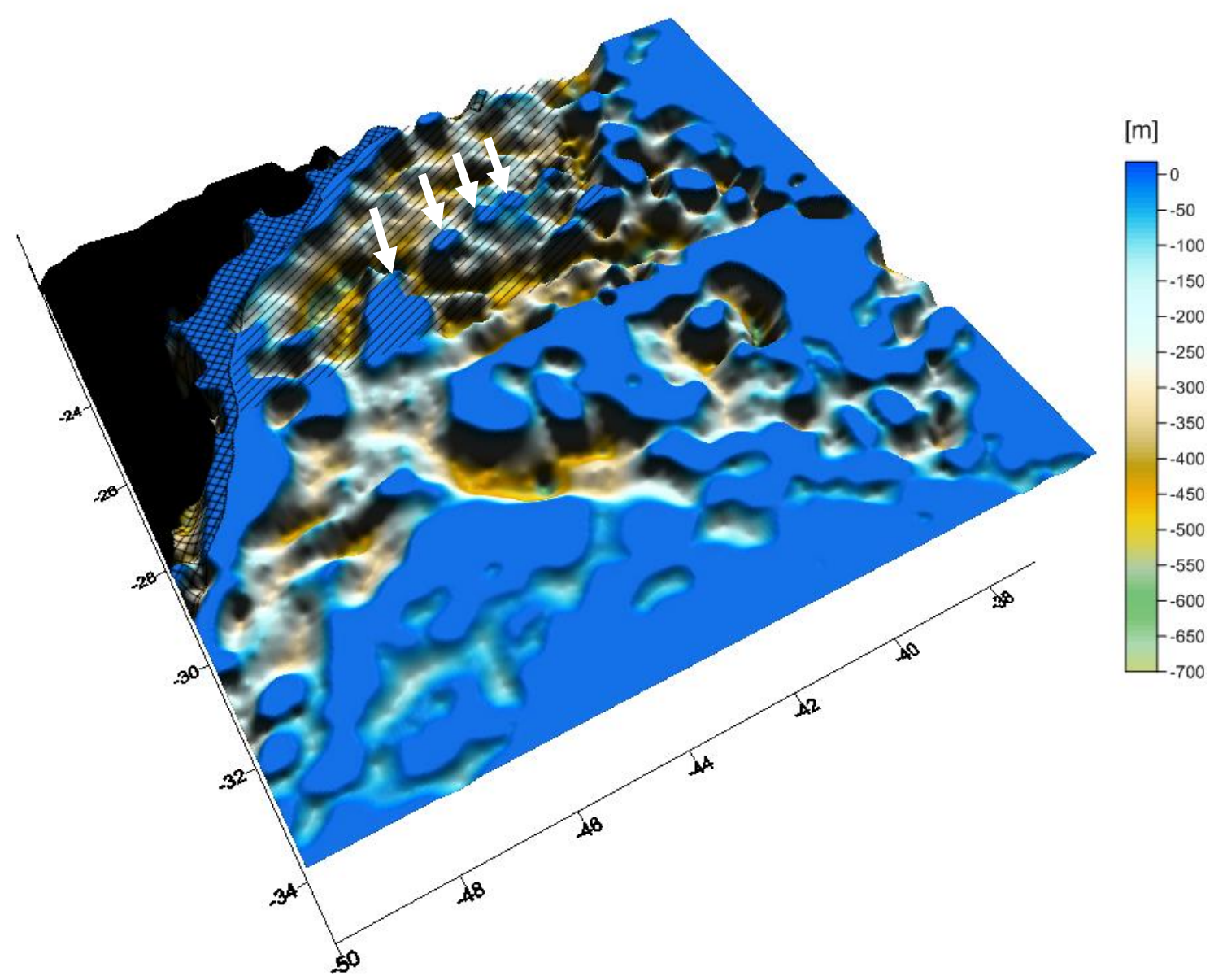

Figura 35: Estruturas do embasamento encontrado neste trabalho. As setas brancas indicam feições de interesse encontradas no modelo obtido. As regiões hachuradas (listras e quadriculado) representam, respectivamente, a área da Bacia de Santos, delimitada segundo Moreira (2007) e área onde os dados gravimétricos não são confiáveis.

Essas feições descritas por Meisling et al. (2001) foram mapeadas por Demercian (1996) e chamadas de Alto do pré-sal, e a interpretação sugerida é mostrada na figura 36. As setas sugerem as mesmas feições demarcadas na figura 35.

A porção norte da Bacia de Santos é caracterizada por feições tectônicas de larga escala e intenso diapirismo. Os processos que geraram estas feições foram originados, principalmente, pelo soerguimento do embasamento durante o Cretáceo Superior na porção adjacente da bacia. Segundo Macedo (2004), a espessa pilha de sedimentos costeiros gerada por esse evento criou um deslocamento de larga escala nos sedimentos marinhos da bacia em direção ao Platô de São Paulo, sobre o topo da camada evaporítica (Aptiano). Este deslocamento encontra-se acomodado ao longo da Falha de Cabo Frio. 


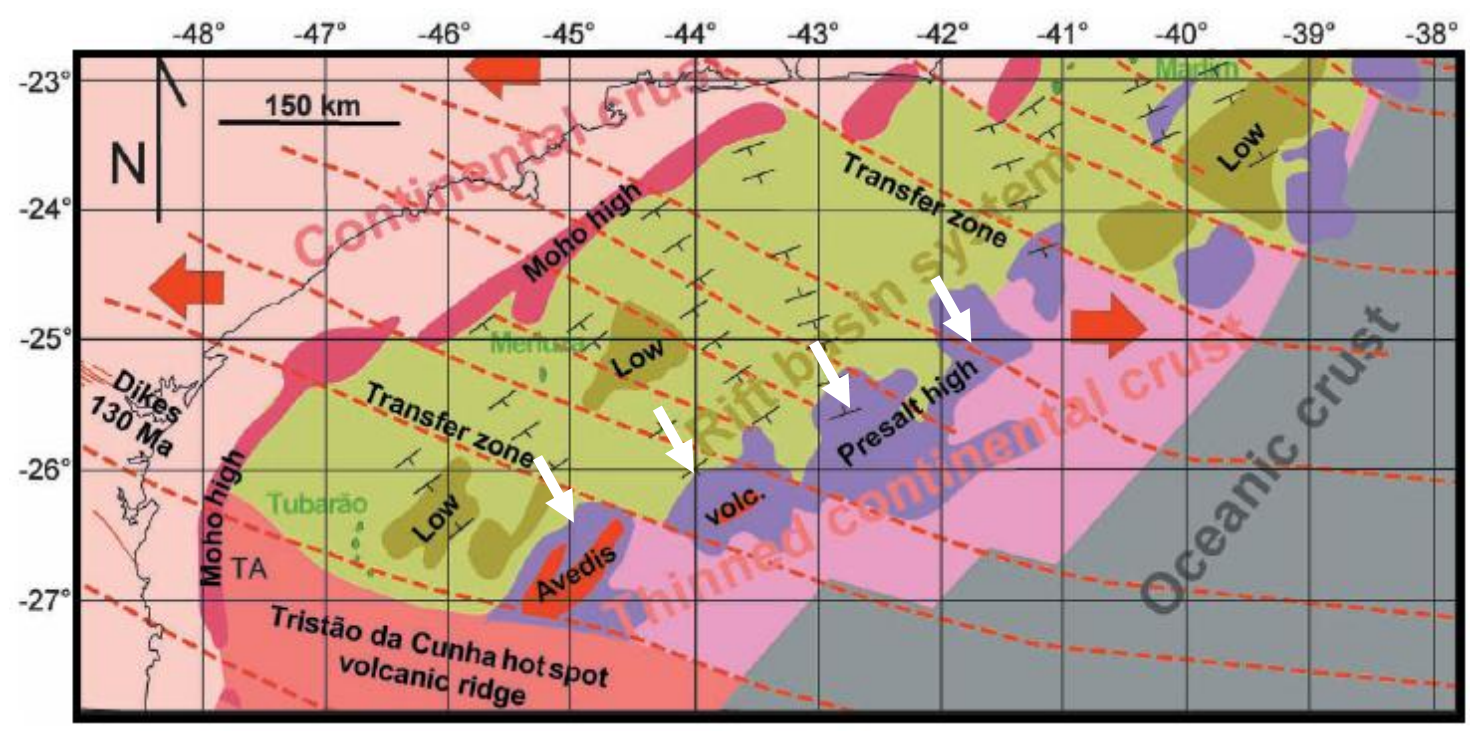

Figura 36: Mapa estrututal da Bacia de Santos, adaptado de Meisling et el (2001). As setas brancas indicam a cadeia vulcância Avedis, mapeada como alto do pré-sal por Demercian (1996).

A profundidade do embasamento é mostrada nas figuras 27,28 e 29 . A análise da estrutura do embasamento em projeção ortográfica (figura 29), permite ver dois conjuntos de feições marcantes. Um deles é referente às feições inferidas como alto do pré-sal, discutidas anteriormente, e outra é referente a uma feição longilínea, com profundidades que atingem aproximadamente $10500 \mathrm{~m}$ entre as coordenadas $(26 \mathrm{~S}, 46 \mathrm{~W})$ e $(24 \mathrm{~S}, 42 \mathrm{~W})$, coincidindo com a Falha de Cabo Frio.

Para vincular os dados de profundidade do embasamento, cinco valores de profundidade foram utilizados retirados de Assine (2008), Cainelli \& Moriak (1999) e ANP (Agência Nacional do Petróleo).

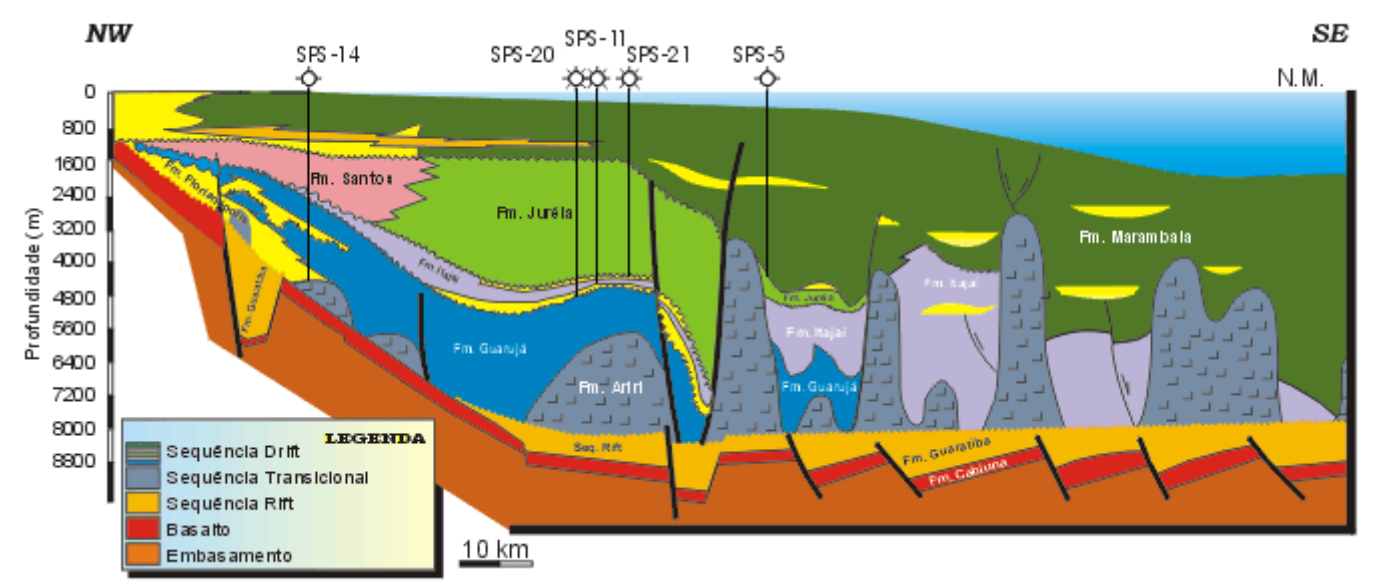

Figura 37: Seção Geológica da Bacia de Santos. Figura adaptada de Cainelli e Moriak (1999) e ANP. As linhas pretas que seguem os poços são referentes a profundidade de perfuração. 


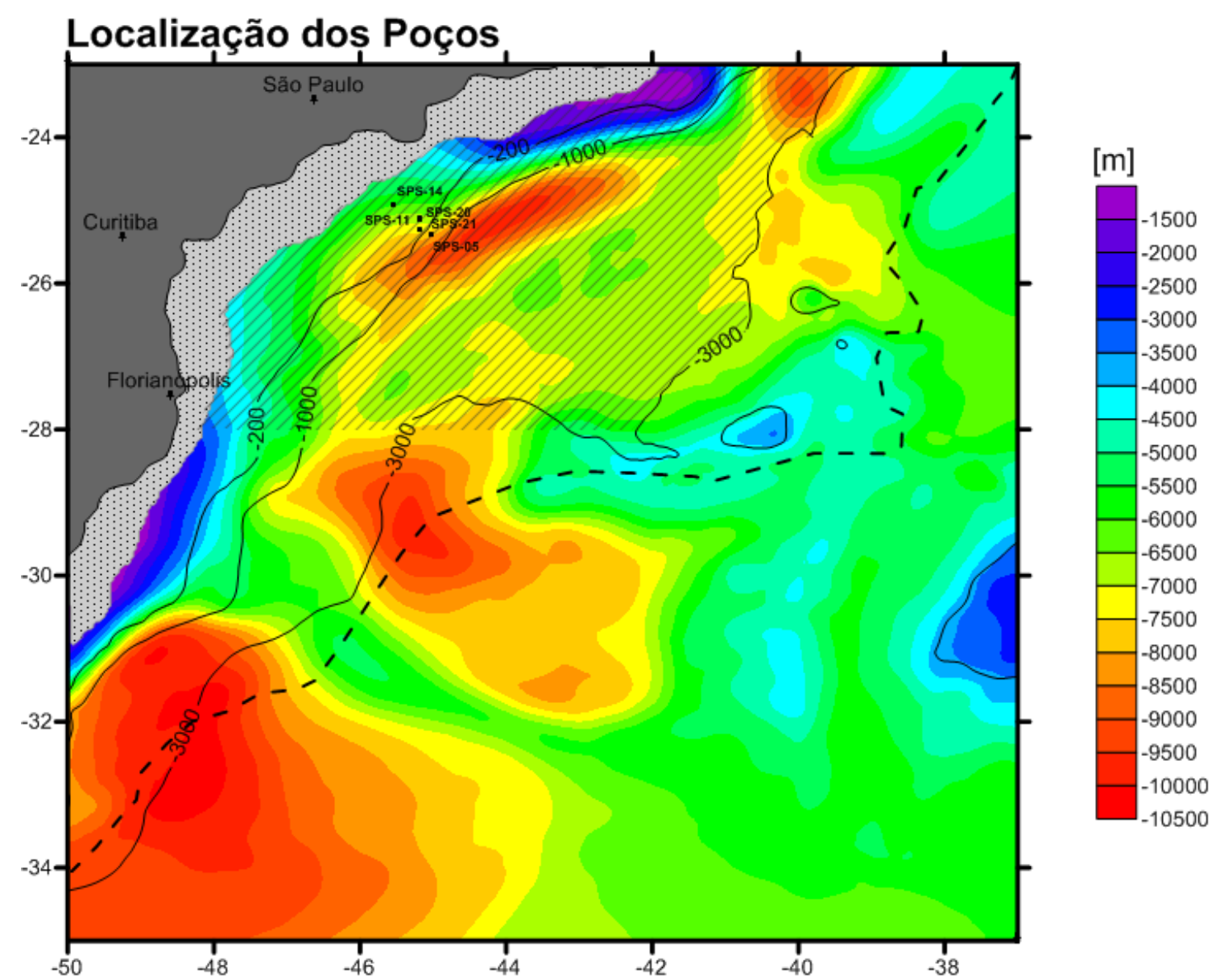

Figura 38: Localização dos poços. 0 mapa representa a profundidade do embasamento. As regiões hachuradas (listras e pontilhados) representam, respectivamente, a área da Bacia de Santos, delimitada segundo Moreira (2007) e área onde os dados gravimétricos não são confiáveis. 0 limite crustal, segundo Cainelli \& Moriak (1999) é representado pela linha tracejada. As isolinhas batimétricas referente às profundidades 200, 1000 e 3000 são mostradas.

Os valores referentes à profundidade do embasamento usados como vínculo, os valores encontrados durante este trabalho e as respectivas diferenças e são mostradas na tabela 2.

\begin{tabular}{|l|l|l|l|}
\hline Poço & Vínculo (m) & Profundidade (m) & Diferença (m) \\
\hline SPS-14 & 5400 & 5990 & 590 \\
\hline SPS-20 & 9200 & 6775 & -2425 \\
\hline SPS-11 & 8900 & 7841 & -1059 \\
\hline SPS-21 & 9100 & 6650 & -2450 \\
\hline SPS-05 & 9300 & 7310 & -1990 \\
\hline
\end{tabular}

Tabela 2: Valores utilizados como vínculos, profundidades do embasamento encontradas durante 0 trabalho e as respectivas diferenças. 
Nota-se que em algumas situações os valores são consideravelmente altos. Tratando-se do embasamento, uma diferença na ordem de $2 \mathrm{~km}$ de profundidade é crucial para alguns tipos de aplicação. A exceção é referente ao poço 14, com uma diferença de 590m. A profundidade na localização desse poço foi a única que se mostrou mais profunda no modelo do que no vínculo. Em todos os outros poços (SPS-05, SPS-11, SPS-20 e SPS-21) o embasamento é mais raso.

A possível explicação para essa diferença pode ser o alcance de perfuração dos poços. Como mostrado na figura 37, o poço 14 é o único que está próximo ao embasamento, quase atingindo sua superfície. Os demais apresentam apenas estimativas e suas perfurações estão a mais de $3 \mathrm{~km}$ de distância do embasamento.

Segundo Souza, I.A. (Comunicação Pessoal), poucos dos poços SCP da ANP atingiram o embasamento durante suas perfurações Os dados destes poços foram solicitados para uso neste trabalho, porém, até o fechamento da dissertação (fev/2012), estes ainda não haviam sido disponibilizados. 


\section{Capítulo 7}

\section{Conclusões}

Os resultados obtidos neste trabalho permitem mostrar que feições do embasamento encontram-se ocultas pela camada sedimentar na Região da Bacia de Santos. Para isto, a topografia do embasamento foi determinada a partir dos dados disponíveis seguindo a metodologia proposta por Braitenberg et al. (2006).

A aplicação da primeira etapa desta metodologia permitiu a determinação da profundidade da Interface Crosta Manto (ICM) a partir da inversão do campo gravimétrico corrigido, utilizando como vínculos dados sísmicos obtidos por Leyden (1972) e Zalán (2011). Os resultados obtidos mostraram-se satisfatórios, com um erro RMS de aproximadamente $1.9 \mathrm{~km}$.

Para checar a consistência dos resultados obtidos, a profundidade da ICM foi determinada através de um método independente, envolvendo análise flexural. Os valores, quando comparados, mostraram pequenas diferenças. As maiores diferenças podem estar associadas a intrusões salinas presentes entre as camadas de sedimentação da Bacia de Santos, descritas em literatura (Miesling et al., 2001; Izeli, 2008; Caldas \& Zalán, 2009 e Souza et al., 2009).

Subtraindo do sinal gravimétrico observado o sinal gravimétrico da ICM e dos sedimentos, obteve-se o campo gravimétrico residual referente ao embasamento. 0 sinal gravimétrico dos sedimentos foi calculado com base no modelo de Sclater e Christie (1980) e o sinal referente à ICM, calculado pelo método de Parker (1972).

A inversão desse campo gravimétrico residual resultou na topografia do embasamento, que apresentou feições de destaque com até $700 \mathrm{~m}$, que parecem estar em concordância com feições discutidas em trabalhos pretéritos, como por exemplo, a cadeia vulcânica Avedis (Meisling et al., 2001; Demercian, 1996).

A profundidade do embasamento estimada durante este trabalho mostrou profundidades que vão de 1500 à $10500 \mathrm{~m}$. A região mais profunda do embasamento condiz com a falha de Cabo Frio (Macedo, 2004; Assine, 2008; Zalán 2009) 
A metodologia utilizada durante este trabalho mostrou que é possível obter um modelo tridimensional do embasamento em áreas oceânicas a partir de dados gravimétricos obtidos por navio e por altimetria por satélite, dados batimétricos e informações sobre a espessura sedimentar e sobre a estrutura crustal da região. 


\section{Capítulo 8}

\section{Referências}

Assine, M.L., F.S. Correa e H.K. Chang, (2008). Migração de depocentros na Bacia de Santos: importância na exploração de hidrocarbonetos. Revista Brasileira de Geociências. v. 38, n.2 (Jun.), p. 111-127

Blakely, R.J. (1995). Potential Theory in Gravity and Magnetic Applications, Cambridge Univ. Press, 441 pp., New York.

Braitenberg, C. e M. Zadro, (1999). Iterative 3D gravity inversion with integration of seismologic data, Bollettino Di Geofisica Teorica ed Applicata, v.40, n.3-4, p. 469475.

Braitenberg, C., J. Ebbing, e H.-J. Gotze, (2002). Inverse modelling of elastic thickness by convolution method: The Eastern Alps as a case example, Earth Planet. Sci. Lett., 202, 387- 404.

Braitenberg, C., Y. Wang, J. Fang, e H. T. Hsu, (2003). Spatial variations of flexure parameters over the Tibet-Quinghai plateau, Earth Planet. Sci. Lett., 205, 211- 224.

Braitenberg, C., S. Wienecke, e Y. Wang, (2006). Basement structures from satellitederived gravity field: South China Sea ridge, J. Geophys. Res., 111, B05407, doi:10.1029/2005JB003938.

Braitenberg, C., S. Wienecke, J. Ebbing, W. Born e T. Redfield, (2007). Joint Gravity and Isostatic Analysis for Basement Studies - A Novel Tool, Extended Abstracts, EGM 2007 International Workshop, Innovation in EM, Grav and Mag Methods: a new Perspective for Exploration, Villa Orlandi, Capri - Italy , 15-18 April 2007.

Cainelli, C. e W. U. Moriak, (1998). Some remarks on the evolution of sedimentary basins along the Eastern Brazilian continental margin. Episodes, v. 22, n. 3, p. 206216, 1999.

Caldas, M.F. e P.V. Zalán, (2009). Reconstituição cinemática e tectono-sedimentação associada a domos salinos nas águas profundas da Bacia de Santos, Brasil. Boletim de Geociências da Petrobrás, V. 15, n.2, 531-549., v.17, n.2, 227-248. 
Calmant, S., e N. Baudry, (1996). Modelling bathymetry by inverting satellite altimetry data: A review, Mar. Geophys. Res., 18, 123-134.

Chang, H. K., Assine, M.L., Corrêa, F. S., Tinen, J.S., Vidal, A.C. e Koike, L. (2008). Sistemas petrolíferos e modelos de acumulação de hidrocarbonetos na Bacia de Santos. Revista Brasileira de, 38(2 - suplemento): 29-46.

Demercian, L. S., (1996). A halocinese na evolução do Sul da Bacia de Santos do Aptiano ao Cretáceo Superior: Master's thesis, Universidade Federal do Rio Grande do Sul, Porto Alegre, Brazil, 201 p.

Divins, D.L., NGDC Total Sediment Thickness of the World's Oceans \& Marginal Seas, Retrieved date goes here.

http://www.ngdc.noaa.gov/mgg/sedthick/sedthick.html

Ebbing, J., C. Braitenberg, e H.-J. Götze, (2006). The lithospheric density structure of the Eastern Alps, Tectonophysics, 414, 145-155

Heiskanen, W. e H. Moritz, (1967). Physical Geodesy. W.H. Freeman and company, san Francisco, 364 p.

Hertz, H. (1884) Über das Gleichgewicht schwimmender elastischer Platten. Annalen der Physik und Chemie, Ausgabe Wiedemann G. ,pp.449-455.

Hwang, C. (1999). A bathymetric model for the Souch China Sea from Satellite altimetry and depth data, Mar. Geod., 22,37-51.

Izeli, M.G.B. (2008). Controle estrutural do embasamento emerso na porção central da Bacia de Santos, utilizando sensoriamento remoto e interpretação sísmica. Trabalho de conclusão de curso de Geologia do Instituto de Geociências e Ciências Exatas - UNESP, Rio Claro, Brasil, 65p.

Karner, G.D. e A.B. Watts, (1982). On isostasy at Atlantic-Type Continental Margins. J. Geophys. Res., 87(B4):2923-2948.

Kumar, R.T.R., T.K. Maji, S.C. Kandpal, D. Sengupta, e R.R. Nair, (2011). Elastic Thickness estimates at northeast passive margin of North America and its implications. J. Earth Syst. 120, No.3, 447-458. 
Leyden, R. W.J. Ludwig e J. Ewing (1971). Structure of the continental margin of Punta del Este, Uruguay, and Rio de Janeiro, Brazil. AAPG Bulletin, 55: 2161-2173.

Lowrie, W. (1997). Fundamentals of Geophysics. Cambridge University Press. 354 pp.

Macario, A., A. Malinverno e W.F. Haxby, (1995). On the robustness of elastic thickness estimates obtained using the coherence method, J. Geophys. Res. - Solid Earth, 100, 151 63-15, 172.

Macedo, J.M, L.H. Drehmer, D.E. Andrade, M.R. Mello e M.A. Martinéz (2004). Falha de Cabo Frio: um importante fator condicionante do sistema petrolífero na Bacia de Santos.

Meisling, K.E., P.R. Cobbold, V.S. Mount (2001). Segmentation of an obliquely rifted margin, Campos and Santos basins, southeastern Brazil. AAPG Bull, 85(11):19031924.

Mio, E. (2005). Modelagem crustal da Bacia de Santos pela integração de métodos geofísicos. Rio Claro. 94 p.

Mio, E., H. K. Chang e F.S. Correa, (2006). Integração de métodos geofísicos na modelagem crustal da bacia de santos. Revista Brasileira de Geofísica, 23(3): 275284.

Molina, E.C., (2009). O uso de dados de missões geodésicas de altimetria por satélite e gravimetria marinha para a representação dos elementos do campo de gravidade terrestre. Tese de livre docência. Departamento de Geofísica do IAG-USP. Universidade de São Paulo. 100pp.

Moreira, J.L.P., C.V. Madeira, J.A. Gil, Machado, M.A.P Machado, (2007). Bacia de Santos, Boletim de Geociências da Petrobrás, V. 15, n.2, 531-549.

Nagy, D. (1966). The gravitational attraction of a right rectangular prism, Geophysics, 30, 362-371.

Oliveira, R.,G. (2008). Isostasia e estimativas da espessura elástica efetiva para a margem continental da província Borborema. Tese de Deoutorado. UFRN/CCET. Cap. 6, 157-243.

Parker, R. L. (1972).The rapid calculation of potential anomalies. Geophys. J. R. Astr. Soc., 31, 447-455. 
Ramillien, G., e A. Cazenave (1996), Global bathymetry derived from altimeter data of the ERS-1 geodetic mission, J. Geodyn., 23, 129-149.

Russo, R. M., e R. C. Speed (1994), Spectral analysis of gravity anomalies and the architecture of tectonic wedging, NE Venezuela and Trinidad, Tectonics, 13(2), 613- 622.

Sandwell, D. T., e W. H. F. Smith (2001), Bathymetric estimation, in Satellite Altimetry and Earth Sciences, edited by L. - L. Fu and A. Cazenave, 441 - 457, Elsevier, New York.

Sclater, J. G. e P. A. F. Christie (1980), Continental stretching: An explanation of the post mid-Cretaceous subsidence of the central North Sea basin, J. Geophys. Res., 85, $3711-3739$.

Souza, I.A., H.D. Ebert, Castro, J.C. Castro, A.S. Soares, G.H.T. Silva e Benvenutti, C.F. (2009), Caracterização das falhas de transferência na porção norte da Bacia de Santos a partir da integração de dados geológicos e geofísicos, Boletim de Geociências da Petrobras, V.17,n.1, p.109-132.

Smith, W. H. F., e D. T. Sandwell (1997), Global sea floor topography from satellite altimetry and ship depth soundings, Science, 277, 1956-1962.

Smith, W.H.F. e P. Wessel, (1990), Gridding with Continuous Curvature Splines in Tension, Geophysics, V. 55, n.3, p.293-305.

Supko, P. R., Perch-Nielsen, K. e Carlson, R. L. (1997) doi:10.2973/dsdp.proc.39.101.

Tassara, A., et al. (2007), Elastic thickness structure of South America estimated using wavelets and satellite-derived gravity data, Earth and Planetary Science Letters, 253, 17-36.

The GEBCO One Minute Grid, version 2.0, http://www.gebco.net

Turcotte, D. L. e L. Schubert, (1982), Applications of Continuum Physics to Geological Problems, John Wiley and Sons, New York, 450 pp. 
Watts,A.B. (1988), Gravity-anomalies, crustal structure and flexure of the lithosphere at the baltimore canyon trough, Earth Planet. ci. Lett., 89, 221-238.

Watts, A. B. (2001), Isostasy and Flexure of the Lithosphere, Cambridge University Press, Cambridge, 458 pp.

Wienecke, S. (2006). A new analytical solution for the calculation of flexural rigidity: significance and applications, PhD thesis, Free University of Berlin, Berlin, http://www.diss.fu-berlin.de/2006/42

Woodward, D. e R. Wood, (2000), Bathymetry sediment thickness and crustal structure from satellite gravity data, Exploration Geophysics 31(2) 89 - 93 doi:10.1071/EG00089

Zalán, P.V., M.C.G. Severino, C.A. Rigoti, L.P. Magnaviva, J.A.B. Oliveira e A.R. Vianna, (2011), An Entirely New 3D-View of the Crustal and Mantle Structure of a South Atlantic Passive Margin - Santos, Campos and Espírito Santo Basins, Brazil, Search and Discovery Article \#30177 